UNIVERSIDADE DE SÃO PAULO

ESCOLA DE EDUCAÇÃO FÍSICA E ESPORTE

\title{
ANÁLISE DE UM PROGRAMA DE ATIVIDADE FÍSICA \\ PARA IDOSOS EM ACADEMIA - UM ESTUDO EXPLORATÓRIO
}

Simone Carvalho Simões Pinheiro Lima 


\section{ANÁLISE DE UM PROGRAMA DE ATIVIDADE FÍSICA PARA IDOSOS EM ACADEMIA - UM ESTUDO EXPLORATÓRIO}

SIMONE CARVALHO SIMÕES PINHEIRO LIMA

Dissertação apresentada à Escola de Educação Física e Esporte da Universidade de São Paulo, como requisito parcial para obtenção do grau de Mestre em Educação Física.

ORIENTADOR: PROF. DR. ANTÔNIO CARLOS MANSOLDO 
Pinheiro Lima, Simone Carvalho Simões

Análise de um programa de atividade física para idosos em academia: um estudo exploratório /

Simone Carvalho Simões Pinheiro Lima. - São Paulo: [s.n.], 2005.

$$
\mathrm{xx}, 176 \mathrm{p} \text {. }
$$

Dissertação (Mestrado) - Escola de Educação Física e Esporte da Universidade de São Paulo.

Orientador: Prof. Dr. Antônio Carlos Mansoldo.

1.Educação Física - Idosos. I.Título. 


\section{AGRADECIMENTOS}

Ao Prof. Dr. Antonio Carlos Mansoldo pela orientação, colaboração c respeito às minhas idéias e ao meu ritmo de trabalho.

Ao Prof. Dr. Alberto Carlos Amadio pelo carinho, incentivo e orientação durante a realizaçâo da minha Dissertação.

À Prof ${ }^{\mathrm{a}} \mathrm{Dr}^{\mathrm{a}}$. Silene Sumire Okuma pelos conhecimentos e vivências valiosas transmitidas durante as suas aulas e pelas sugestões e orientações quando da elaboração do trabalho.

Ao Prof. Dr. Afonso Antonio Machado, pela colaboração e sugestões apresentadas para a finalização do trabalho.

Aos funcionários da EEFEUSP, Ana Lúcia , Ilza e Lourdes pela paciência e presteza com que sempre me atenderam.

À amiga Simone Massetto que em todos os momentos de dificuldades e apreensão me ajudou e estimulou para perseverar na busca dos meus objetivos.

Aos meus amigos idosos do Programa Platinum, o meu eterno amor e agradecimento.

À Cia Athletica, pela oportunidade dada ao meu crescimento pessoal e profissional, bem como ao desenvolvimento do presente trabalho.

Ao Richard Bilton - diretor geral do grupo Cia Athletica e da Unidade Morumbi - e à gerente administrativa Fernanda Thot por terem acreditado e apoiado o meu projeto.

À Patrícia Lobato e Cláudia Ronzi por terem me incentivado e avalizado desde o início o meu projeto para que fosse aceito pela rede e se tornasse 
realidade. Aos meus amigos de todos os momentos, gerentes, professores e secretárias, Ana Rozov, Fabiana Tassi, Paola Michelotti, Paulão Jaouiche, Karolina Afonso, Ronaldo Villela e Silvana pelo apoio e admiração para a concretização do trabalho.

Aos amigos da FAUUSP, Prof. Dr. Marcelo Romero de Andrade, arquiteto Tadeu e técnico Cidão, pela colaboração e presteza na finalização do trabalho.

Ao Prof. Dr. Júlio da Mota Singer, do IME/USP pela colaboração prestada na análise estatística.

Aos meus queridos pais Neuce e Roberto Simões pelo incentivo material e espiritual, colaboração e apoio físico e emocional permanente à realização desta Dissertação.

Ao Ricardo, meu irmão e sempre grande amigo e à Valéria, meus agradecimentos pelo apoio, colaboração e incentivo.

Às tias Neusa e Neide e à prima Neila pelas orações e pensamentos positivos para a realização deste objetivo.

À família Pinheiro Lima pela colaboração e incentivo.

Ao Flávio, meu companheiro de todos os momentos e aos meus queridos filhos, Rafael e Marina, pela paciência e compreensão pelas horas de ausência e irritação durante estes três anos de luta, na busca da realização deste projeto de vida. 


\section{SUMÁRIO}

Página

LISTA DE TABELAS …................................................................ vii

LISTA DE FIGURAS...................................................................... ix

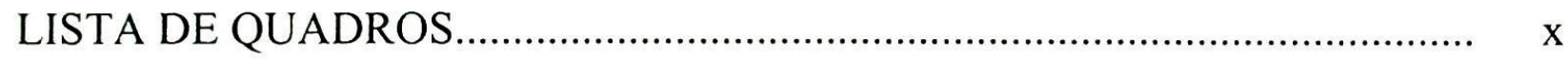

LISTA DE SIGLAS, ABREVIAÇÕES E SÍMBOLOS.......................... xi

LISTA DE ANEXOS ......................................................................... xii

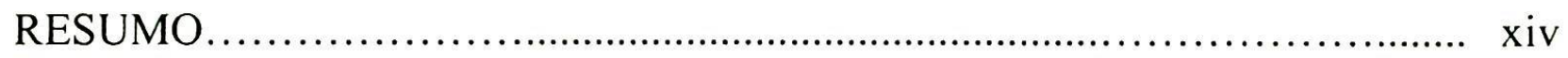

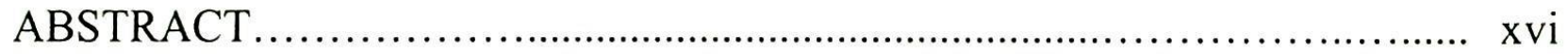

1 INTRODUÇÃO ................................................................... 1

1.1 Justificativa......................................................... 5

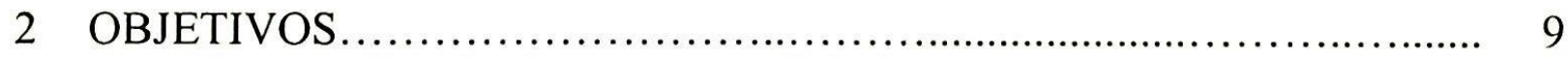

2.1 Objetivo geral............................................... 9

2.2 Objetivos específicos................................................ 9

3 REVISÃO DE LITERATURA...................................................... 10

3.1 Perfil dos Idosos no Brasil................................................................. 10

3.2 Academias de Ginástica- Uma tendência de mercado.................. 17

3.3 Efeitos da atividade física em idosos................................................. 20

3.3.1 Na Aptidão Física.................................................................. 24

3.3.1.1 Variáveis antropométricas...................................... 25

3.3.1.2 Variáveis neuromotoras......................................... 27

3.3.1.3 Variáveis metabólicas.............................................. 32

3.3.2 Capacidade funcional e nível de AF.................................... 34 
3.3.3 Efeito da AF nos aspectos sociais e psicológicos.................. 39

3.4 Programa de Atividade Física para idosos - Características Gerais... 43

3.4.1 Estruturação de um programa de AF................................... 47

3.4.1.1 Características dos indivíduos praticantes............... 53

3.4.1.2 Características da atividade física.......................... 56

3.4.2 Organização/Planejamento................................................. 57

3.4.3 Funcionamento/Atendimento................................................. 61

3.4.4 Programas diversos de AF para idosos................................ 64

3.4.4.1 Programa de Autonomia da AF (PAAF)................ 64

3.4.4.2 Programa de Exercícios e Saúde............................. 66

3.4.4.3 Programa Mexa-se Itaguaçú................................... 68

3.5 O Programa Platinum - Características............................................... 70

3.5.1 Objetivos do Programa Platinum............................................ 72

3.5.2 Roteiro do aluno Platinum...................................................... 73

3.5.3 Integração de áreas- Programa Platinum............................... 78

3.5.4 Atividades Platinum............................................................. 79

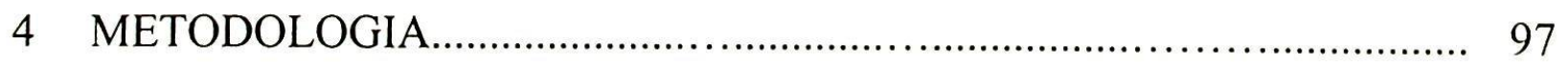

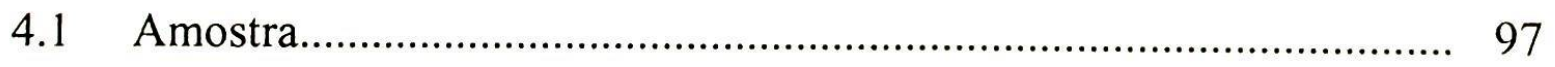

4.2 Questionário................................................................................. 99

4.3 Coleta de dados......................................................................... 100

4.4 Tratamento Estatístico.................................................................... 100

5 APRESENTAÇÃO E DISCUSSÃO DOS RESULTADOS....................... 101

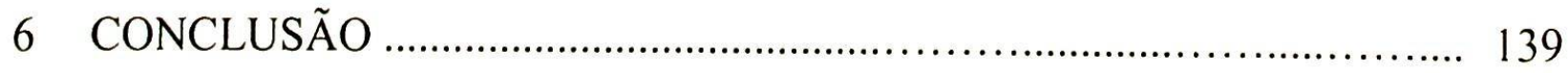

7 CONSIDERAÇÕES FINAIS.................................................. 141 
REFERENCIAS _....................................................................... 145

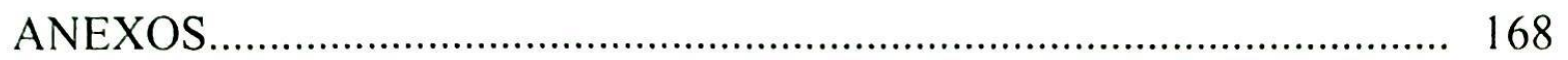




\section{LISTA DE TABELAS}

Página

TABELA 1 - Distribuição dos entrevistados quanto à idade e sexo..... 103

TABELA 2 - Estado conjugal segundo o sexo...................................... 105

TABELA 3 - Tempo de permanência no Programa Platinum.............. 106

TABELA $4 \quad$ - Período de freqüência no Programa Platinum................. 108

TABELA 5 - Determinantes de freqüência no Programa Platinum...... 110

TABELA 6 - Atividades praticadas no Programa Platinum................. 113

TABELA 7 - Nível de Satisfação (NS) dos entrevistados quanto às atividades freqüentadas no Programa Platinum............. 117

TABELA 8 - Nível de Satisfação (NS) dos entrevistados quanto aos objetivos atingidos ao freqüentar o Programa Platinum.

TABELA 9 - Nível de Satisfação (NS) dos entrevistados quanto ao estímulo do professor para melhora de desempenho.....

TABELA 10 - Nível Atendimento da Recepção ao ingressar no

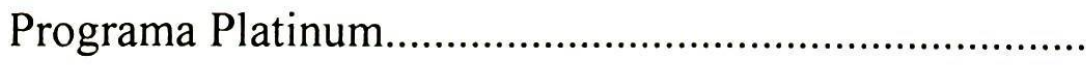

TABELA 10A - Principais qualidades quanto ao atendimento da recepção da academia para o sexo masculino.

TABELA 10B - Principais qualidades quanto ao atendimento da recepção da academia para o sexo feminino....................

TABELA 11 - Nível de Atendimento dos Professores do Programa Platinum. 
TABELA $11 \mathrm{~A}$ - Principais qualidades quanto ao atendimento dos professores do Programa Platinum para o sexo masculino.

TABELA 11B - Principais qualidades quanto ao atendimento dos professores do Programa Platinum para o sexo feminino

TABELA 12 - Explicações precisas e claras quanto ao funcionamento do Programa Platinum

TABELA 12A - Principais qualidades de informação sobre o funcionamento do Programa Platinum para o sexo masculino.

TABELA 12B - Principais qualidades de informação sobre o funcionamento do Programa Platinum para o sexo feminino.

TABELA 13 - Pontos Positivos do Programa Platinum

TABELA 14 - Pontos Positivos do Programa Platinum.

TABELA 15 - Sugestões dos entrevistados para melhorar o Programa Platinum. 


\section{LISTA DE FIGURAS}

Página

FIGURA 1 - Roteiro (Fluxograma) aluno Platinum................................. 74

FIGURA 2 - Alongamento Platinum......................................................... 83

FIGURA 3 - Multi Platinum.................................................................. 87

FIGURA 4 - Musculação e Cardiovascular Platinum.................................. 92

FIGURA 5 - Hidroginástica Platinum........................................................ 96 


\section{LISTA DE QUADROS}

QUADRO 1 - $\mathrm{N}^{\circ}$ de Academias em São Paulo (cidade e estado), Brasil e América Latina

QUADRO 2 - Percentual das principais queixas e dificuldades. 36

QUADRO 3 - Percentual das principais impossibilidades........................ 37 


\section{LISTA DE SIGLAS, ABREVIAÇÕES E SÍMBOLOS}
AAHPERD - American Alliance for Health Physical Education, Recreation and Dance
ACMS
- American College of Sports Medicine
AEA
- Aquatic Exercise Association
AF
- Atividade Física
AVD
- Atividade de vida diária
BID
- Banco Interamericano de Desenvolvimento
CEPAL
- Comissão Econômica para América Latina e o Caribe
CIE
- Centro Internacional de Informações para o Envelhecimento Saudável
CREF
- Conselho Regional de Educação Física
DeCS
- Descritores em Ciências da Saúde
Depto.
- Departamento
DP
- Desvio Padrão
IBGE
- Instituto Brasileiro de Geografia e Estatística
FEA
- Faculdade de Economia e Administração
FIA
- Fundação Instituto de Administração
FNUAP
- Fundo de População das Nações Unidas
IHRSA
- International Health Racquet Sportsclub Association
HD
- Hidroginástica
NS
- Nível de Satisfação
OIT
- Organização Internacional do Trabalho 


$\begin{array}{ll}\text { OMS } & \text { - Organização Mundial de Saúde } \\ \text { ONU } & \text { - Organização das Nações Unidas } \\ \text { OPAS } & \text { - Organização Panamericana de Saúde } \\ \text { PA } & \text { - Pressão Arterial } \\ \text { PG } & \text { - Programa } \\ \text { PROFUTURO } & \text { - Programa de Estudo do Futuro } \\ \text { RM } & \text { - Repetição Máxima } \\ \text { SABE } & \text { - Saúde, Bem-estar e Envelhecimento } \\ \text { RML } & \text { - Resistência Muscular Localizada } \\ \text { SINDESPORTE } & \text { - Sindicato dos Funcionários de Academias do Estado de São } \\ & \text { Paulo } \\ \text { SEEATESP } & \text { - Sindicato das Academias Patronal }\end{array}$




\section{LISTA DE ANEXOS}

Página

ANEXO I - Termo de Consentimento Livre e Esclarecido.................... 168

ANEXO II ～- Carta de Apresentação.................................................. 169

ANEXO III - Questionário................................................... 170

ANEXO IV - Ficha Controle Aluno Platinum......................................... 173

ANEXO V - Escala de Auto-Percepção do Desempenho de Atividades de Vida Diária....................................................................... 174

ANEXO VI - Programa de Treinamento.................................................. 175

ANEXO VII - Grade de Horários - Programa Platinum............................ 176 


\title{
RESUMO
}

\section{ANÁLISE DE UM PROGRAMA DE ATIVIDADE FÍSICA PARA IDOSOS EM ACADEMIA - UM ESTUDO EXPLORATÓRIO}

\author{
Autor: SIMONE CARVALHO SIMÕES PINHEIRO LIMA \\ Orientador: Prof. Dr. ANTÔNIO CARLOS MANSOLDO
}

O objetivo desta pesquisa foi o de analisar o programa (PG) de atividade física (AF) para idosos - "Programa Platinum" - por meio de uma amostra extraída de uma academia de grande porte, na cidade de São Paulo, Zona Sul, pertencente à unidade do bairro Morumbi. Foi observado o grau de satisfação (NS) do praticante idoso, quanto à estruturação, organização/planejamento e funcionamento/atendimento do $\mathrm{PG}$ de $\mathrm{AF}$. A população desta pesquisa é composta pelos indivíduos de 60 anos ou mais $(n=43)$ que participam do PG há pelo menos três meses. Desta forma, foi possível traçar o perfil dos praticantes do PG: é de maioria feminina e de casados, com idade média de 68,70 anos, freqüência média no PG de 13 à 24 meses, principalmente de manhã com maior participação nas aulas de Alongamento, Musculação e Esteira. Os principais motivos de freqüência do Programa Platinum para ambos os sexos foram: saúde, qualidade de vida, indicação médica. $\mathrm{O}$ seu (NS) em relação às atividades desenvolvidas e aos objetivos atingidos, obteve na sua maioria a nota máxima (cinco, muito satisfeito) e quanto ao estímulo do professor mostrou que os praticantes estão muito satisfeitos com a sua intervenção para a melhora de desempenho. Quanto ao atendimento prestado pela recepção e pelos 
professores, os resultados revelam um ótimo desempenho, agradando a todos os participantes do programa, revelando total aprovação.Portanto, a avaliação positiva relatada pelos praticantes idosos do Programa Platinum revelam que as estratégias utilizadas no programa são compatíveis ao que o programa de $\mathrm{AF}$ se propõe.

Palavras-chave: Perfil dos praticantes idosos, Programa de atividade física, Academia. 


\begin{abstract}
PHYSICAL ACTIVITY PROGRAM ANALYSIS FOR ELDERLY PEOPLE ON HEALTH CLUB - AN EXPLORATION STUDY

\author{
Author: SIMONE CARVALHO SIMÕES PINHEIRO LIMA \\ Adviser: Prof. Dr. ANTÔNIO CARLOS MANSOLDO
}

The main objective of this research was to analyze the Older Adults Physical Activities Program called "Platinum Program" belongs to a large fitness academy in São Paulo city - South Area. This study observed the satisfaction levels of Platinum Program when analyzed the following aspects: organization, planning, functionality and attending. The participants include individuals with more than sixty hears $(n=43)$ whose are in the Platinum Program at least three month. The profile of participants is mostly female and married; average 68.7 years old; from 13 to 24 months in the Platinum Program; doing theirs activities in the morning period with major participation on extension, muscular exercise and walking machine classes. The main reasons for these people (man and female) belong to the Platinum Program were health, life quality and medical indication. The satisfaction level of activities, reached goals and teacher incentive obtained the maximum score (very satisfied $=5$ ). The following aspects: front desk attending and teachers, obtained a good score (satisfied) for the hold participants. Therefore, the participants feed-back of Platinum Program shows us that the strategies chosen in this program are compatible with the physical activities intended.

Keywords: Profile of older adults participants, Physical Activity Program, Fitness Academy 


\section{INTRODUÇÃO}

Após os 60 anos, atividades do dia-a-dia como subir e descer escadas, ir ao banco, preparar refeições, recolher o lixo, passear com o cachorro, fazer o supermercado semanal, por exemplo, não são mais tarefas tão simples de serem realizadas. Muitas vezes a falta de disposição para realizar as atividades de vida diária torna-se uma constante na vida dos idosos.

Com o objetivo de diminuir o impacto das limitações funcionais da vida dos idosos, empresas oferecem serviços que aumentam a segurança, dentro e fora de sua residência, sem restringir a sua liberdade. Os indivíduos idosos podem contar com serviços diversos que vão dos cuidadores de idosos a empresas de turismo, promoção cultural, academias de ginástica, clínicas médicas, etc.

Devido à melhora na qualidade de vida, ou seja, alimentação, moradia, educação, saneamento básico e os avanços da medicina, a população de indivíduos idosos vive cada vez mais, ou seja, pelo aumento significativo da longevidade o seu crescimento é visto com um fenômeno mundial (SCHOUERI JUNIOR, RAMOS \& PAPALÉO NETTO, 1994).

Estima-se que em 2020 haverá 25 milhões de brasileiros com mais de 60 anos. O Brasil está deixando de ser um país jovem, de acordo com levantamento da ONU e em 2025, será o $6^{\circ}$ país do mundo com maior número de idosos.

É fato que o idoso é o consumidor do futuro, segundo constatações do levantamento realizado pelo PROFUTURO (Programa de Estudos do Futuro) da FIA/USP (2001). De acordo com os dados da pesquisa, o envelhecimento da população brasileira terá uma transformação significativa: estima-se que em 
$201020 \%$ da população terá mais de 50 anos com um crescimento representativo de $5 \%$, face a isto o mercado vinculado à prestação de serviços deve estar mais atento às atividades para os idosos, incrementando produtos relacionados a lazer e saúde, turismo, serviços médicos, construção civil e transportes.

Em outro significativo projeto que teve grande impacto no Brasil realizado recentemente por LEBRÃO e PELÁEZ (2003), o SABE (Saúde, Bemestar e Envelhecimento), no qual foram reunidos diversos países do mundo e mais especificamente o Brasil e América Latina, pode-se verificar que a população de idosos pertence a um contingente populacional que tem experiência de vida, qualificação e potencialidades a oferecer à sociedade.

Muito ainda está por se fazer no que diz respeito à população de idosos, tanto no segmento da saúde e do lazer que recebam maiores incentivos governamentais, campanhas educacionais que promovam a prática da atividade física regular e a adoção de um estilo de vida saudável.

Apesar da população ter o conhecimento que com a prática regular da atividade física pode ter uma melhor qualidade de vida, o índice de não praticantes, ou seja, de indivíduos sedentários ainda é muito elevado no mundo e no Brasil. Estudos realizados em diferentes países revelam que $70 \%$ da população é próxima de sedentária e que $90 \%$ seria insuficientemente ativa (MATSUDO, MATSUDO, ANDRADE, ARAÚJO, ANDRADE, OLIVEIRA \& BRAGGION 2001). No Brasil, os levantamentos populacionais existentes apontam resultados semelhantes. Dados publicados pelo último levantamento do IBGE (1998) estimam que 60 a $65 \%$ da população são fisicamente inativos.

Assim sendo, a estruturação de vários setores da economia deveria ser feita de maneira adequada para que se possa atender à população adulta a partir 
dos 60 anos, que incluam também programas de atividade física, inclusive em academias de ginástica (ANDREOTTI, 2001).

Atualmente temos diversos espaços acessíveis e com segurança destinados à prática de atividade física (AF) que está cada vez mais presente em academias, clubes, centros de convivência (SESC), escolas, hotéis, condomínios residenciais, empresas, spas, hospitais e clínicas de reabilitação. No geral, a população está se interessando também pelas academias (SABA \& ANTUNES, 2004).

Desta forma, é possível haver uma atenuação das ações do envelhecimento pela prática de atividade física regular utilizando as academias e locais apropriados como uma importante ferramenta de trabalho e de pesquisa. Segundo dados de uma pesquisa da IHRSA (2003) dos Estados Unidos, 23\% dos alunos matriculados em academias têm mais de 55 anos, ou seja, um alto índice percentual para futuros idosos do ponto de vista cronológico que já são fisicamente ativos e poderão contribuir no aumento de adesão da academia.

Com base nessas colocações, como profissional de Educação Física e exercendo atividades em academias há mais de 10 anos, o fortalecimento de relações com os idosos ganhou cada vez mais espaço no meu dia-a-dia. Passei a refletir mais sobre o seu universo e suas necessidades, e a identificar as limitações das academias quanto aos programas de exercícios físicos oferecidos aos idosos.

De acordo com os dados que se seguem no capítulo 3.1 em relação às tendências de mercado quanto ao perfil do idoso e do número de academias existentes no país (QUADRO 1), percebe-se que temos um mercado crescente e que deve ser tratado com respeito e atenção. Sabe-se que o crescimento da população de idosos é considerado um fenômeno mundial, assim sendo, pode-se 
esperar uma demanda maior de idosos à procura de programas de exercícios físicos nestas instituições.

Recentemente, há dois anos na academia avaliada para esta pesquisa, foi encontrado um meio propício junto à comunidade, diretoria e colegas para desenvolver o projeto denominado "Programa Platinum". Este programa iniciouse na unidade de Brasília, no departamento de Musculação, sob a orientação do Prof. Doutorando Sandor Bálsamo, gerente técnico de Musculação e Cardiovascular, que implantou o programa de musculação para os idosos que freqüentavam a sua unidade. Após nosso ingresso, atualmente o programa da unidade Morumbi, na cidade de São Paulo, trabalha de maneira integrada com uma equipe multidisciplinar, incluindo recepção/vendas, professores de Educação Física, Avaliador Físico, Nutricionista e Fisioterapeuta, abrangendo todos os departamentos da academia - Recepção, Ginástica, Musculação e Cardiovascular, Hidroginástica e Natação e Esportes.

Foram incluídas novas atividades em grupo: no departamento de Ginástica, com aulas de Alongamento Platinum e Multi Platinum; no departamento Aquático, com aulas de Hidroginástica e Natação e no departamento de Musculação e Cardiovascular, com um acompanhamento mais personalizado a cada hora por um professor de Educação Física, nos horários de maior concentração de idosos na academia. Com essas ações, proporcionou-se maior socialização ao grupo e aumento do número de alunos participantes e de alunos novos.

Acreditamos que este projeto de vida e de pesquisa irá contribuir com dados atualizados técnico-funcionais visando a avaliar uma proposta de programa de AF para idosos e assim, melhorar a estrutura do "Programa Platinum", bem como contribuir com novas informações com a comunidade 
cientifica e com a sociedade, principalmente em nível local para a melhoria da qualidade de vida dos idosos.

\section{$1.1 \quad$ Justificativa}

A pesquisa justifica-se, primeiramente, pela importância do trinômio Programa de Atividade Física / Idoso / Academia, por meio de um tema de caráter social fundamental e determinante para a melhoria da qualidade de vida dos indivíduos idosos, visto que é crescente o número de academias na cidade de São Paulo e poucas possuem um programa de exercícios estruturado para a população idosa.

BERQUÓ (1996), estudiosa na área de demografia brasileira e constantemente referida pela Geriatria e Gerontologia, preocupou-se na quantificação, avaliação e análise da população de idosos no Brasil. Segundo a autora, no período entre 2010 e 2020, a população brasileira de idosos crescerá em torno de $3,8 \%$, enquanto que o crescimento da população total será de $1 \%$. Portanto, o Brasil será o sexto país no mundo com o equivalente a 33 milhões de idosos, ficando apenas atrás da China, Índia, Rússia, Estados Unidos e Japão.

Com o cenário de um maior número de indivíduos que vivem mais é necessário que se determine a amplitude e os mecanismos em que o exercício e a atividade física podem melhorar de maneira significativa a saúde, a capacidade funcional, a qualidade de vida e a independência dos idosos (ACSM, 1998).

Devido a esse crescimento populacional, com reflexos também no aumento da população nos centros urbanos, associado a uma escassez de áreas verdes disponíveis e seguras para a prática regular de atividade física, as 
academias estão, cada vez mais, se tornando locais ideais para a prática (SABA, 1999).

Segundo dados publicados pelo IBGE (2000) no último CENSO, a população idosa brasileira está cada vez mais urbanizada. Houve, entre 1991 e 2000, um aumento do percentual de pessoas com 60 anos ou mais que vivem na área urbana, passando de $76,7 \%$ para $81,4 \%$.

As academias oferecem uma diversidade de produtos que buscam incentivar a prática de atividades físicas, visando não só a estética, ou seja, a obtenção de um corpo bonito, como também a saúde, o bem - estar e a qualidade de vida, de acordo com o perfil dos usuários que as freqüentam. Segundo os Descritores em Ciências da Saúde (BIREME, 2004) as academias de ginástica são definidas como instalações que têm programas que pretendem promover e manter um estado de bem-estar físico para ótimo desempenho e saúde.

TOSCANO (2001) corrobora as afirmações anteriores e aponta a academia de ginástica como sendo um centro com potencial para demanda em serviço de saúde primário, sendo possível sua ampliação para outros níveis de prevenção. Sugere, ainda, que a relação entre atividade física e saúde se justifica pelas diversas evidências de que indivíduos com níveis adequados de aptidão física, mantidos por meio de exercícios regulares no decorrer do curso de vida, apresentam efeitos benéficos nas funções dos órgãos em geral e, como conseqüência, o prolongamento da vida com qualidade.

Disseminar a idéia da adoção da prática de exercícios físicos como um estilo de vida saudável para todos os períodos da vida é de fundamental importância, inclusive para os idosos. Assim sendo, as academias têm um papel fundamental neste processo que pode ser considerada uma estratégia a mais que 
auxilie no processo de envelhecimento da população idosa, proporcionando atividade física orientada e segura, informação e reintegração social.

Pela experiência vivida por nós anteriormente, tendo trabalhado em diversas academias tanto de pequeno quanto de grande porte, podemos dizer que, nesse segmento, poucas academias na cidade e região metropolitana da cidade de São Paulo, possuem atualmente programas de atividade física embasados cientificamente e desenvolvidos especificamente para idosos. A pequena quantidade de pesquisas e estudos científicos, tanto nacionais quanto internacionais, sobre programa de AF para idosos que abordam tanto a área técnica quanto a operacional, leva a uma carência generalizada de conhecimentos, que geram dúvidas no plano dessas aplicações.

Desta maneira, estudos que avaliam uma proposta de programa de AF para idosos podem aumentar a possibilidade em oferecer indicativos mais críveis às academias, sendo aplicados com eficiência e segurança.

Ao levar em consideração a percepção do usuário quanto ao que o "Programa Platinum" se propõe em conjunto com os seus próprios objetivos e anseios, pode-se identificar com sua avaliação se os seus objetivos foram alcançados, tendo em vista a importância da qualidade no atendimento aos participantes e sua relação com a sua adesão e tomadas de decisão dos professores para a programação de exercícios, que são fatores essenciais na interação do programa/participante como descritos por PAINTER e HASKELL (1994).

É importante ainda ressaltar a necessidade de se implantar uma sistematização dos programas desenvolvidos, ou seja, preocupar-se desde o primeiro momento em que o idoso vêm à recepção pedir informações gerais 
sobre o programa de $\mathrm{AF}$ até o encaminhamento para a área técnica na prescrição das atividades.

Segundo AMORIM, MIRANDA, CHIAPETA, GIANNICHI, SPERANCINI e OSÉS (2002), em seu estudo, conclui-se que a adesão a programas de atividades físicas sistematizadas parece promover ou estimular a adoção de um estilo de vida mais ativo. Portanto, para nós professores de Educação Física, torna-se imprescindível a compreensão e o conhecimento da realidade local, do estilo de vida dos idosos praticantes, para que se possa viabilizar intervenções positivas que repercutam diretamente na autonomia dos praticantes.

Atualmente, o profissional de Educação Física é um prestador de serviço que deve estar muito bem preparado para poder dar ao praticante/usuário a desejada qualidade com competência e um bom atendimento. O conhecimento técnico dentro dos princípios científicos atuais é pré-requisito básico, como também o envolvimento de todos os profissionais de um programa de AF para idosos numa academia, com o foco direcionado para os objetivos comuns, tanto dos praticantes/usuários quanto do programa de AF (SABA \& ANTUNES, 2004).

Faz-se necessário então, a identificação da população de idosos que pratica atividade física nas academias, mais especificamente no universo da academia avaliada, na cidade de São Paulo, local escolhido por conter um significativo número de idosos (150), que já freqüentam o programa de atividade física denominado "Programa Platinum", há três anos. 


\section{OBJETIVO GERAL}

Analisar o programa de atividade física para idosos - "Programa Platinum" - quanto ao grau de satisfação do participante em relação à sua estruturação, organização / planejamento e funcionamento / atendimento.

\subsection{Objetivos Específicos}

- Identificar o perfil dos participantes do Programa Platinum quanto ao sexo, idade, estado civil, período de freqüência, tempo de prática e atividades mais freqüentadas;

- Identificar fatores determinantes que levaram os participantes a freqüentar o "Programa Platinum";

- Analisar o nível de satisfação dos praticantes do Programa Platinum em relação às atividades desenvolvidas, aos objetivos atingidos e ao estímulo dos professores;

- Analisar se o atendimento da recepção e dos professores ao participante é um fator determinante na sua continuidade do "Programa Platinum";

- Analisar se o "Programa Platinum" atende aos anseios dos praticantes idosos. 


\subsection{Perfil do idoso no Brasil}

O idoso e a mulher são os consumidores que ditarão as novas regras no mercado para 2010. O levantamento realizado pela PROFUTURO (Programa de Estudo do Futuro) FIAUSP (2001) que reuniu opiniões de diversos especialistas, buscou definir o perfil que o consumidor brasileiro terá daqui a dez anos (WRIGHT, 2001). As tendências foram obtidas utilizando-se a técnica Delphi, um instrumento de análise que faz previsões numéricas por meio de questionários repassados, anônima e repetidamente, a profissionais envolvidos com a área em estudo. Essa técnica pode ser usada em previsões a longo prazo, em casos onde há mudanças estruturais envolvidas ou quando se observa a falta de dados históricos concretos.

Os resultados da primeira parte da pesquisa acima citada mostraram que o mercado voltará suas atenções para as atividades voltadas para a mulher e para o idoso, incrementando produtos relacionados ao lazer e saúde, turismo, serviços médicos, construção civil e transportes. De acordo com WRIGHT (2001), temos uma demanda nova com suas particularidades, um público com propensão a gastar mais tempo e recursos financeiros com novos serviços. Será necessário melhorar o atendimento ao público agregando valores e serviços aos produtos com preços mais competitivos.

De acordo com MARTINS, JANUÁRIO e TABACH (2000) ao traçar o perfil do consumidor futuro, deve-se distinguir os grupos de indivíduos, separando-os por interesses comuns e estilos de vida para que se possa intervir 
de maneira precisa, adequando o produto de acordo com o que cada grupo necessitará mais. Consumidores com mais 50 anos de idade representam, hoje, $14 \%$ da população e logo após, estão os segmentos do mercado de idosos.

No projeto, "O Portal para a Terceira Idade", foi desenvolvido um estudo que procurou retratar o atual mercado brasileiro de idosos de maneira segmentada, de acordo com os seus perfis de estilos de vida. A expressão estilo de vida refere-se a coleções de padrões de pensamento e ações que as pessoas demonstram em vários graus (MOSCHIS \& GEORGE, 1992) e que podem, também, ser utilizados como variáveis de segmentação de mercados. Verificouse com este levantamento, cinco grupos distintos de idosos, com sua representação percentual atual e suas projeções percentuais para 2010, de cada um dos grupos listados da mesma faixa de idade:

1) Trabalhadores Seguros - representam atualmente 13,7\% do grupo de idosos, projeção para 2010 em 16\%. São sociáveis, não se permitem gastos consigo próprio. Não apresentam características de insegurança física, não se julgam saudáveis. Não são voltados à família, apresentam forte componente de engajamento. Grupo com grau de instrução médio e baixo (o maior peso de pessoas com o curso primário incompleto) e situação econômica pouco confortável. Grande incidência de pessoas que ainda trabalham. Contém, proporcionalmente, o maior número de pessoas com menos de 70 anos $(85,4 \%)$. Juntamente com os ativos despreocupados, constituem o segmento mais engajado em atividades de engrandecimento pessoal. Uma recomendação possível sobre qual seu padrão de consumo seria o oferecimento de atividades filantrópicas ou educativas. 
2) Jovens pródigos - representam atualmente $10,0 \%$ do grupo de idosos, projeção

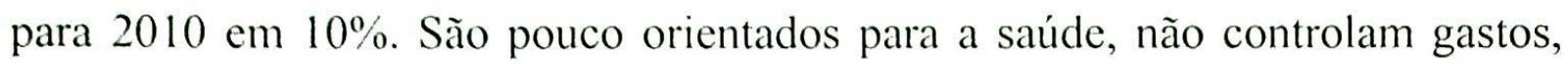
não se engajam em atividades de engrandecimento espiritual e são avessos às atividades físicas. O nível médio de instrução é o segundo nível mais alto dos grupos, $50 \%$ têm curso superior. Alta incidência de trabalhadores, que se deve mais à jovialidade própria do que à necessidade em si. Não exercem severo controle sobre gastos. O que se poderia sugerir em função do alto nível sócioeconômico-cultural do grupo, é oferecer bens e serviços de prestígio ou de um certo grau de motivação intelectual ou, então que visassem à manutenção da jovialidade, como atividades físicas, apesar de serem avessos a elas.

3) Aposentados saudáveis - representam atualmente 19,5\% do grupo de idosos, projeção para 2010 em 25\%. São muito sociáveis, adoram trabalhos manuais, exercem controle sobre gastos, têm muito tempo livre e se permitem poucos prazeres e novidades. São avessos às atividades físicas, constituem o grupo mais orientado para a família e o que menos se engaja em atividades de engrandecimento, mais orientado para a saúde e o que menos se percebe em mau estado. A grande quantidade de tempo livre e a extrema sociabilidade demonstrada pelos integrantes desse segmento sugerem o oferecimento de serviços que os congreguem. Sua forte orientação para a saúde pode gerar uma oportunidade de marketing; revistas e palestras sobre manutenção de um bom estado físico e alimentação na terceira idade poderiam constituir um atrativo para esse público.

4) Instruídos reservados - representam atualmente $16,5 \%$ do grupo de idosos, projeção para 2010 em 18\%. Não apresentam as características de sociabilidade e 
desprendimento, exercem severo controle financeiro sobre seus próprios gastos. Metade deles trabalham, apresentam o maior grau de instrução de todos os grupos. Seu consumo é seletivo, renunciam a supérfluos em detrimento de produtos de utilidade comprovada. Pode-se imaginar preliminarmente que devido ao alto grau de instrução, os integrantes deste segmento serão atraídos por ofertas que lhes demandem investimento intelectual.

5) Ativos despreocupados - representam $40,4 \%$ do grupo de idoso, projeção para 2010 em 40\%. Embora controlem os gastos, é o grupo que mais se permite prazeres (compras, novidades, etc.). São engajados em atividades, tanto físicas quanto de engrandecimento pessoal, privilegiam atividades externas e em grupo, são sociáveis e orientados para a família, não se preocupam com a saúde, dedicam-se pouco às atividades manuais. Possuem graus de instrução que vão do nível colegial completo ao superior incompleto. Têm a maior incidência de aposentados (57,4\%), com idades entre 60 e 79 anos e maior incidência de mulheres. Por estarem propensos a estar rodeados de pessoas, assim como a se dedicarem a atividades físicas e espirituais, sugere-se uma oferta de serviços onde haja oportunidade de serviços de caráter comunitário, ou ainda atividades nas quais se sobressaiam o encontro de pessoas, como excursões, academias, centros de convivência, etc.

Portanto, podemos verificar que o grupo número cinco, ativos despreocupados teve maior representatividade e embora tenham os seus gastos controlados, são engajados em atividades físicas e possuidores de um nível de instrução médio/bom. Os grupos dois e três, respectivamente; jovens pródigos e aposentados saudáveis representam juntos 29,5\%, um índice significativo e preocupante, pois são avessos às atividades físicas e apresentam uma relação 
inversa ao que as pesquisas apontam quanto ao nível de escolaridade e adesão à prática de AF. São dois grupos onde, de acordo com os autores do projeto, possa haver uma possivel intervenção voltada para os serviços que visem à manutenção da jovialidade como também ações orientadas para a saúde, focadas na manutenção de um bom estado de saúde e alimentação.

Em outra análise recente, a empresa Indicator GFK , $6^{\text {a }}$ posição no ranking mundial das empresas de pesquisa, que faz parte do grupo GFK alemão, realizou recentemente uma pesquisa que entrevistou 1800 indivíduos com mais de 60 anos denominada "Panorama da Maturidade", uma das maiores pesquisas sobre idosos realizadas pela rede privada no país. Este estudo foi desenvolvido em parceria com o IBGE, ONU e uma organização não governamental, o CIE (Centro Internacional de Informações para o Envelhecimento Saudável) nas questões relativas à maturidade.

Para representar de maneira adequada a população investigada, foi utilizada como base o perfil demográfico do IBGE nas dez principais regiões metropolitanas, além de Brasília e Goiânia para representar o Centro-Oeste do Brasil. Os dados publicados recentemente pelo IBGE, ONU, Indicator GFK (2003) revelaram que os brasileiros sexagenários ou mais somam hoje mais de 15 milhões de pessoas e são $9 \%$ da população adulta. Têm uma renda média de $\mathrm{R} \$ 589,00$ reais, o que significa $\mathrm{R} \$ 7,5$ bilhões mensais injetados na economia. É uma renda média superior à renda média da população entre 18 e 39 anos, que é de $\mathrm{R} \$ 513,00$ reais, e só perdem para a faixa etária de 40 a 59 anos, que tem média de $\mathrm{R} \$ 812,00$ reais.

Alguns dados anteriormente citados são confirmados por outro projeto publicado por LEBRÃO e PELÁEZ (2003), que envolveu várias organizações nacionais e internacionais, o SABE (Saúde, Bem-estar e Envelhecimento). Essa 
pesquisa teve grande impacto e contou com a colaboração da Organização Pan Americana da Saúde (OPAS/OMS), em convênio interagencial integrado pela Comissão Econômica para América Latina e o Caribe (CEPAL), o Fundo de População das Nações Unidas (FNUAP), o Programa de Envelhecimento das Nações Unidas, a Organização Internacional do Trabalho (OIT) e o Banco Interamericano de Desenvolvimento (BID), além da colaboração de diversos países da região com o objetivo de coletar sistematicamente informações sobre as condições de vida do idoso quanto aos aspectos sociais, econômicos, de saúde, redes de apoio, acesso aos serviços públicos, etc.

Esta pesquisa envolveu 2143 indivíduos com 60 anos e mais no Município da cidade de São Paulo e seus resultados caracterizaram amplamente o perfil das condições de vida e necessidades do idoso. Os principais resultados que emergiram da pesquisa revelaram que $\mathbf{5 8 , 6 \%}$ do universo dos idosos é feminino, uma em cada quatro tem 75 anos ou mais e para os homens a proporção é de um para cinco, confirmando que a velhice é feminina, pela maior longevidade da mulher.

Com relação ao estado conjugal, $57 \%$ dos idosos são casados, $29,5 \%$ viúvas, $8,5 \%$ separados ou divorciados e $4,9 \%$ solteiros. O índice significativo de viúvas pode ser explicado pelo fato das mulheres terem uma expectativa de vida maior do que os homens e estes, com casamentos mais tardios e maior facilidade de recasamento.

Outra característica interessante é que atualmente $\mathbf{1 3 , 1 \%}$ dos idosos vivem sozinhos enquanto que há cinco anos eram apenas $6 \%$; entre os que têm 80 anos ou mais temos uma porcentagem ainda maior de $21,5 \%$. Ainda que apresentem dificuldades para realizar as AVDs (atividades de vida diária) (17\% relatam dificuldades para se vestir, 51\% mal conseguem agachar-se e $17 \%$ mal 
conseguem caminhar uma quadra), 70\% não recebem ajuda de ninguém, ou seja, se consideram independentes.

O nível de escolaridade foi considerado muito baixo, representando $21 \%$ da população de analfabetos e $46,4 \%$ com menos de quatro anos de estudo, sendo que as mulheres apresentaram menor nível de educação. Quanto maior o nível de escolaridade, maior a renda mensal, em torno de $2 / 3$ dos idosos ganham entre hum a cinco salários mínimos (hum salário mínimo $=R \$ 150,00$ dados coletados em 2001).

Com relação à prática regular de atividade física, ou seja, prática regular nos últimos 12 meses, $\mathbf{2 6 , 5 \%}$ dos idosos são praticantes regulares, sendo mais freqüente no grupo de 60 a 75 anos, com $29,5 \%$ para os homens e $24,5 \%$ para as mulheres. Verificou-se que os homens, em qualquer idade, fazem mais exercícios do que as mulheres (60 a 75 anos, 75 anos e mais).

Desta maneira, ao traçar o perfil dos consumidores futuros, podemos distingui-los por interesses comuns, necessidades e estilos de vida. Quando pensamos no indivíduo idoso isso tende a se agravar, pois são consumidores com características diferenciadas e que necessitam de atendimento mais personalizado. Algumas tendências apontadas pelo questionário Delphi, corroboram a afirmação anterior, mostrando que devemos ter uma preocupação com o comportamento do consumidor, bem como com a exigência de um melhor atendimento e a valorização de produtos com serviços agregados (WRIGHT, 2001). 


\subsection{Academias de Ginástica - Uma tendência de mercado}

A história das academias no mundo e no Brasil podem explicar a sua origem e características atuais. Muitas delas, infelizmente, ainda estão voltadas, em grande parte, para a melhoria dos aspectos estéticos dos usuários/ praticantes, como principal objetivo a ser conquistado, que pode ser um aspecto restritivo à população idosa. De acordo com LARIZZATTI (1999), não podemos esquecer que a estética do corpo é um conceito mutável, de sociedade para sociedade e de tempos em tempos.

Desta maneira é importante salientar que a instituição Academia, de acordo com a resolução $n^{\circ} 104963$, do Ministério do Trabalho, publicada no Diário Oficial da União de 10 de fevereiro de 1984, à página 2112, seção I, pode ser conceituada como a empresa que se dedica a ministrar cursos de ginástica, ballet, danças, musculação, lutas e cultura física de modo geral, lecionados por professores diplomados em Cursos Superiores de Educação Física.

TOSCANO (2001) conceitua as academias de ginástica como centros de atividades físicas onde se prestam serviços de avaliação, prescrição e orientação de exercícios físicos, sob supervisão direta de profissionais de Educação Física.

De acordo com SABA (1999), os centros de AF como as academias, vêm se tornando um local cada vez mais procurado por diversas populações, dentre elas os idosos. Nas grandes cidades, as academias se tornaram locais importantes para a prática de exercício físico na aquisição e manutenção da saúde física e psicosocial.

Por outro lado, as academias possuem recursos financeiros e humanos (profissionais formados em Educação Física), com infra-estrutura física 
(instalações, aparelhagens) e programas de exercícios variados que facilitam e incentivam o convívio social dos praticantes. Oferecem aulas variadas com exercícios específicos, respeitando sempre que possível as diferenças individuais dos praticantes.

Se tentarmos enxergar as academias como um laboratório, percebemos que as variáveis (diversidade de aulas, horários, salas, equipamentos) podem ser isoladas mais facilmente para que os elementos (objetivo inicial, aptidão física inicial, prescrição de programa experimental de treinamento, socialização/ integração) sejam trabalhados de maneira adequada, propiciando ao aluno a aquisição de um conhecimento básico e opção posterior de fazer atividades físicas onde preferir (LARIZZATTI, 1999). Acredita-se que com uma atividade física mais controlada e bem orientada pode-se obter benefícios tanto para os indivíduos idosos quanto para o restante da população.

De acordo com dados quantitativos, fornecidos pelos SINDESPORTE (Sindicato dos Funcionários de Academias do Estado de São Paulo), SEEATESP (Sindicato das Academias Patronal), CREF (Conselho Regional de Educação Física), IHRSA (International Health Racquet Sportsclub Association), em 2003, foram relacionadas as academias existentes na América Latina, no Brasil, no Estado e na cidade de São Paulo representando, conforme QUADRO 1 que se segue: 


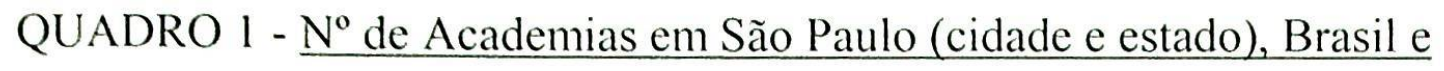
América Latina.

\begin{tabular}{|c|c|c|}
\hline LOCAL & $\mathbf{N}^{\mathbf{0}}$ ACADEMIAS & FONTE \\
\hline $\begin{array}{c}\text { Interior e litoral de São } \\
\text { Paulo }\end{array}$ & 1276 & SINDESPORTE \\
\hline \multirow{3}{*}{\begin{tabular}{c} 
Grande São Paulo \\
\cline { 2 - 3 }
\end{tabular}} & 2694 & CREF \\
\cline { 2 - 3 } & 1190 & SINDESPORTE \\
\hline Estado de São Paulo & 2875 & SINDESPORTE \\
\hline Brasil & 2466 & IHRSA \\
\hline América Latina & 7000 & IHRSA \\
\hline
\end{tabular}

Deve-se ressaltar que os dados fornecidos pela IHRSA não incluem clubes, hotéis, spas e fitness center. Nos números do SINDESPORTE estão incluídas 793 academias que não possuem funcionários. O SEEATESP informa que temos aproximadamente 1000 academias vinculadas a sindicatos que se dizem representantes das escolas de cursos livres e/ou estabelecimentos de ensino. O SEEATESP é o representante de academias responsáveis pelo condicionamento físico e pela iniciação e prática de atividade física, podendo o número de academias estar entre 6000 a 6500 no Brasil.

Atualmente as academias são procuradas não somente pela melhora do aspecto visual corporal, mas principalmente pelo conceito de Wellness (bemestar e qualidade de vida), oferecendo atividades que sociabilizam como hidroginástica, esportes, artes marciais, ginástica localizada, circuitos, etc. 
Percebe-se que muitos idosos iniciam a atividade fisica por recomendação médica (ANDRADE, MATSUDO, MATSUDO, ARAÚJO, ANDRADE, OLIVEIRA \& FIGUEIRA, 2000). Atualmente, a AF se tornou uma aliada na busca de melhorar a qualidade de vida e hoje vai muito mais além.

É crescente o número de academias de ginástica no Brasil e no mundo. Nos Estados Unidos, por exemplo, mais conhecidas por medical fitness centers, estão cada vez mais filiadas a hospitais. Nos anos 80, eram menos de 100 e em 2003 subiram o seu número para quase 700 (NADEL, 2003). STOUT (1995) cita, que muitos hospitais, interessados na promoção da saúde e bem-estar da comunidade, têm construído academias como forma de oferecer serviços que ajudem na aquisição de um estilo de vida mais saudável pela comunidade.

Atualmente, o maior mercado mundial é os Estados Unidos, com 34 milhões de alunos, em 17.800 academias, com faturamento de 12,2 milhões de dólares. O Brasil, $4^{\circ}$ mercado mundial de academias de ginástica, é também representado com números expressivos constituído por 2,8 milhões de alunos em 6000 academias, com um faturamento de 3 bilhões de reais (FITNESS BRASIL, 2005).

\subsection{Efeitos da Atividade Física em idosos}

Atualmente, grandes evidências epidemiológicas sustentam um efeito positivo de um estilo de vida ativo e/ou do envolvimento dos indivíduos em programas de atividade física ou exercício na prevenção e diminuição dos efeitos deletérios do envelhecimento (ACSM, 1998). Cada vez mais é enfatizada pelos pesquisadores, a necessidade de que a atividade física seja parte fundamental dos programas mundiais de promoção da saúde. 
Visto que, após os 20 anos o envelhecimento começa a deteriorar muitas funções, SPIRDUSO (1995) cita que em torno de 50\% desse declínio pode ser atribuído ao desuso ou inatividade física.

Verificou-se em estudos longitudinais a diminuição da incidência das enfermidades quando se adotam comportamentos positivos em relação à saúde $\mathrm{e}$ a um estilo de vida mais ativo. Deve-se aumentar os anos de vida com qualidade, ao invés de se caracterizar essa fase da vida por um período de maior sofrimento, limitações e morbidade (MATSUDO, 1997).

Com o objetivo de analisar os padrões de AF durante o curso de vida de mulheres idosas ativas e sedentárias, COUSINS e KEATING (1995) determinaram os eventos similares que aconteceram na vida dessas mulheres. Foi verificado que as mulheres ativas direcionaram de maneira diferente os desafios, pois começaram ou mantiveram a prática da $\mathrm{AF}$, enquanto que as inativas tentaram conservar suas energias reduzindo ou parando de se exercitar.

HILLSDON, BRUNNER, GURALNIK e MARMOT (2005) comprovaram que os praticantes de atividades físicas regulares têm menos possibilidades de ter problemas físicos no futuro. Este estudo longitudinal, realizado por cientistas ingleses e estadunidenses, verificou que durante os 8,8 anos de pesquisa, com 6.398 voluntários, na faixa etária dos 39 aos 63 anos, a atividade física deve ser iniciada mesmo antes do início do declínio físico vinculado com a idade. $\mathrm{O}$ estudo afirma que homens e mulheres de meia-idade que praticam exercícios regularmente correm menos risco de sofrer limitações físicas na velhice.

PINI (1983) afirma que a saúde corresponde a uma condição harmônica de desenvolvimento físico, funcional e mental do indivíduo, dinamicamente integrado no seu ambiente natural e social, aliado a um estado de 
perfeita eficiência da pessoa como um todo. Desta maneira, os benefícios que a prática de exercício físico proporcionam estão relacionados, portanto, aos campos biológicos, psicológicos e sociais do ser humano.

Existe um consenso entre os profissionais da área da saúde que a prática regular de atividades físicas seja um fator determinante para se atingir um envelhecimento saudável (MATSUDO, 2001). Seria lamentável que após tantas pesquisas e esforços para se estender a vida humana por um tempo maior, não possuíssemos as mínimas condições necessárias para vivê-la com qualidade.

O exercício físico torna-se, então, um elemento fundamental no processo de envelhecimento, possibilitando viver esta fase de vida como um processo saudável e natural. Para que isso ocorra, o indivíduo idoso necessita de um nível mínimo de aptidão física que lhe permita realizar as AVDs com mínimo de esforço, ter energia para que participe de outras atividades de lazer, ter reservas energéticas para que se restabeleça rapidamente de uma doença, minimizar riscos de futuras doenças e promover um sentimento de bem-estar e de sentido de existência pessoal (CARVALHO \& MOTA, 2002).

O combate ao sedentarismo, de acordo com DISHMAN (1988a), é um elemento fundamental para melhorar a qualidade de vida, quando associado com a prática de atividade física. A qualidade de vida pode ser definida como uma percepção individual relativa às condições de saúde e a outros aspectos gerais da vida pessoal.

Segundo GONÇALVES (1999), mesmo sabendo dos efeitos positivos da prática da atividade física em todas as fases de vida, ainda é preciso mais investimentos em pesquisas para se compreender sua influência no comportamento humano, especialmente no comportamento de indivíduos idosos que são fortemente influenciados por diversas variáveis sociais. 
A Organizaçào Pan-americana de Saúde, OPAS ligada à OMS, afirma que: "a importância da promoção de saúde cntre os idosos deve basear-se no conjunto de ações que promovam mudanças no estilo de vida. objetivando a diminuição do risco de adoecer e morrer, estabilizando e melhorando a saúde dos individuos em sua totalidade, aliando a sua saúde fisica à sua complexidade social".

De acordo com SANTARÉM (1997), as pessoas fisicamente ativas diminuem a probabilidade de desenvolver doenças crônicas e melhoram seus níveis de aptidão física e disposição mental. Alguns estudos associam pouca atividade física com altas taxas de mortalidade por todas as causas, e estima-se que 250.000 mortes por ano nos Estados Unidos da América poderiam ser evitadas pela prática de atividade física habitual.

Temos como principais benefícios e melhoras significativas nas condições de saúde dos idosos pela prática regular de exercício físico a diminuição da P.A. (pressão arterial), diminuição da incidência de doenças cardiovasculares, retardamento do aparecimento de diabetes mellitus, controle do estresse e da obesidade, redução da ocorrência de alguns tipos de cânceres, aumento da expectativa de vida, melhora da auto-estima, auto-imagem e autoconceito, diminuição da ansiedade e depressão, melhora da integração social e principalmente da aptidão funcional (CORBIN \& LINDSEY, 1996; DISHMAN \& SALLIS, 1994; NIEMAN, 1999; NÓBREGA, FREITAS, OLIVEIRA, LEITÃO, LAZZOLI, NAHAS, BATISTA, DRUMMOND, REZENDE, PEREIRA, PINTO, RADOMINSKI, LEITE, THIELE, HERNANDEZ, ARAÚJO, TEIXEIRA, CARVALHO, BORGE \& DE ROSE, 1999; SANTARÉM, 1997; ZAGO \& GOBBI, 2003). 
Em outra revisão recente de KELL, BELL e QUINNEY (2001), concluiu-se que a atividade física reduz os riscos de doenças cardiovasculares, aumenta a densidade mineral óssea retardando a osteoporose, melhora a flexibilidade, aumenta a tolerância à glicose, melhora o desempenho para a realização das AVDs.

Julga-se que esses benefícios são comuns a qualquer tipo de atividade física, entendida como contração muscular, envolvendo movimento ou não (contração muscular isométrica) e com gasto calórico sempre. Por meio de diversos mecanismos de movimento, como o trabalho braçal, as diversas modalidades esportivas, o lazer com atividades físicas e os programas sistematizados de condicionamento físico é que se consegue proporcionar efeitos benéficos no organismo do idoso (SANTARÉM, 1997).

Assim sendo, para se implantar um programa de AF para idosos devemos levar em consideração alguns aspectos do envelhecimento humano que influenciam diretamente na aplicação das diretrizes do programa. Faz-se necessário ter o conhecimento dos efeitos da atividade física nas principais variáveis de aptidão física quanto às variáveis antropométricas, neuromotoras e metabólicas, na capacidade funcional e nos aspectos psicológico e social.

\subsubsection{Na Aptidão Física}

São consideradas neste estudo sobre as principais variáveis de aptidão física - antropométricas, neuromotoras e metabólicas, conforme segue. 


\subsubsection{Variáveis antropométricas}

Considerando as variáveis antropométricas, o efeito do exercício físico regular para o idoso está associado com o controle do peso corporal, diminuição e/ou manutenção da gordura corporal central e periférica e da massa muscular.

FIATARONE-SINGH (1998a) realizou uma grande revisão dos aspectos antropométricos do envelhecimento e sua relação com a atividade física. Nesta revisão, enfatiza que grande parte dos estudos transversais sugere que a atividade física tem um papel de modificação das alterações do peso e composição corporal relacionadas à idade. De acordo com sua análise, aqueles indivíduos que se classificam como mais ativos têm menor peso corporal, índice de massa corporal, porcentagem de gordura corporal e relação cintura/quadril do que os indivíduos da mesma idade sedentários.

Entretanto, de acordo com MATSUDO e MATSUDO (2000) parece que o exercício não evita completamente o acúmulo de gordura corporal que acontece com a idade, particularmente após os 60 anos. Segundo verificações transversais e longitudinais, a participação voluntária em programas de exercício sugere uma atenuação no declínio da taxa metabólica de repouso relacionado à idade e o aumento dos estoques centrais e totais de gordura corporal.

Um outro estudo longitudinal, realizado por HAGERMAN, FIELDING, FIATARONE, GAULT, KIRKENDALL, RAGG e EVANS (1996), por um período de 20 anos com atletas olímpicos, verificou que houve um aumento da gordura corporal dos atletas de $12,3 \%$ para $15,6 \%$ entre os 24 e 44 anos de idade; o mais interessante é que só na primeira década houve a maioria do acúmulo de gordura, quando justamente se evidenciou uma diminuição do volume de treinamento dos atletas, mas mesmo assim, a média de gordura dos 
atletas olimpicos foi menor do que os não atletas. Portanto, apesar das evidências positivas da influência do exercício físico na composição corporal de idosos, temos resultados conflitantes em relação aos efeitos do exercício físico na porcentagem de gordura corporal desses indivíduos.

RANTANEN e HEIKKINEN (1998), em um estudo longitudinal de 5 anos em homens e mulheres dos 80 aos 85 anos, revelou que o peso e a massa magra corporal no sexo masculino não se modificou e que no sexo feminino houve uma pequena diminuição significativa destas variáveis. Quando comparados em relação ao nível de atividade física, os homens fisicamente ativos, em relação aos sedentários, mostraram um pequeno aumento da massa magra durante o período de seguimento, sendo estatisticamente pouco significativo em relação aos sedentários; quanto às mulheres, o grupo de sedentárias apresentou valores maiores de massa magra, mostrando um resultado contrário ao esperado pelos pesquisadores.

De maneira similar FIATARONE-SINGH (1998a) relatou uma diminuição, nenhuma alteração e até aumentos do percentual de gordura corporal de indivíduos idosos em 10 anos contínuos de treinamento de endurance .

Apesar dos poucos estudos randomizados, controlados e com mensurações adequadas da gordura corporal, principalmente em mulheres com 60 anos e mais, MATSUDO e MATSUDO (2000) acreditam que o incremento da atividade física é fundamental no controle do peso e da gordura corporal durante o processo de envelhecimento, podendo contribuir na prevenção e controle de algumas condições clínicas, como as doenças cardiovasculares, o diabetes, a hipertensão, o acidente vascular cerebral, a artrite, a apnéia do sono, o prejuízo da mobilidade e o aumento da mortalidade, como citadas por FIATARONE-SINGH (1998b). 


\subsubsection{Variáveis neuromotoras}

As qualidades de aptidão física como coordenação, velocidade, força, flexibilidade, potência, resistência e condição aeróbia são reduzidas na população de idosos devido ao sedentarismo ou a hipocinesia induzida por doenças que podem comprometer a capacidade de realizar atividades diárias, dificultando a locomoção, aumentando os riscos de quedas e criando até situações de risco cardiovascular nas atividades do dia-a-dia (SANTARÉM, 1997).

As principais qualidades de aptidão física neuromotora que mais comprometem a qualidade de vida do indivíduo idoso quando reduzidas são a força e a flexibilidade (SANTAREM, 1997).

Segundo OKUMA (1998), a aptidão muscular, outro termo denominado pelo American College of Sports Medicine (ACSM) como sendo o conjunto das diversas capacidades motoras tais como, força muscular, resistência muscular localizada (RML) e flexibilidade, é de maior importância do que a aptidão cardiovascular para o idoso, para que se mantenha independente nas realizações das AVDs. POWERS e HOWLEY (2000) acreditam que o processo de envelhecimento acarreta uma perda de massa muscular, mas que essa redução deve-se também à atrofia associada à ausência ou limitação de atividade física praticada pela população de idosos.

MATSUDO, MATSUO e BARROS (2000) corroboram as afirmações anteriores e enfatizam que a perda da massa muscular tem sido relacionada com alguns riscos à saúde do idoso, trazendo prejuízo na capacidade aeróbica 
máxima, maior intolerância à glicose, baixa taxa metabólica de repouso, disfunção imune, diminuiçào da velocidade de andar e dependência funcional.

Assim sendo, o treinamento específico da força muscular é um elemento fundamental na prevenção, no controle e na reabilitação da saúde do idoso.

Quanto à capacidade de manutenção da postura, do equilíbrio e da locomoção do idoso verificou-se que são diretamente dependentes da ação da força muscular (GURALNIK, FERRUCI, SIMONSICK, SALIVE \& WALLACE, 1995).

Apesar dos diversos protocolos existentes sobre o treinamento de força em idosos, o que torna difícil fazer comparações entre os estudos, muitos pesquisadores relatam aumentos de força após o treinamento de resistência em indivíduos idosos (FRONTERA, DAWSON \& SLOVIK, 2001).

Em um estudo longitudinal realizado por FIATARONE, MARKS e RYAN (1990), no qual foram avaliados indivíduos de 86 a 96 anos, com participação num programa de treinamento de oito semanas, com freqüência semanal de três vezes, visando o fortalecimento da musculatura dos membros inferiores, observou-se uma melhora em média, de $174 \%$ na força e $48 \%$ na velocidade do passo. Apesar dessa melhora, após 4 semanas de suspensão do treinamento houve uma diminuição de $32 \%$ na força, o que reforça ainda mais a importância da continuidade do treinamento na população de idosos.

Os efeitos do treinamento de força assim como o do treinamento aeróbico dependem diretamente da intensidade, da duração, da freqüência e da extensão. BUCHNER (1993) verificou que intensidades mais altas levam a aumentos significativos de força, enquanto que as intensidades mais baixas em 
idosos levaram a aumentos inferiores a $20 \%$ nos ganhos de força (FISCHER, PENDERGAST \& CALKINS, 1991; LARSSON, 1982).

Em outro estudo de FIATARONE (1996) concluiu-se que o treinamento de força muscular no idoso trouxe benefícios na melhora da velocidade de andar, do equilíbrio, no aumento do nível de atividade física espontânea, na melhora da auto-eficácia, na contribuição para manter ou aumentar a densidade óssea, na melhora da ingestão dietética e na diminuição da depressão. BROWN, McCARTNEY e SALE (1990) corroboram esta informação mostrando que o treinamento de força também melhora a performance muscular submáxima em idosos. Em seu estudo verificaram que a resistência muscular-definida como a capacidade de levantar o peso de 1 RM (repetição máxima) a máxima inicial - aumentou de uma repetição para até 10 repetições, ou seja, houve uma mudança de uma atividade máxima para uma atividade submáxima. Desta maneira, poderia influenciar diretamente na melhora da realização de atividades do dia-a-dia que requerem um esforço submáximo constante, como subir escadas.

Quanto ao aspecto neuromotor, o treinamento específico da força muscular leva à hipertrofia das fibras musculares I (14-48\%) e II (20-62\%), aumento da força muscular (9-227\%) dos membros superiores (18-67\%) e inferiores (32-227\%) (PORTER, VANDERVOORT \& LEXELL, 1995), assim como da capilaridade e capacidade oxidativa muscular (CARTEE, 1994; ROGERS \& EVANS, 1993), melhora na flexibilidade e diminuição das quedas (HURLEY \& HAGBERG, 1998).

Outra variável neuromotora tão importante quanto a força muscular é a flexibilidade. Ela se desenvolve até à idade adulta dos 20 aos 25 anos aproximadamente e diminui de maneira mais acentuada a partir dos 55-60 anos 
(CARVALHO \& MOTA, 2002). A flexibilidade do quadril ou dos ísquio-tibiais e paravertebrais, principais musculaturas envolvidas na manutenção da postura e na estabilização do tronco, declina de 20 a 30\% entre os 20 e 70 anos (ADAMS, 1998) e de maneira mais acentuada a partir dos 80 anos (SHEPHARD \& BERRIDGE, 1990). Tais declínios se devem ao próprio envelhecimento, trauma por estresse mecânico, artrite (RAAB, AGRE, McADAM \& SMITH, 1988), desuso ou imobilização pela diminuição da atividade física e inatividade física (HEYWARD, 1991). Desta maneira, a redução da flexibilidade do quadril poderá causar uma limitação no desempenho funcional das AVDs, ocasionando muito desconforto e dependência física ao idoso (POLLOCK, 1998; JETTE \& BATTOMLLEY, 1987).

GURALNIK et al. (1995) e MATSUDO, MATSUDO e BARROS (2000) reafirmam que a redução da flexibilidade pode dificultar a realização de movimentos ou até mesmo impedi-los, tais como na dificuldade do andar, subir escadas, levantar-se de uma cadeira ou da cama. Deste modo, a diminuição da atividade fisica com o envelhecimento parece ser uma das principais causas da perda da flexibilidade (BROWN \& HOLLOSZY, 1991), pois produz o enrijecimento dos tecidos conectivos (ligamentos, tendões e músculos) diminuindo a amplitude articular, que por sua vez reflete diretamente na mobilidade articular.

O exercício físico pode ser considerado um elemento importante para a manutenção e o aumento de flexibilidade em idosos. Os ganhos na flexibilidade parecem atenuar os declínios desta capacidade motora favorecendo uma melhora na realização das AVDs (UENO, OKUMA, MIRANDA, FILHO \& HO, 2000). Segundo os autores, devido à pequena quantidade de estudos e aos conflitos entre os pesquisadores que estudam a relação de programas de exercício com 
ganhos de flexibilidade em idosos, não podemos tomar essas relações como referências verdadeiras ou definitivas.

Pesquisas como a de MOREY, COWPER, FEUSSNER, DiPASQUALLE, CROWLEY, KITZMAN e SULLIVAN (1989) verificaram uma melhora significativa da flexibilidade do quadril nos indivíduos idosos, com idades acima dos 64 anos. Este estudo longitudinal teve a duração de 12 semanas com três sessões semanais e duração de 90', contendo atividades diversas como a bicicleta, caminhada, exercícios de força e flexibilidade.

MATSUDO, MATSUDO e BARROS (2000) citam um outro estudo de BENEDETTI e PETROSKI (1999), realizado com 38 mulheres asiladas durante cinco semanas que incluía exercícios físicos variados no programa de intervenção. Foram verificadas melhoras significativas na força muscular, principalmente no músculo quadríceps e da flexibilidade, com maior ênfase na flexão do ombro.

Percebe-se então que os ganhos de flexibilidade adquiridos por meio de programas de exercícios variados que incluem os alongamentos parecem atenuar os declínios desta capacidade motora na população de idosos.

Quanto à variável coordenação, percebe-se que com o envelhecimento há uma diminuição da velocidade e da combinação de movimentos que geram um maior risco de acidentes, WEINECK ${ }^{1}$ (1991, apud ZAGO \& GOBBI, 2003). SPIRDUSO (1995) num estudo com 70 idosos, verificou que $13 \%$ da sua amostra tinha dificuldades de coordenação em várias tarefas, como por exemplo, inserir uma chave na fechadura.

\footnotetext{
' WEINECK, J. Biologia do esporte. São Paulo:Manole.1991.599p.
} 
Estudos como o de POLASTRI²et al. (1999, apud ZAGO \& GOBBI, 2003) mostrou que a atividade física pode melhorar o nível de coordenação motora em idosos por meio de um programa de AF generalizada de intensidade moderada. Foi realizado o teste de coordenação proposto pela AAHPERD (AMERICAN ALLIANCE FOR HEALTH PHYSICAL EDUCATION, RECREATION AND DANCE) no decorrer de um ano com quatro avaliações que demonstraram melhoras significativas na coordenação dos idosos ativos.

De acordo com PUGGAARD, PEDERSEN, SANDAGER e KITGAARD (1994), a coordenação pode ser melhorada por meio da aprendizagem e da prática regular de uma determinada tarefa. A atividade física melhora a integridade do tecido cerebral, ajudando na manutenção da capacidade de atenção e concentração, o que irá interferir diretamente no tempo de reação e de movimento. Assim sendo, estimular exercícios dessa natureza, que incluam atenção, concentração e memória são de extrema importância para os idosos.

\subsubsection{Variáveis metabólicas}

A capacidade para se exercitar depende da integração de vários sistemas: sistema cardiovascular, motor e neural durante o estresse físico. Temos como medida fisiológica padrão para se determinar a capacidade total de um indivíduo para o exercício o consumo de $\mathrm{O}_{2}$ ou $\mathrm{VO}_{2}$ máx.

Com relação à capacidade aeróbica, normalmente avaliada pelo consumo máximo de oxigênio $\left(\mathrm{VO}_{2}\right.$ máx), se não for exercitada diminui com o

\footnotetext{
2 POLASTRI, P. F.; SILVA, V. M.; VILLAR, R.; ZAGO, A. S.; GOBBI, S. Alterações nos níveis de coordenação de pessoas da terceira idade através de um programa de atividade física generalizada. Revista Motriz, Rio Claro, v.5, n.1, p.115, 1999.
} 
passar dos anos, em torno de 5 a 15\% por década e, por volta dos 70 anos esta perda pode chegar até 50\% (RICKLI \& JONES, 2001). De acordo com SHEPHARD (1997), essa alteração pode ser atenuada pelo treino de resistência ou de condicionamento cardiovascular.

MATSUDO, MATSUDO e BARROS (2000) citam um estudo realizado por MACEDO, DUARTE e MATSUDO (1987), no laboratório CELAFISCS, em que foi comparado o $\mathrm{VO}_{2}$ em diferentes faixas etárias a partir dos 18 anos até os 81 anos. Verificou-se que as mulheres ativas (praticantes regulares de atividade física) nas faixas etárias de 60-69 e de 70-81 anos, possuíam valores maiores de $\mathrm{VO}_{2}$ quando comparadas às mulheres sedentárias (não praticantes de atividade física) da mesma faixa etária.

Recentemente, HAKIM, PETROVITCH, BURCHFIELD, ROSS, RODRIGUEZ, WHITE, CURB e ABBOT (1998) verificaram, num estudo longitudinal de 12 anos, que a prática da caminhada regular está diretamente relacionada com uma mortalidade diminuída. FRIES, GURKIRPAL, SINGH, MORFELD, HUBERT, LANE e BRAWN (1994), num outro estudo longitudinal de oito anos, com corredores de 50 a 72 anos, verificaram que os benefícios do exercício aeróbico a longo prazo também atenuou a morbidade, os escores de incapacidades e os custos com cuidados da saúde.

De acordo com ANDREOTTI (1999), com a prática regular de AF, principalmente com atividades aeróbicas, a função cardiovascular respiratória melhora tanto em jovens quanto em idosos. OKUMA (1998) cita que em virtude das adaptações fisiológicas pela prática da AF, há aumento da densidade capilar nos músculos, um possível desenvolvimento de vascularização colateral, regressão de lesões arteroscleróticas, aumento ventricular, declínio na duração da 
contração do miocárdio, redução da freqüência cardíaca de esforço e aumento no volume sistólico.

Foi observado por LEE, HSIEH e PAFFENBARGER (1995) um importante aumento, em até dois anos, em média de vida para os indivíduos homens que estavam envolvidos num treinamento de exercício vigoroso. Esses benefícios se estenderam inclusive para os indivíduos que tinham uma vida sedentária antes de iniciar o programa.

Deste modo, a necessidade de indivíduos idosos sedentários iniciar ou permanecer em atividades aeróbias se faz necessária pelo fato de que as atividades de vida diária em níveis submáximos irão requerer menos esforço.

Neste sentido, a maioria dos estudos de acordo com HURLEY e HAGBERG (1998) mostra que a atividade física aeróbica e de força muscular podem melhorar a função neuromuscular, o andar e o equilíbrio que são fatores determinantes nas quedas.

\subsubsection{Capacidade funcional e nível de AF}

Uma das maneiras de se conceituar o estado de saúde do idoso é pela capacidade funcional (KATZ, 1983), que se refere à potencialidade no desempenho das AVDs, ou seja, tanto para realizar uma ação quanto para garantir condições mínimas de sobrevivência que proporcione qualidade de vida e bem-estar (YUASO \& SGUIZZATTO, 2002). A participação do idoso em um programa de exercício regular é considerado como um recurso eficiente de intervenção na redução ou na prevenção dos declínios funcionais próprios do envelhecimento. Sendo assim, os benefícios associados à atividade física e o 
exercicio regular contribuem para um estilo de vida mais saudável e independente (ACSM, 1998).

De acordo com MATSUDO e MATSUDO (2000), a diminuição do nivel de atividade fisica e capacidade funcional com o decorrer dos anos é um fenômeno amplamente difundido. Poucas informações científicas têm sido verificadas quanto ao comportamento do nível de atividade física e da capacidade funcional.

Este declínio relacionado à idade é explicado devido a uma redução na liberação do neurotransmissor dopamina (associado especialmente com a motivação) ou pela perda dos receptores de dopamina que estão relacionados com alteração de diversos parâmetros da locomoção (INGRAM, 2000).

É fato que na velhice o homem tem declínios na qualidade e quantidade de seus movimentos por fatores de diversas naturezas. Estimativas de prevalência da capacidade funcional apontam que grande porcentagem das pessoas acima dos 60 anos tem dificuldade ou incapacidade de realizar atividades cotidianas, como carregar um peso ou caminhar alguns quarteirões (OKUMA, 1997).

Faz-se necessário ressaltar que as principais queixas e dificuldades dos idosos muitas vezes são provenientes da falta de movimento. Segundo LEBRÃO e PELÁEZ (2003), apesar de 70\% dos idosos relatarem não precisar receber ajuda de ninguém, ou seja, se consideram independentes, 17\% deles relatam dificuldades para se vestir, $51 \%$ mal conseguem agachar-se e $17 \%$ mal conseguem caminhar uma quadra,

O Centro Nacional de Estatística para a Saúde apresentou uma estimativa assustadora em que cerca de $84 \%$ dos indivíduos com idade igual ou superior a 65 anos são dependentes para realizar as AVDs. As projeções para 
2020 é que haja um aumento de 84 a 167\% no número de idosos que tenham um nivel moderado ou grave de incapacidade (NÓBREGA et. al, 1999)

Recentemente, o projeto SABE (2003), relatado por LEBRÃO e PELÁEZ (2003), verificou as principais queixas e limitações dos idosos na cidade de São Paulo. As que mais se destacaram estão relacionadas no QUADRO 2 com dificuldades físicas e funcionais, no QUADRO 3, as principais impossibilidades estão relacionadas com a capacidade funcional das AVDs.

QUADRO 2 - Percentual das principais queixas e dificuldades

\begin{tabular}{|c|c|}
\hline \multicolumn{2}{|c|}{ Principais relatos } \\
\hline Dor e problema nas costas & $39,7 \%$ \\
Não recebem ajuda nas AVDs & $70 \%$ \\
Vestir-se & $17 \%$ \\
Deitar e levantar da cama & $11,7 \%$ \\
Tomar banho & $10 \%$ \\
Ir ao banheiro & $7,1 \%$ \\
Comer & $6 \%$ \\
\hline
\end{tabular}

Projeto SABE: Saúde, bem-estar e envelhecimento.

Projeto da FSPUSP + OPAS + FAPESP.

Pesquisa realizada na cidade de São Paulo, 2000, 972 mil idosos.

Fonte: Revista Pesquisa FAPESP, n.87, maio, 2003. 
QUADRO 3 - Percentual das principais impossibilidades

\begin{tabular}{|c|c|}
\hline \multicolumn{2}{|c|}{ Impossibilidades } \\
\hline Agachar-se & $51 \%$ \\
Levantar-se da cadeira & $36 \%$ \\
Subir um andar de escada & $33 \%$ \\
Caminhar uma quadra & $17 \%$ \\
Levantar os braços acima do ombro & $15 \%$ \\
\hline
\end{tabular}

Projeto SABE: Saúde, bem-estar e envelhecimento.

Projeto da FSPUSP + OPAS + FAPESP.

Pesquisa realizada na cidade de São Paulo, 2000, 972 mil idosos.

Fonte: Revista Pesquisa FAPESP, n.87, maio, 2003.

Frente a este cenário comprometedor, mais do que nunca a saúde tornase um componente vital para os idosos. Uma boa saúde é essencial na manutenção ou aumento da sua qualidade de vida, para que possa garantir a continuidade da sua inserção social (ALVES, 2004).

Na medida em que a atividade física exerce efeitos positivos sobre vários componentes da aptidão física, nas capacidades motoras, na prevenção e no tratamento de doenças e em alguns componentes psicológicos, espera-se também que possa otimizar qualitativa e quantitativamente as ações motoras do cotidiano (AVD). Assim sendo, é de extrema importância procurar manter o desempenho físico na velhice para preservar as AVDs e conseqüentemente proporcionar uma melhor qualidade de vida para os idosos (ANDREOTTI, 1999). 
SANTARÉM (1997) afirma que a atividade física praticada pelo idoso tende a manter níveis adequados de aptidão física durante o envelhecimento, contribuindo para a redução do risco de quedas, o que auxilia na realização das AVDs de maneira confortável e segura. Portanto, indivíduos idosos ativos de maneira adequada apresentam menor risco de confinamento no leito devido a fraturas ósseas ou incapacidade física, apresentando uma taxa de mortalidade menor por infecções pulmonares e tromboembolismo.

Conforme SPIRDUSO (1995), o exercício físico é um eficiente aliado na contribuição da prevenção de quedas pelos diversos mecanismos que contribuem no fortalecimento muscular das pernas e costas, melhora dos reflexos, melhora da sinergia motora das reações posturais, melhora da velocidade de andar, incremento da flexibilidade, manutenção do peso corporal, melhora da mobilidade e diminuição do risco de doença cardiovascular (MATSUDO, MATSUDO \& BARROS, 2000).

Um estudo longitudinal realizado por LAUKKANEN, KAUPPINEN e HEIKKINEM. (1998) em idosos de 75 a 80 anos, avaliados antes e após um período de cinco anos, evidenciou que os sujeitos com maior nível de AF tiveram melhor saúde e habilidade funcional em relação aos indivíduos sedentários.

FIATARONE, O'NEILL, DOYLE, CLEMENTS, ROBERTS, KEHAYIAS, LIPSITZ e EVANS (1994), num estudo com idosos frágeis institucionalizados, com idades entre 72 e 98 anos, verificaram os efeitos do treinamento de resistência e suplementação nutricional nesta população. Houve um incremento de $11 \%$ na velocidade de andar, $28 \%$ na potência de subir escadas, mas o fato mais interessante da pesquisa foi verificado quanto ao 
incremento de 34\% na atividade física espontânea, o que evidenciou uma melhora das AVDs com os ganhos de força.

HARRIS, KOVAR, SUZMAN, KLEIMAN e FELDMAN (1989) avaliaram aproximadamente 2000 idosos, com mais de 80 anos, que devido a problemas cardiovasculares tiveram que modificar a sua habilidade de andar ou subir escadas. Ficou constatado com este estudo que 56\% das mulheres e $42 \%$ dos homens mantiveram a mesma habilidade física após dois anos de acompanhamento. Já os indivíduos que eram ajudados em alguma das AVDs tiveram quatro vezes mais probabilidade de morrer, seis vezes mais probabilidade de necessidade de internação em asilos ou fazer mais de seis visitas ao médico e duas vezes mais probabilidade de ter duas ou mais hospitalizações.

Estes dados corroboram a premissa que os idosos envolvidos em um programa regular de exercícios mantém um nível de atividade física diária adequado para a realização das AVDs, ou seja, manter a capacidade funcional é mecanismo eficiente para se diminuir as taxas de mortalidade e o risco de institucionalização, principalmente nos últimos anos de vida.

\subsubsection{Efeitos da AF nos aspectos sociais e psicológicos}

Dependendo da cultura em que vive o idoso, podemos encontrar diferenças na sua posição social, podendo ser vistos como um peso social ou sendo respeitados e valorizados pela experiência e sabedoria adquiridas com os anos de vida, chegando a ocupar posições que os dignificavam e eram aspiradas por todos. A longevidade poderia ser considerada um privilégio, o velho tinha papéis e padrões comportamentais apropriados no valor da respeitabilidade, 
muitas vezes exercendo as funções de conselheiro, visto como um possuidor de um saber digno de respeito e admiração pela maior experiência acumulada (SALGADO, 1982).

Com a evolução tecnológica a nova sociedade também denominada sociedade contemporânea, industrial e pós-industrial, tem a juventude numerosa e a experiência de vida nem sempre conta decisivamente para o equilíbrio e a organização social. Os papéis que os velhos desempenhavam foram sendo alterados pela valorização da força de trabalho e o envelhecimento passou a ser visto principalmente pela decadência com a sua figura desvalorizada (MAZO, LOPES \& BENEDETTI, 2001; SALGADO, 1982).

De acordo com FREIRE e RESENDE (2001), o sentido pessoal de viver está relacionado com a preocupação que cada indivíduo tem com a sua própria existência, sendo composto pelos aspectos cognitivos, motivacionais e afetivos. Em relação ao aspecto cognitivo, cada indivíduo constrói um sistema de crenças, uma visão do mundo para enfocar as preocupações existenciais. Quanto ao aspecto motivacional, ele está relacionado ao sistema de valores construídos, à busca e ao alcance de metas pessoais do indivíduo que deveriam estar de acordo com as suas necessidades, valores e desejos. Finalmente, em relação ao aspecto afetivo, os sentimentos de satisfação e preenchimento acompanham uma conviçção de que a vida deve valer a pena.

Atualmente, viver e envelhecer com tantas mudanças sociais e econômicas, associadas às incertezas do dia-a-dia tem sido muitas vezes uma experiência difícil para muitos indivíduos. A pós-modernidade está caracterizada pelas rápidas mudanças de conhecimentos, pelo questionamento de valores, pela globalização, pela descartabilidade de objetos, pessoas e relações. Desta forma, o medo de viver diante das perspectivas e incertezas do futuro, encontrar uma 
razão para continuar a existir e ser feliz nesta nova fase de vida, torna-se um desafio quase que diário na vida dos idosos.

De acordo com GHORAYEB (2000), estudos como o de ROTH e SILVA FERNANDES (apud VARGAS, 1983) revelam as principais causas que determinam os aspectos sociais do envelhecimento: o isolamento social, a diminuição dos rendimentos econômicos, a situação econômica crítica, o impacto da ruptura com a vida profissional e a perda da função e do status.

Há um processo comum de vivência negativa para o idoso, como a aposentadoria (ausência de produção), viuvez (morte), mudanças físicas, como rugas e cabelos brancos (desgaste) e ninho vazio.Tal conjuntura seria um caminho fácil para a imagem depreciativa do velho, que pode estar associada à falta de utilidade e à perda de papel social (GONÇALVES, 1999).

No entanto, os estereótipos de abandono e solidão estão gradativamente sendo substituídos por uma imagem de que os idosos são ativos e têm capacidade para oferecer mecanismos de respostas criativas a essas mudanças sociais que redefinem o envelhecimento (DEBERT, 1999; GHORAYEB, 2000).

Podemos verificar que existem indivíduos que têm prazer em viver e não têm o menor interesse em ficar esperando a chegada da morte, pelo contrário, eles vivem como querem, mantendo os contatos e atividades sociais e acreditam que sua própria existência é o que mais importa no momento (OKUMA, 1997).

Atualmente, verificamos uma gama maior de associações, clubes, espaços coletivos de convivência para a vivência de novas experiências nas quais os idosos podem desmistificar a idéia de que a velhice é somente uma fase de perdas, doenças e solidão. 
Segundo LOPES e SIEDLER (1997), a atividade física regular favorece uma mudança comportamental, que poderá proporcionar transformações sociais, visto que o idoso quando se valoriza pode desencadear, junto à sua família e no seu meio social, significativas mudanças. A atividade física pode dar um novo sentido à vida, ser um possível substituto do trabalho nos aspectos da regularidade, esforço e organização. Pode ainda acarretar valores sociais como integração em novos grupos e incremento das relações humanas, auxiliando o idoso a superar a solidão e o isolamento (CARVALHO \& MOTA, 2002).

Em uma revisão de 38 estudos, McAULEY e RUDOLPH (1995) verificaram que na maioria existiu uma relação positiva entre atividade física e bem-estar psicológico com resultados relativamente similares entre gêneros e diferentes faixas etárias. OKUMA (1997) constatou, nos relatos dos idosos, que a atividade física possibilitou vivenciar novas sensações, aumentou a disposição geral e favoreceu a comunicação entre eles e as gerações mais jovens. Estas experiências fizeram com que se sentissem mais independentes, tanto em relação aos recursos externos quanto aos medicamentos.

Assim sendo, a participação de idosos em atividades que geram responsabilidade social, compromisso e interação social são necessárias na manutenção do seu auto-conceito, da auto-estima positiva, do sentimento de auto-eficácia e da possibilidade de crescimento pessoal. De acordo com OKUMA (1997), o bem-estar na velhice está justamente nesta satisfação pessoal e no significado para a continuidade da vida.

O emprego de um programa de atividades físicas para pessoas idosas tende a melhorar o seu estado de saúde, diminuindo a dependência, a ociosidade, favorecendo a socialização e com isso melhorando sua qualidade de vida. 
Com a prática regular da atividade física o idoso percebe mudanças corporais e conseqüentemente uma transformação na sua imagem corporal, e deste modo há naturalmente uma melhora no auto-conceito e na auto-estima. Essa nova percepção sobre o seu corpo e sua aptidão física faz com que se torne mais confiante em relação a si mesmo (OKUMA, 1997).

Desta maneira, todas essas evidências apontam para os efeitos da atividade física nos aspectos psicológicos e sociais do envelhecimento: melhora do auto-conceito, melhora da auto-estima, melhora da imagem corporal, contribuição no desenvolvimento da auto-eficácia, diminuição do estresse, ansiedade e insônia, melhora da tensão muscular, diminuição do consumo de medicamentos, melhora das funções cognitivas e da socialização (McAULEY \& RUDOLPH, 1995; OKUMA 1998,1999; SWOAP, NORVELL, GRAVES \& POLLOCK, 1994; VAN BOXTEL, PAAS, HOUX, ADAM, TEEKEN \& JOLLES, 1997; WOOD, REYES - ALVAREZ, MARAJ, METOYER \& WELSCH, 1999).

\subsection{Programa de Atividade Física para idosos - Características Gerais}

O significado da atividade física pode ser entendido como um dos caminhos para a descoberta interior dos idosos, indo além da qualidade de vida, aptidão física e saúde, capacidade funcional, preenchimento do tempo livre. A atividade fisica pode contribuir para as transformações no nível pessoal de cada indivíduo, repercutindo no seu modo de ser e estar no mundo. 
O que dá um sentido maior à vida é o nosso corpo. Dar competência a esse corpo faz-se necessário para que se possa existir a partir do próprio corpo e poder optar em viver pela dor ou pelo prazer (OKUMA $\left.{ }^{3}, 2002\right)$.

Segundo OKUMA (1997), o idoso tem um novo interesse pela vida e pelo que ela oferece quando conhece e lida com o seu próprio corpo, interage socialmente, tem saúde e autonomia física, realizando as AVDs com mais disposição sem a necessidade de ajuda. CARVALHO e MOTA (2002) têm uma visão similar afirmando que a atividade física pode constituir, para os idosos, um elemento essencial na sua valorização pessoal e integração social.

O "envelhecimento saudável" deve ser uma das preocupações em nível mundial pelo desenvolvimento de políticas cujo objetivo tem sido estimular as pessoas a tornarem-se fisicamente mais ativas de forma regular (MARQUES, 1994). Deste modo, faz-se necessário implantar ações voltadas para o atendimento à população idosa, benefícios especiais, programas adequados, profissionais capacitados para lidar com o processo de envelhecimento, oferta de serviços objetivando a prevenção, a cura e o controle de doenças.

Os programas devem estar voltados para melhorar a qualidade de vida $^{4}$ e bem-estar dos idosos (OMS), reforçar a sua independência $e$ autoconfiança (CARVALHO \& MOTA, 2002), incentivar a prevenção de doenças (GEIS, 1996), informar sobre os beneficios da atividade fisica, maximizar a saúde psicológica (CHEN, CHANG, POLLOCK, GRAVES,

\footnotetext{
${ }^{3}$ OKUMA, S. S. Citação em aula de Pós-Graduação, Disciplina:Educação física para o idoso:qualidade de vida e satisfação na velhice, 2002. Escola de educação Física e Esporte, Universidade de São Paulo.

${ }^{4}$ WHO. The World Report 1998: Life in the $21^{\circ}$ Century - A Visison for All. Geneva: World Health Organization, 1998.
} 
PROBART \& SPLITTER, 1992; SPIRDUSO \& CRONIN, 2001), melhorar a sua situaçào social, aperfeiçoar ou restabelecer a capacidade funcional (GEIS, 1996; SPIRDUSO \& CRONIN, 2001). De acordo com a OMS, que conta com um grupo de Qualidade de Vida, a definiu como a percepção do indivíduo sobre a sua posição na vida, no contexto cultural e de sistema de valores em que se insere em relação aos seus objetivos pessoais, expectativas e preocupações (WHO, 1998).

Deste modo, um programa de AF dirigido para atender à população de idosos deve voltar-se para a melhoria da capacidade física do indivíduo, diminuindo a deterioração das variáveis antropométricas (estatura, peso e IMC), das variáveis neuromusculares (sarcopenia, perda das fibras musculares, degeneração muscular, perda da força muscular) e das alterações cardiovasculares e respiratórias, como também voltar-se para a ampliação do contato social e a redução dos problemas psicológicos, como ansiedade e depressão (CHEN et al., 1992).

Segundo GHORAYEB (1993), quanto maior o número de atividades que o idoso tiver, quanto mais exercício físico fizer melhor será sua qualidade de vida. Para o idoso fisicamente ativo, o sentimento de inutilidade e improdutividade deve diminuir, o que conseqüentemente poderá beneficiar a sua auto-estima.

As atividades devem proporcionar alegria, descontração, bem-estar físico e psicológico (CARVALHO \& MOTA, 2002; WOOD et al., 1999), mas também devem fundamentar-se na prevenção, manutenção, reabilitação e recreação (GEIS, 1996). O conteúdo pode ser diversificado envolvendo ginástica, musculação, atividades aquáticas, jogos, recreação e esportes, respeitando as características dos idosos ou do grupo de idosos. Os programas de 
exercícios devem incluir atividades que melhorem a aptidão cardiovascular, os niveis de força muscular, flexibilidade, coordenação, equilíbrio e tempo de reação (SPIRDUSO, 1995).

Em sintese, de acordo com o mais recente posicionamento do ACSM (2004), os programas de atividade física para idosos devem:

1) promover atividades multidimensionais que incluam o treinamento de resistência, força, equilíbrio e flexibilidade, que são ótimos para a saúde e para os benefícios funcionais;

2) conter os princípios da mudança de comportamento incluindo: suporte social, auto-eficácia, escolha de atividades, comprometimento com a saúde, confiança na segurança e reforço positivo no aumento da aderência;

3) administrar os riscos, iniciando com uma baixa intensidade, mas aumentar gradualmente as atividades para um nível moderado, com as quais o professor tenha uma boa relação entre os riscos $\mathrm{X}$ beneficios e obtenha resultados com os participantes;

4) numa emergência, ter um plano de procedimentos já estabelecidos no programa;

5) monitorar a intensidade aeróbica para verificar o progresso e a motivação. É necessário também selecionar uma revisão de conteúdos de programas de atividade física de organizações e instituições maiores.

Por estas razões, cada vez mais são necessárias novas estratégias de ações, com o propósito de estimular as pessoas idosas a mudar o seu estilo de vida, incorporando no dia-a-dia hábitos saudáveis, como por exemplo a reeducação alimentar e sem dúvida nenhuma a adesão à prática regular de 
atividade física, que é vista como uma importante medida de prevenção e intervenção na mudança de comportamento e na aquisição de um estilo de vida mais ativo (ACSM, 2004; NIEMAN, 1999; SPIRDUSO, 1995) .

\subsubsection{Estruturação de um programa de AF}

$\mathrm{Na}$ estruturação de um programa supervisionado de AF para idosos devemos considerar alguns fatores fundamentais, como os determinantes que influenciam a adesão nos programas supervisionados de AF.

Entre os determinantes que influenciam a adesão estão os fatores pessoais- perfil sócio-demográfico definido pelo gênero, idade, grau de instrução, renda econômica, raça, etnia e estado civil do praticante - além de saúde, aptidão física percebida, participação anterior em programas de $\mathrm{AF}$, razões para fazer $\mathrm{AF}$, conhecimentos e crenças dos benefícios da $\mathrm{AF}$ voltados para a saúde, benefícios percebidos da $\mathrm{AF}$, traços psicológicos dos participantes e fatores fisiológicos (peso corporal e problemas de saúde); os fatores comportamentais (fumo, tipo de ocupação) e os fatores situacionais- apoio social e participação da família, falta de tempo percebida, clima, proximidade do local da prática, características do programa de $\mathrm{AF}$, como intensidade da $\mathrm{AF}$, programa individual ou em grupo e características do professor e os pertinentes ao programa de AF (DISHMAN, 1993).

Os fatores pessoais em termos de adesão inicial exercem grande influência sobre o comportamento para a prática de $\mathrm{AF}$ e permite ainda traçar um perfil do praticante de AF (ANDREOTTI \& OKUMA, 2003). A saúde percebida é considerada como um fator pessoal e deve ser citada por ser uma variável que influencia na adesão inicial da $\mathrm{AF}$, exercendo grande influencia sobre o 
comportamento em relaçào à prática de $\mathrm{AF}$. A saúde percebida está relacionada com a avaliação subjetiva que cada indivíduo faz de si mesmo em relação à qualidade de funcionamento de sua saúde física e mental (ANDREOTTI, 2001). Em geral as mulheres idosas relatam mais doenças e são menos satisfeitas com a própria saúde do que os homens (NERI, 2001).

De acordo com a análise de ANDREOTTI (2001), pode-se concluir que apesar de informações conflitivas em relação à saúde percebida, vários estudos afirmaram que um dos primeiros motivos para a adesão à AF são os benefícios da saúde. Cita ainda outros autores como STONES, KOZMA e STONES (1987) que apontaram em seus estudos que os ganhos de saúde percebidos e a condição física têm sido associados com o aumento do tempo de adesão entre homens e mulheres de 63 anos de idade.

Segundo DISHMAN (1993) os aspectos sócio-demográficos têm grande importância na medida que podem identificar os indivíduos que possivelmente terão uma resistência maior em participar de programas de AF e assim requerendo intervenções.

Quanto às variáveis dos aspectos sócio-demográficos, parece que as diferenças entre os sexos são mais significativas para as atividades de alta intensidade e menores para as de nível moderado COUSINS $^{5}$ \& KEATING, 1995 apud ANDREOTTI \& OKUMA, 2003). Em indivíduos com idades entre 50 e 65 anos, YOUNG, KING e OKA (1995) verificaram que as mulheres $(12,2 \%)$ eram mais sedentárias que os homens $(7,8 \%)$, mas em relação a serem

\footnotetext{
${ }^{5}$ CAUSINS, S. O.; KEATING, N. Life cycle patterns of physical activity among sedentary and active older women. Journal of Aging and Physical Activity. Champaign, v.3, n.4, p. 340-59, 1995.
} 
regularmente ativos os índices encontrados foram os mesmos (15,5\%), tanto para as mulheres quanto para os homens.

FARIA JUNIOR (1994) verificou no Brasil que com relação a programas supervisionados de $\mathrm{AF}$ para idosos, há uma predominância maior de mulheres do que de homens. Temos como exemplo a Universidade da $3^{\text {a }}$ Idade da Pontíficia Universidade Católica, de Campinas, com uma representação total de $80 \%$ para as mulheres e a Universidade da $3^{\mathrm{a}}$ Idade de Silesian com a maioria dos participantes entre os 50 e 70 anos (79\%), alto nível de escolaridade (94\%) e com $(70 \%)$ de mulheres participantes do programa (SLEZYNSKI ${ }^{6}$ \& BLONSKA, 1994 apud ANDREOTTI \& OKUMA, 2003)

Alguns fatores apareceram como motivos para se explicar a origem de uma predominância de mulheres nos programas supervisionados: mais oportunidades de encontros sociais aceitáveis socialmente fora de casa (clubes, grêmios, bares) para os homens e o preconceito masculino em relação às atividades por serem consideradas não exaustivas o suficientes para os "machos", ou seja, muito leves, ou ainda por serem consideradas femininas (ginástica) (ANDREOTTI \& OKUMA, 2003).

\footnotetext{
- SLEZYNSKI, J.; BLONSKA, W. Physical activity of the third age population. In: MARQues, A. T.; GAYA, A.; CONSTANTINO, J. M. (Eds.). Physical activity and health in the elderly. Porto. University of Porto, 1994. p.414-415. (Procendings of the First Conference of EGREPA).
} 
RAMILO $^{7}$ (1994, apud ANDREOTTI \& OKUMA, 2003) afirma que nos programas supervisionados, dentre os participantes, as mulheres são as que mais aderem e divulgam a atividade optando por um novo estilo de vida.

Em relação à idade, a adesão da $\mathrm{AF}$ diminui conforme o indivíduo vai envelhecendo; esse processo inicia-se na fase da adolescência e em torno dos 50 anos declina pelo menos até os 65 anos, com proporções maiores de não adesão entre homens e mulheres aos 80 anos $\left(\mathrm{KING}^{8}\right.$ et al, 1992 apud ANDREOTTI \& OKUMA, 2003). Em comparação com os adultos mais jovens, os idosos se exercitam menos e numa intensidade mais moderada, apesar de aparecerem dados diferentes em dois países desenvolvidos como o Canadá e Finlândia, onde se reporta um aumento da AF para os grupos mais velhos em relação aos mais jovens, com evidências de AF aumentada para os indivíduos com mais de 65 anos (STEPHENS' \& CASPERSEN, 1994 apud ANDREOTTI \& OKUMA, 2003).

\footnotetext{
${ }^{7}$ RAMILO, M. T. Programa de atividade física e adaptada. In: MARQUES, A.T.; GAYA, A.; CONStantino, J. M. (Eds.), Physical Activity and health in the elderly. Porto. University of Porto, 1994. p.375-79. (Proceedings of the first conference of EGREPA).

${ }^{8}$ KING, A. C.; BLAIR, S. N.; BILD, D. E.; DISHMAN, R. K.; DUBBERT, P. M.; MARCUS, B. H.; OldBRIDGE, N. B.; PAFFENBARGER, R. S.; POWELL, K. E.; YEANGER, K. K. Determinants of physical activity and interventions in older adults. Medicine and Science Sports and Exercise. Madison, v.4, n.6, p.S221-36, 1992.

9 STEPHENS, T.; CARSPERSEN, C. J.; The demography of physical activity. In: BOUCHARD, C.; SHEPHARD, R. J.; STHEPHENS, T. (Eds.) Physical activity, fitness and health: international proceedings and consenses statement. Champaign: Human Kinectics, 1994. cap. 12 , p. $205-13$.
} 
Outro aspecto relevante está relacionado ao estado conjugal dos idosos praticantes de AF; quanto aos homens sedentários, têm maior probabilidade de serem solteiros quando comparados aos homens irregular e regularmente ativos (YOUNG ${ }^{10}$ et al, 1995 apud ANDREOTTI \& OKUMA, 2003). Os autores afirmam ainda que, a condição de solteiro está associada com índices mais altos de depressão e com níveis mais baixos de apoio social, o que levaria a uma menor adesão de AF.

Finalizando, os principais aspectos sócio-demográficos abordados neste capítulo, são as principais razões e as dificuldades para a prática de AF. Segundo ANDREOTTI (2001), os indivíduos são motivados por diversas razões a iniciar um programa de AF, tais como: conhecimento e crença nos benefícios da AF quanto aos aspectos fisiológicos e pscicológicos (WEINBERG \& GOULD, 1995), indicação médica (DISHMAN, 1988), reabilitação (FARIA JÚNIOR, 1994), prevenção de patologias e manutenção da saúde, melhora do condicionamento físico e das capacidades intelectuais e mentais (DANTAS, 1994; FARIA JÚNIOR, 1994), ocupação do tempo livre com atividade saudável (DANTAS, 1994), possibilidade de convivência, socialização (DANTAS, 1994) e ampliação das relações interpessoais (FARIA JÚNIOR, 1994), bem-estar (FARIA JÚNIOR, 1994), sentir-se participante e produtivo (DANTAS, 1994), retardar o envelhecimento (DANTAS, 1994), buscar uma melhor estética corporal (DANTAS, 1994).

Deve-se ressaltar que a promoção efetiva da AF pelos médicos é um determinante potencialmente forte de adesão para os indivíduos idosos, pois muitos têm o contato aumentado à medida que envelhecem (DISHMAN, 1988b).

\footnotetext{
${ }^{10}$ YOUNG, D. R.; KING, A. C.; OKA, R. K. Determinants of exercise level in the sedentary versus underactive older adult: implications for physical activity program development. Journal of Aging and Physical Activity, v.3, n. 1, p, 4-25, 1995
} 
De acordo com ANDRADE, MATSUDO, MATSUDO, ARAÚJO, ANDRADE, OLIVEIRA e FIGUEIRA (2000), os agentes facilitadores no ambiente para o envolvimento regular com a prática da atividade física revelaram que os individuos acima dos 50 anos realizam as atividades em ordem de prioridade em função de: orientação médica, amigos, familiares, procura por companhia e colegas de trabalho.

Assim sendo, o estreitamento entre o professor do programa e o médico do aluno, pode ser um recurso a mais a ser utilizado, que o permita acompanhar o tratamento médico e sugerir modificações se necessário (COTTON, 1998).

Com relação às dificuldades encontradas para a participação em programas de AF as principais causas apontadas por ANDREOTTI (2001) encontradas num estudo de WHALEY e EBBECK (1997) foram: falta de tempo disponível (estão ocupados o tempo todo), horário de aula incompatível, tipo de aula oferecida, excesso de comprometimento em relação ao PG de AF, problemas de saúde,muitas mulheres na classe, exercícios insuficientemente intensos, preguiça, medo de lesões, preferência por atividades sozinhos, falta de companhia para exercitar-se, entre outras.

Desta maneira, faz-se necessário compreender as atitudes e comportamentos dos indivíduos que aderem ao programas de AF, possibilitando adequar os objetivos propostos pelo programa de AF aos interesses e anseios dos praticantes idosos.

Assim sendo, as características dos indivíduos praticantes, podem ser consideradas um dos principais motivos de adesão, bem como as características da atividade física em si para que leve a sua adesão permanente. De acordo com ANDREOTTI (2001), parece que uma das questões importantes para a área de 
Educação Física é identificar quais são as características desta população que adere a programas sistemáticos de $\mathrm{AF}$, pois essas influências não podem ser compreendidas a menos que os componentes sejam analisados (características da pessoa, do ambiente e da AF em si).

\subsubsection{Características dos indivíduos praticantes}

Segundo DISHMAN (1988b), o conhecimento inadequado dos determinantes da prática da atividade física difícultam a elaboração de mecanismos de intervenção e promoção que efetivem o encorajamento da prática de AF pela população de idosos. Deste modo, corrobora as afirmações anteriores, enfatizando que um primeiro passo para o planejamento e implantação de programas efetivos é ter o conhecimento das características dos indivíduos participantes, para que se possa atender de maneira adequada aos interesses, necessidades e dificuldades da população a que se propõe.

Deve-se estar atento a algumas características específicas da população de idosos ao se implantar um programa de atividade física, levando-se em consideração alguns aspectos como:

a) Histórico pessoal - corresponde ao passado do indivíduo em relação à prática de atividade física (DISHMAN, 1993). Aspecto de grande importância para se interpretar os determinantes passados e presentes, como também predizer as atividades futuras em relação à prática de atividade física.

Os fatores pessoais passados e presentes são considerados como uma das variáveis que determinam maior ou menor fixação dos indivíduos aos programas de AF. De acordo com OKUMA (1997), as atividades passadas com 
experièncias negativas, tanto na infância quanto na adolescência ou na fase adulta podem influenciar sentimentos de incapacidade na prática atual. Porém, DISHMAN (1994) e SABA (1999) acreditam que o histórico passado pode ser analisado de forma mais recente, dando mais fidedignidade à participação presente. Se o idoso teve alguma participação recente em programas de atividade física de boa qualidade, não necessariamente ele terá maiores dificuldades a aderir a um novo programa.

Os fatores presentes prazerosos podem alterar o estado passado, levando o indivíduo à aderência ao programa de atividade física (OKUMA, 1997).

b) Grau de apreciação - refere-se ao grau de apreciação que o indivíduo tem em relação à atividade praticada. É uma das variáveis que está relacionada com os determinantes da prática de $\mathrm{AF}$, estando relacionada quanto ao fator comportamental (SABA, 1999).

BERGER e Mc INMAN (1990) citam que a atividade quando praticada com prazer tende a produzir uma melhoria na qualidade de vida. Esta atividade deve ser significativa e os objetivos devem estar de acordo com a proposta de exercícios, enfatizar sempre a importância de sentir-se bem tanto fisicamente como emocionalmente durante e após a atividade realizada (OKUMA,1997; SABA, 1999).

A experiência do praticante idoso deve ser enriquecedora e gratificante com incentivo à participação na busca de realização dos objetivos comuns. É a oportunidade que eles podem ter de utilizar as suas experiências adquiridas ao longo de suas vidas e realizar trocas. 
Programas criativos, variados com envolvimento contínuo sustentado no exercício podem se tornar muito mais agradável e importante do que as especificações da prescrição tradicional de exercícios (FRONTERA, DAWSON \& SLOVIK, 2001).

c) Automotivação - o idoso, ao ingressar num programa orientado de atividade física, pode vir motivado sob três aspectos: pela motivação autogerada (ou intrínseca, vai porque quer), pela motivação não autogerada (ou extrínseca, vai coagido, porque o médico mandou) e pela ausência de motivação (não tem significado).

De acordo com DISHMAN (1984), o indivíduo deve ser reforçado mais pelas suas próprias idéias, do que pelas dos outros. SABA (1999) destaca a importância da auto-motivação na efetividade, segurança e aderência a longo prazo no programa de AF.Assim sendo, descobrir o tipo de motivação que levou o idoso a ingressar num programa de $\mathrm{AF}$, inicialmente, durante a primeira entrevista, pode ser um preditor de aderência ao programa de atividade física.

d) Reforço social - o apoio social e a participação da família é um outro componente dos determinantes da prática de AF em relação aos fatores situacionais (DISHMAN, 1993). Ter o conhecimento se o indivíduo idoso tem apoio do companheiro ou a influência de grupos tem uma associação positiva na prática de atividade física. OKUMA (1997) enfatiza que o grupo social no qual o praticante está inserido parece ser tão importante quanto a natureza da atividade.

WANKEL (1988) corrobora esta afirmação citando que a preferência da maioria das pessoas é querer se exercitar em grupo. Deve-se então estar atento a este indicativo para se obter melhor manutenção no programa. Segundo o 
autor, a busca da interação social é uma das fortes razões para o envolvimento na atividade fisica.

Na medida em que o grupo propicia a identificação com os pares, o comprometimento, a confiança, o reforço social e o estímulo competitivo, se envolve mais na atividade física (atratividade) (MURREL \& DIETZ, 1992; OKUMA, 1997; SPINK \& CARRON, 1993). Fazer parte de um grupo permite aos idosos uma nova identidade física e social. Deste modo, o idoso passa a ter um compromisso maior com esse grupo, a viver o sentimento de confiança, sentir-se estimulado a competir, ser companheiro e apoiar-se mutuamente (OKUMA, 1997).

\subsubsection{Características da Atividade Física}

Basicamente, o programa de exercícios deve incluir atividades aeróbicas de baixo impacto nas estruturas musculares, esqueléticas e articulares, de intensidade moderada e com os exercícios realizados de forma mais gradual para permitir melhor adaptação ao treinamento.

O programa de exercícios deve incluir atividades que melhorem a função cardiovascular, os níveis de força, a flexibilidade, a coordenação e o equilíbrio (ACSM, 2004). MATSUDO (2001) corrobora estas informações afirmando que os exercícios específicos de força, flexibilidade e equilíbrio são fundamentais para que o idoso mantenha boa aptidão física funcional, coloca como prioridade na prescrição das atividades físicas para os idosos:

1.) Exercícios para força muscular;

2.) Exercícios de equilíbrio; 
3.) Atividades aeróbicas;

4.) Movimentos corporais totais;

5.) Mudanças do estilo de vida.

A prescrição dos exercícios deve basear-se nos princípios gerais de treinamento quanto ao modo, intensidade, duração e freqüência da atividade, devido à diversidade nos níveis de saúde e aptidão física característicos da população de idosos (ACSM,1998, 2000).

\subsubsection{Organização / Planejamento}

Ao analisarmos uma proposta de programa de AF para idosos devemos obter como elemento básico o planejamento. Planejar implica em método de trabalho, ou seja, não improvisação (LABORINHA, 1997).

De acordo com TURRA, ENRICONE, SANTANNA e ANDRÉ (1992) as etapas de um planejamento devem referir-se ao:

1.) Conhecimento da realidade - refere-se ao conhecimento da população alvo e do meio. O professor obtém um diagnóstico que irá fornecer todas as informações que necessite para a elaboração de um plano. De acordo com os autores CARVALHO e

MOTA (2002), a prática da atividade física para o idoso deve ser realizada de acordo com as características e limitações específicas desta população. Assim sendo, é muito importante que se faça o levantamento das informações sobre a necessidade de cada indivíduo por meio de auto - relato sobre os antecedentes médicos e entrevista (anamnese). 
Com a entrevista inicial, temos uma diminuição de riscos durante os testes da avaliação fĩsica e na prescrição do programa, o que possibilita a indicaçào dos exercícios mais adequados, cuidados especiais que cada idoso requer, e saber como lidar com as diferenças individuais.

Deve-se ressaltar que neste momento estabelecemos um contato pessoal em que se identificam alguns aspectos quanto à sua história pessoal em relação à prática de atividade física, o seu grau de apreciação com relação à atividade que deseja praticar ou que já praticou e a sua automotivação. Sabemos que todos estes fatores nos ajudam a identificar o perfil dos idosos, e assim encaminhá-lo à prática mais adequada, evitando desistência precoce do programa.

2.) Determinação dos objetivos - os objetivos devem ser observáveis e mensuráveis, realistas e alcançáveis, explícitos quanto aos conteúdos, claros, importantes e significativos para os praticantes e relacionados com as atividades de vida diária. Assim como o jovem, o idoso precisa sentir que terá êxito em suas tentativas (SKINNER, 1993).

3.) Seleção e organização dos conteúdos - os conteúdos e objetivos devem estar interligados, ou seja, a seleção de conteúdo deve ser realizada em função dos objetivos propostos e do nível do aluno, de maneira hierárquica e progressiva, ou seja, do fácil para o difícil.

4.) Seleção e organização dos procedimentos- são as estratégias que o professor utiliza como um facilitador no processo de ensino-aprendizagem. Novamente os objetivos, conteúdos, características do praticante e do professor 
envolvidos no programa de $\mathrm{AF}$ são os elementos básicos na seleção e organização dos procedimentos. De acordo com GEIS (1996), devemos compreender a finalidade da prática seguindo um modelo sob os seguintes aspectos:

a) Gratificante - a atividade deve ser agradável e deve corresponder a um bem-estar físico e psicológico;

b) Utilitária - é um bom meio de manter ou melhorar as capacidades físicas e intelectuais, de prevenir possíveis atrofias, patologias e de reabilitar após um período de inatividade, lesão ou patologia;

c) Motivante - deve-se constituir como centro de interesse e criar necessidade dos praticantes;

d) Adaptada - deve-se respeitar as possibilidades de movimento de cada um, respeitando as diferenças de faixa etária. Nem todos trabalham no mesmo ritmo e intensidade, considerar atividades alternativas para os menos aptos;

e) Integradora - a atividade deve abranger a todos, estimular a integração;

f) Fácil realização - o idoso deve compreender e realizar o movimento da melhor forma possível dentro das suas capacidades;

g) Socializadora - a atividade física deve favorecer a relação e comunicação; 
h) De qualidade mais do que quantidade - a atividade física deve estar centrada nos objetivos propostos, realizar as repetições necessárias e bem executadas.

5.) Seleção dos recursos - são elementos auxiliadores no processo ensino-aprendizagem na aquisição dos conteúdos. Podem ser humanos (professor, assistente) ou materiais (halter, caneleira, band, step, core condition, fit ball, medicine ball, corda, bastão, cone, música, etc). Sabe-se que o professor é uma parte importante dentro do processo de identificação do praticante nas atividades escolhidas do programa. O bom andamento de um programa de AF para idosos também depende do perfil do professor. A sua marca pessoal pode determinar o sucesso ou o fracasso do programa de AF (BARBOSA, 2000).

O conhecimento e a simpatia que o professor exerce pode aumentar o nível de adesão ao programa, assim sendo, o tipo de atividade, o conhecimento e a característica do professor deve ser levada em consideração (WEINBERG \& GOULD, 1995). De acordo com OKUMA (1997), a relação professor - aluno revelou ser de grande importância na motivação de muitos alunos para continuarem a participar no programa de AF. De acordo com a autora, o foco de atenção deve estar centrado mais no aluno do que nas atividades em si.

CARVALHO e BARBOSA (2003) enfatizam ainda que o bom andamento de um programa de AF para idosos depende muito do perfil do professor. Deve ser treinado na área de AF e envelhecimento e identificar-se com os conteúdos da área em questão como também com o praticante. Os autores ressaltam que ter simpatia, ser paciente, interessado e disposto são pré-requisitos importantes para o professor envolvido no programa de AF para idosos. 
6.) Seleção dos procedimentos de avaliação - deve haver a seleção das técnicas, instrumentos, recursos que atestem o progresso da população alvo em relação aos objetivos propostos por cada atividade no programa de AF.

A avaliação da aptidão física e funcional do idoso é muito importante, pois a partir dos seus resultados é que o planejamento, prescrição e aplicação do programa de treinamento serão mais eficientes. De acordo com POLLOCK e WILMORE (1993), uma avaliação pré-treinamento dará subsídios para análise das alterações que possivelmente ocorrerão.

A avaliação da aptidão física deve ser feita periodicamente com o objetivo de acompanhamento da evolução do indivíduo idoso com o treinamento prescrito; desta maneira, pode-se subsidiar as devidas comparações e os procedimentos utilizados anteriormente, reestruturando assim o programa de treinamento se for necessário (OKUMA, 2000; POLLOCK \& WILMORE, 1993).

\subsubsection{Funcionamento/ Atendimento}

Individualizar o atendimento aos idosos, adequar as tarefas às suas possibilidades, fazer com que se sintam competentes emergindo o sentimento de prazer, divertimento e satisfação são fundamentais para continuarem interessados pelo que fazem.

$\mathrm{O}$ atendimento inicial que o idoso recebe ao chegar à academia deve ser levado em consideração. Normalmente, as academias se preocupam muito com os tipos de aula a serem oferecidas aos seus clientes, com a qualidade técnica, com os equipamentos, com as instalações e nem sempre estão atentos 
para como devem ser as características das pessoas que trabalham diretamente na recepção/vendas, pois a recepção é o cartão de visitas da academia.

Atualmente, é percebido que o grande diferencial está nos procedimentos de atendimento, ou seja, na forma como se atende o possível cliente que chega à recepção pedindo informações sobre os programas e preços praticados.

A empresa do futuro deverá ainda ter ótimo suporte às vendas, facilidade de comunicação, agilidade e, sobretudo, dar prioridade ao atendimento, pois a qualidade e a confiabilidade são elementos-chave para esse consumidor idoso, o mais exigente de todos. Deve ter a visão das tendências e necessidades do consumidor (WRIGHT, 2001).

No projeto PROFUTURO (2001), WRIGHT (2001) comenta em sua análise sobre um professor da Escola Superior de Propaganda e Marketing (ESPM), do setor de marketing de serviços e gestão em pessoas e estudioso do mercado sênior que afirma que: este é o momento de se criar estratégias de marketing, técnicas de vendas e relacionamentos para atender à necessidade dos consumidores mais velhos. Medidas simples como: atendimento personalizado ou até mesmo ambientes bem iluminados podem ser o grande diferencial com o público sênior. Apesar de serem consumidores mais experientes e portanto, mais exigentes, alerta também, quanto aos cuidados a serem tomados para que não haja discriminação com rótulos de melhor idade ou assemelhados.

Assim sendo, a excelência no atendimento deve ser uma ferramenta significativa para cativar o cliente, pois sabemos que, atualmente, a globalização e o desenvolvimento tecnológico equilibram a qualidade dos produtos esportivos. Portanto, a instituição é representada por todos que fazem parte dela, todos devem estar preparados como facilitadores no processo de entendimento 
da necessidade do cliente para auxiliá-lo a conquistar os seus objetivos e realizar os seu desejos (SABA, 2004).

Atendimento a clientes significa basear-se nas horas da verdade. Uma hora da verdade significa qualquer episódio no qual o cliente entra em contato com qualquer aspecto da organização obtendo uma impressão da qualidade do serviço (ALBRECHT, 1992). De acordo com o autor, considerando que o cliente passa em média duas horas na instituição, o número de vezes que ele comprova as horas da verdade são inúmeras.

Desta maneira, a instituição ganha ou perde um cliente em função dessa harmonia na interação cliente/instituição, como por exemplo: quando solicita informações na recepção sobre as atividades e aulas, professores, eventos, acesso às dependências, matrícula, quando questiona os professores sobre os métodos didáticos e benefícios das AFs que freqüenta, quando utiliza os vestiários e verifica as condições do local (limpeza, conservação e volume de pessoas), quando utiliza as instalações e equipamentos verificando seu estado de conservação e atualização entre outras situações diversas que ocorrem no dia-adia da academia.

Conforme ROJO (1998), as empresas atualmente estão se esforçando cada vez mais para reter os seus consumidores, o que é plenamente justificado pelo fato de que o custo para atrair novos consumidores pode chegar a cinco vezes o custo para se manter um consumidor feliz.

Portanto, o caminho do sucesso está baseado no gerenciamento e no sistema de atendimento como um todo, onde todos os envolvidos na organização participem e mantenham um contato direto e indireto com o cliente. Logo, o sistema de atendimento deve ser planejado e organizado, pois, quando se 
valoriza o cliente, há um aumento de adesão e diminuição de rotatividade (SABA \& ANTUNES, 2004).

\subsubsection{Programas diversos de AF para idosos}

Neste item são apresentados diferentes programas de AF para idosos com um breve descritivo quanto aos objetivos, atividades desenvolvidas, conteúdos desenvolvidos.

3.4.4.1 Programa de Autonomia da AF (PAAF) - EEFEUSP - (OKUMA, 2003)

O PAAF é um programa de educação física desenvolvido na Escola de Educação Física e Esporte da USP destinado aos indivíduos com idade igual ou superior a 60 anos. O curso é composto de atividades práticas e teóricas com duas sessões semanais de 120 minutos e duração de 12 meses. Seu objetivo principal é levar o idoso a ter autonomia para auto-gerir um programa de AF. O curso foi criado e é coordenado por uma professora de Educação Física, sendo desenvolvido por um grupo de professores de educação Física.

As atividades práticas têm como objetivo levar o idoso a:

a) adquirir conhecimentos sobre o seu corpo e conscientizar-se dele, das suas capacidades funcionais, das suas habilidades motoras e das suas limitações;

b) desenvolver domínio mínimo das suas habilidades motoras, e aumentá-lo, na medida do possível, de modo a ampliar o domínio do corpo e do espaço; 
c) melhorar a capacidades físicas e motoras (força, flexibilidade, capacidade aeróbia, agilidade, equilíbrio, tempo de reação e de movimento para aumentar a aptidào física);

d) descobrir o prazer de movimentar-se e de dominar o próprio corpo em diferentes situações motoras.

O conteúdo desenvolvido nas aulas práticas compreende:

a) atividades de reestruturação corporal realizada através de atividades com movimentos lentos, sutis e isolados, de cada parte do corpo;

b) relaxamento, massagem e auto-massagem, atividades que levam o idoso a perceber o próprio corpo em situações de tensão e lidar adequadamente com tais situações;

c) exercícios respiratórios;

d) atividades aeróbias;

e) atividades para melhorar a força muscular e flexibilidade, através de exercícios de ginástica com diferentes tipos de materiais (bolas, bastões,bancos, plintos, halteres, caneleiras, etc.);

f) atividades para melhorar o controle motor como agilidade, tempo de reação e de movimento, equilíbrio e atividades rítmicas.

As atividades teóricas têm como objetivo:

a) levar o idoso a reconhecer o valor da AF para manter sua própria qualidade de vida;

b) informar sobre a estruturação e o funcionamento do corpo humano e suas alterações decorrentes do processo de envelhecimento;

c) conhecer as implicações positivas das AFs nesse processo;

d) saber quais AFs praticar para lidar esse processo e como desenvolvê-las. 
A avaliação é proposta por um diagnóstico inicial constituído de avaliaçào funcional, teste ergométrico, avaliação da aptidão física e avaliações posteriores realizadas anualmente. Existe também uma entrevista periódica para verificar dados referentes aos aspectos psicológicos, como auto-eficácia e autovalorização.

\subsubsection{Programa Exercício e Saúde - (MOTA \& CARVALHO, 2002)}

Este programa é fruto de uma experiência de seis anos de trabalho comunitário desenvolvido pelo Gabinete de Recreação e Tempos Livres da FCDEF-UP, em parceria com a Câmara Municipal do Porto no Programa "Exercício e Saúde". O programa é composto de atividades práticas com sessões que podem variar de 45 a 60 minutos com intensidades entre 50 e $75 \%$ da FC máxima.

Sugerem que é necessário criar atividades que propiciem aos idosos bem-estar, com atividades adequadas a sua aptidão física para que iniciem e mantenham a sua participação nas AFs. Aconselham a realização de exame médico que permita avaliar a condição física do indivíduo antes de se iniciar o programa de AF evitando possíveis riscos e contra-indicações.

Em relação aos benefícios do exercício físico, referem-se a uma prática sistemática, controlada e adaptada ao estado de saúde e condição física de cada um dos idosos. As AFs devem ser orientadas com o objetivo de melhorar a capacidade física geral do indivíduo, atenuando o efeito deletério do envelhecimento.

O objetivo das atividades propostas é de desenvolver estratégias que permitam ao idoso ser independente dos outros na realização das AVDs. Não se 
pretende atingir o perfeccionismo e tecnicismo mas desenvolver e aperfeiçoar o gesto utilitário indispensável para a realização eficaz das tarefas do dia-a-dia.

Pretendem que a AF se constitua como um meio de excelência para a ocupação alegre e saudável do tempo livre, devendo corresponder a um bemestar físico e psicológico.

A AF fundamenta-se principalmente em quatro fatores: prevenção, manutenção, reabilitação e recreação abrangendo o nível físico, fisiológico, social e psicológico, que se resumem num objetivo principal que é a melhoria do bem-estar e da qualidade de vida dos idosos.

As atividades práticas têm como objetivos físicos e fisiológicos:

a) aperfeiçoar o gesto "utilitário" indispensável para a realização das AVDs;

b) aumentar a aptidão física através do desenvolvimento das diferentes capacidades motoras, como força, resistência, flexibilidade, coordenação e equilíbrio;

c) diminuir o risco de patologias mais freqüentes e "evitáveis", como as do aparelho locomotor e cardiovascular;

d) controle do peso, aumentando o metabolismo e alterando o estilo de vida com a prática de hábitos saudáveis.

Como objetivos psicológicos e sociais:

a) ocupar o tempo livre de forma alegre e saudável;

b) aumentar a integração social, o convívio e a relação com os outros, de maneira a superar ou diminuir a solidão, o isolamento;

c) restituir a consciência do seu corpo e a possibilidade de utilização do mesmo com eficácia;

d) aumentar a auto-imagem, a auto-estima e auto-conceito;

e) diminuir os estados de ansiedade e depressão; 
f) aumentar o bem-estar mental e emocional.

Os conteúdos das sessões são variados, explorando desde a dança e jogos tradicionais, até exercícios mais localizados de força muscular, atividades aquáticas, caminhadas, exercícios de relaxamento e respiratórios de maneira que haja uma combinação das diferentes atividades. Devem ser motivantes e atraentes, simples e de fácil compreensão e realização.

3.4.4.3 Programa Mexa-se Itaguaçu - (Universidade do Estado de Santa Catarina, UDESC, 2005)

A rede de atendimento comunitário aos idosos de Florianópolis, SC iniciou na década de 60 e os Programas de Atividade Física na década de 80. Houve um aumento da rede de atendimento voltada aos programas de atividade física na década de 90, principalmente pela atuação de instituições/entidades governamentais como a participação do Centro de Desportos - CDS da Universidade Federal de Santa Catarina - UFSC e do Grupo de Estudos da Terceira Idade - GETI da Universidade do Estado de Santa Catarina -UDESC.

Em 2000 este trabalho foi fortalecido com o programa Mexa-se pela Saúde na Terceira Idade da Secretaria Municipal de Habitação, Trabalho e Desenvolvimento Social (HTDS) da Prefeitura Municipal de Florianópolis. Entende-se como rede de atendimento comunitário o conjunto de iniciativas/ações para os idosos de entidades/instituições governamentais e nãogovernamentais, mediante o desenvolvimento de atividades que favorecem o convívio social, o fortalecimento de práticas associativas, produtivas e 
promocionais, e o exercício da cidadania, contribuindo para sua autonomia, envelhecimento ativo e saudável, prevenção do isolamento social e socialização.

O programa acontece no espaço físico de um shopping center e oferece gratuitamente aos participantes atividades físicas diárias após terem passado por uma anamnese inicial, com avaliação de risco coronariano, aptidão cardiorespiratória, composição corporal e posterior prescrição de exercício físico.

O Mexa-se no Itaguaçú conta ainda com o apoio do SESI e da Udesc (Universidade Estadual de Santa Catarina). Em 2002, quando os convênios foram renovados, o programa cresceu, conquistou novos parceiros e ganhou ainda mais destaque. $\mathrm{O}$ número de profissionais à disposição dos usuários foi ampliado - incluindo os de dedicação exclusiva - e foram agregadas uma psicóloga e uma nutricionista. Também foi criada uma programação de eventos e atividades complementares, como exames, palestras, campanhas de conscientização, passeios ecológicos e até aulas de hidroginástica no parque Acqua Way, instalado no shopping. Atualmente, sete professores de educação física em dedicação exclusiva atendem cerca de 200 pessoas diariamente, nos horários de 7 às 10:30 e 17:00 às 21:15.

As AFs oferecidas aos idosos são a ginástica, recreação, jogos, dança, natação, hidroginástica, yoga, caminhada entre outras realizadas sistematicamente em entidades/instituições governamentais e nãogovernamentais.

A Prefeitura Municipal de Florianópolis, em 2005 com o programa Mexa-se pela Saúde na Terceira Idade presta atendimento regional a 3.628 idosos por meio da atividade fisica a 61 grupos de convivência para idosos (2.896 idosos) com programa de recreação quinzenal; três instituições asilares (47 idosos); 22 grupos em clubes, associações, posto de saúde e centro 
comunitário (595 idosos) com ginástica duas vezes por semana; dois (2) grupos de dança ( 90 idosos) com aulas duas vezes por semana.

Vislumbra-se a constituição de uma rede articulada de programas e serviços sociais públicos e de demais órgãos disponíveis na comunidade florianopolitana para compor uma política de promoção de uma vida digna e saudável da população idosa, privilegiando o processo de envelhecimento ativo, com qualidade de vida e com um senso subjetivo de bem-estar e felicidade das pessoas idosas residentes no município.

\subsection{O Programa Platinum - Características}

A academia na qual o programa se insere está há 20 anos no mercado e é considerada uma das pioneiras no país a implantar o conceito de Wellness. É o embrião do que chamamos atualmente de rede nacional, pois atua em sete cidades com 10 academias, marcando presença em cinco estados (São Paulo, Rio de Janeiro, Brasília, Minas Gerais e Pará).

Atualmente, a rede atende a 25 mil alunos ativos e disponibiliza 43 tipos de aulas de ginástica, oito modalidades esportivas, 11 aquáticas e oito tipos de lutas. Além das 28 atividades que compõem a programação infantil, o Programa Platinum inclui cinco modalidades direcionadas ao público idoso.

O Programa Platinum é um programa de exercícios voltado para os alunos com 60 anos ou mais, que faz parte das várias atividades oferecidas pela academia avaliada.Teve seu início no ano de 2001, na unidade de Brasília, no departamento de Musculação, sob a orientação do Prof. Doutorando Sandor Bálsamo, gerente técnico de Musculação e Cardiovascular, conforme exposto anteriormente, o qual implantou o programa de musculação para os idosos que 
freqüentavam aquela unidade. Posteriormente, outras atividades foram desenvolvidas, de acordo com o perfil do praticante idoso de cada unidade.

Ao ingressar na academia tivemos a oportunidade de aprimorar e incrementar mais atividades e novas metodologias de trabalho ao Programa Platinum. Este processo durou aproximadamente hum ano e a partir dessa nova fase o programa conquistou mais espaço e reconhecimento pelos gerentes técnicos e pelos gestores administrativos.

Posteriormente o Programa passou por algumas modificações nas quais foram acrescidas novas e complementares atividades, visando ao aprimoramento, a integração entre as áreas da Academia (Depto. Aquático, Depto. de Ginástica e Musculação, Depto. de Esportes) e a sua adequação quanto às necessidades do grupo dos idosos da academia.

Deste modo, o programa passou por diversas fases onde foi realizado um estudo do cenário atual das suas características para a tomada de decisões nas modificações que se seguiram. A partir desta análise preliminar, diversas ações foram realizadas para a sua reestruturação, descritas abaixo:

1) Levantamento quantitativo da população de idosos da unidade pesquisada;

2) Levantamento do $n^{\circ}$ de idosos que freqüentam especificamente as atividades de musculação, natação, hidroginástica, ginástica e cardiovascular;

3) Análise do perfil dos usuários;

4) Treinamento dos profissionais envolvidos da unidade; 
5) Divulgação interna. externa e para a classe médica (fisiatras, geriatras, clinico geral, ortopedistas, reumatologistas, cardiologistas e fisioterapeutas);

6) Implementação das modificações do programa - integração de áreas;

7) Recursos materiais e humanos: foram utilizados os recursos da própria academia, como computador, internet, equipamentos disponiveis e professores e/ou colaboradores, interessados no projeto.

O Programa Platinum atualmente atende a $\mathbf{1 1 5}$ alunos, que podem escolher em freqüentar ou não as atividades oferecidas pelo programa. Essas atividades podem ser realizadas em grupo ou individualmente, prescritas por meio de um atendimento inicial individualizado que determinará a melhor opção de horários e atividades a serem freqüentadas pelo praticante idoso. Posteriormente o aluno Platinum é submetido a uma Avaliação Física que determinará o seu nível de aptidão física quanto aos aspectos antropométricos, metabólicos e neuromotores.

Com base nas informações coletadas no atendimento inicial e na avaliação física é que se faz a prescrição de treinamento experimental de maneira que o aluno Platinum possa iniciar o seu programa de exercícios efetivamente com segurança.

\subsubsection{Objetivos do Programa Platinum}

- melhorar a qualidade de vida dos idosos que a academia atende atualmente, oferecendo serviços adequados às suas necessidades, por meio de incentivos à ajuda mútua, estimulando as suas capacidades 
fisicas e cognitivas (McAULEY \& RUDOLPH 1995; OKUMA, 1998, 1999; SWOAP et. al., 1994; VAN BOXTEL et. al., 1997; WOOD et. al., 1999);

- maximizar a saúde psicológica (CHEN et al., 1992; SPIRDUSO \& CRONIN, 2001);

- aperfeiçoar ou restabelecer a capacidade funcional (SPIRDUSO \& CRONIN, 2001);

- auxiliar na reabilitação de doenças agudas e crônicas quando necessário (SPIRDUSO \& CRONIN, 2001);

- reforçar a sua autonomia e autoconfiança (CARVALHO \& MOTA, 2002);

- incentivar a prevenção (GEIS, 1996) e a informação (ANDREOTTI \& OKUMA, 2003);

- melhorar a sua situação social incentivando o diálogo e a compreensão entre as gerações (CARVALHO \& MOTA, 2002; LOPES \& SIEDLER,1997; OKUMA, 1997).

\subsubsection{Roteiro do aluno Platinum}

1) $\underline{\text { Recepção }}$ - identificar o perfil do cliente Platinum pela recepção, se faz necessário para que se possa oferecer o produto adequado ao perfil do usuário mostrando as suas vantagens e características. 
As recepcionistas devem saber basicamente identificar os idosos pela classificaçào cronológica, (OMS /ONU): Meia idade (45 a 59 anos), Idoso (60 a 74 anos). Velhice (75 a 85 anos), Velhice Avançada (mais de 85 anos). A academia atualmente tem estrutura para atender os idosos de nível funcional III (fisicamente independente), IV (fisicamente ativo) e V (atleta), de acordo com SPIRDUSO (1995). Logo abaixo a seguir tem-se o fluxograma (roteiro) do aluno Platinum ao chegar na academia:

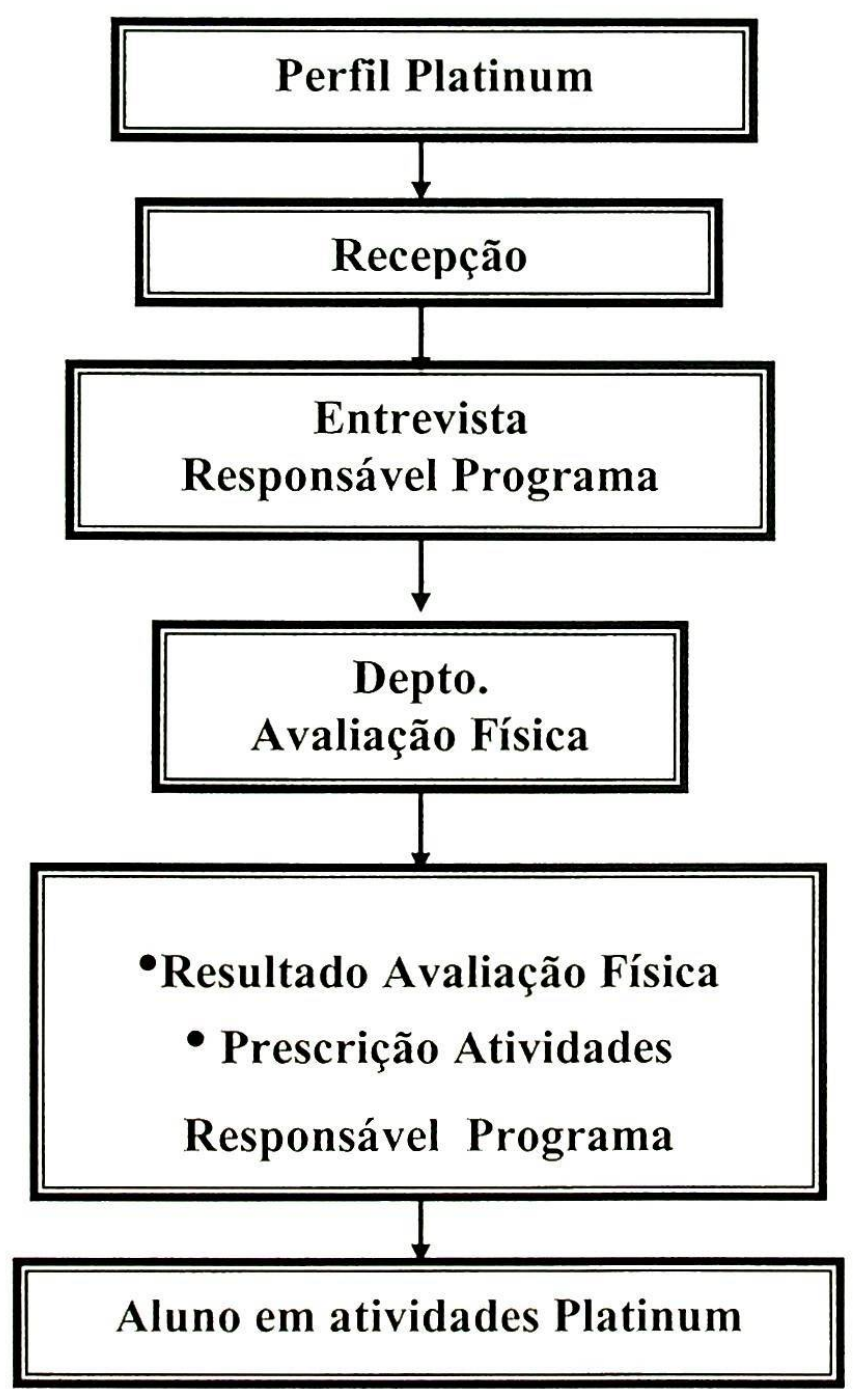

FIGURA 1- Fluxograma aluno Platinum 
Após a identificação inicial, as recepcionistas informam de maneira generalizada o que é o Programa Platinum, explicam os procedimentos da academia ao aluno, mostram as instalações e entregam o folder informativo contendo a grade horária (atividades, horários, local e professor com o mesmo modelo das outras atividades da academia) e sugestões de vestimentas e acessórios mais adequados a cada atividade para iniciar o programa. Finalizam os procedimentos com o agendamento da entrevista inicial com o coordenador/responsável pelo programa para poder iniciar as atividades.

2) Entrevista Inicial (Ficha Controle) - a entrevista inicial deve ser realizada pelo coordenador/responsável pelo Programa Platinum e ser previamente agendada pela recepção. A entrevista inicial é um procedimento de extrema importância na qual verifica-se o histórico pessoal e de saúde do aluno idoso. É a fase de identificação das principais características passadas e presentes do indivíduo em relação à prática de atividade física, como também de predição das atividades futuras em relação à prática de atividade física (DISHMAN, 1993).

Realizada a entrevista inicial (ANEXO IV), o aluno idoso responderá o formulário de avaliação funcional onde são identificadas as principais dificuldades nas realizações das AVDs, de acordo as recomendações de ANDREOTTI e OKUMA (1999), conforme (ANEXO V). Nesse momento o coordenador/ responsável poderá auxiliar o preenchimento, esclarecendo possíveis dúvidas.

Durante a entrevista, o coordenador também deve enfatizar a importância de se fazer a Avaliação Física e de preferência agendá-la neste primeiro contato. O aluno Platinum deverá iniciar o programa efetivamente após ter realizado a avaliação física da academia e ter trazido o atestado médico do 
seu médico particular. Alguns exames complementares como densitometria óssea para as mulheres, colesterol, triglicérides e ergométrico de esforço são pedidos como complementação para o acompanhamento futuro da sua saúde, porém nào sendo condição obrigatória para iniciar o programa.

O aluno Platinum poderá fazer uma ou duas aulas experimentais, com autorização do coordenador do programa para facilitar a identificação da atividade que mais lhe agradar. Estas aulas poderão ser agendadas também na recepção, informando dia, horário e local das atividades de que o idoso irá participar.

3) Depto. de Avaliação Física - após a entrevista inicial com o coordenador/responsável, o aluno será encaminhado para o agendamento da avaliação física na recepção. É de extrema importância que o aluno Platinum realize a avaliação física para termos total segurança quanto à sua condição de saúde inicial e prescrevermos a sua base de treinamento, ou seja, reduzir totalmente os fatores de risco desta população. Sabemos da existência da grande variabilidade entre os idosos, por isso, é recomendado que passem por uma avaliação física adequada antes de iniciarem o programa na academia.

O planejamento, prescrição e aplicação do programa tendem a ser mais eficientes se conhecermos o estado prévio de saúde do indivíduo idoso. A avaliação pré-treinamento nos dá condições de analisar as possíveis alterações (POLLOCK \& WILMORE, 1993). O coordenador/responsável do programa Platinum deve enviar, via rede, a Ficha Controle do aluno para que o avaliador físico já possa saber o nível funcional do idoso e suas patologias. Desta forma, o avaliador físico tem elementos para definir qual protocolo de avaliação será o 
mais adequado para cada caso de acordo com o nível funcional do idoso (MATSUDO, 2000).

Realizada a avaliação física, a prescrição de exercícios depende dos objetivos, necessidades, estado de saúde e condicionamento físico do idoso. O fator disponibilidade de tempo, segurança no local da prática, equipamentos e instalaçōes adequadas devem ser levados em consideração pelo avaliador.

4) Resultado da Avaliação Física / Prescrição das atividades - após ter realizado a avaliação física, o aluno Platinum é orientado pelo coordenador/responsável do programa quanto à programação das atividades e horários mais adequados em função dos resultados da avaliação física e dos exames trazidos. Recebe ainda um programa de treinamento experimental das atividades semanais que irá freqüentar ( $A N E X O V I)$ e a grade de horários das atividades do programa ( $A N E X O V I I)$ com orientações quanto aos acessórios e vestimentas e exames complementares que deverá trazer assim que passar pelo seu médico de confiança.

A avaliação física deve ser feita periodicamente com o objetivo de acompanhamento das evoluções do indivíduo com o treinamento de maneira que dê os subsídios para avaliar os procedimentos utilizados inicialmente e reestruturá-los se necessário (OKUMA, 2000; POLLOCK \& WILMORE, 1993).

Pelo menos a cada quatro meses de freqüência o coordenador/ responsável entrará em contato com o aluno Platinum para verificar o andamento do programa e fazer as modificações necessárias. 


\subsubsection{Integração de áreas - Programa Platinum}

O aluno Platinum deve estar integrado com todos os departamentos que a academia possui - Depto. de Ginástica, Depto. de Musculação e Cardiovascular, Depto. Aquático (Natação e Hidroginástica) e Depto. de Esportes, adequando o programa quanto às necessidades do grupo de idosos.

Segundo CARVALHO e BARBOSA (2003), o entrosamento entre os vários profissionais que trabalham com o idoso é fundamental. As autoras ainda afirmam que quando possível deve-se trabalhar em equipe estabelecendo as relações entre os aspectos estudados quanto às variáveis antropométricas, neuromotoras, metabólicas, nutricionais, sociais e psicológicas. Assim sendo, com uma equipe multidisciplinar podemos trazer retornos práticos e benéficos tanto para os profissionais quanto para os idosos.

Neste novo conceito, o aluno idoso poderá participar de diversas atividades sendo orientado de forma mais personalizada atendendo e respeitando os seus desejos, limitações (restrições/patologias) e necessidades.

\subsubsection{Atividades Platinum}

Um programa de exercícios para idosos deve ser adequado especificamente à sua população usando uma combinação de treinamento cardiovascular (aeróbico), força, resistência muscular localizada (RML), equilíbrio, coordenação e flexibilidade (ACSM, 2004; MATSUDO, 2001). CARVALHO e MOTA (2002) corroboram a citação anterior enfatizando ainda que para que os idosos iniciem e mantenham a sua participação nas atividades 
físicas é necessário criar atividades que thes propiciem bem-estar, o que pressupòe a adequação à sua condição de idoso.

Não existe idade para aprender novos movimentos, sendo apenas necessário adaptar as atividades físicas às características e possibilidades de cada um, ao seu grau de patologia, mobilidade e autonomia (CARVALHO, 1999).

A atividade física para o idoso deve objetivar além dos benefícios físicos, também os psicológicos e sociais que se traduzem num objetivo principal que é o da melhoria do bem-estar e da qualidade de vida (CARVALHO \& MOTA, 2002; McAULEY \& RUDOLPH 1995; OKUMA 1998,1999; SWOAP et. al., 1994; VAN BOXTEL et. al., 1997; WOOD et. al., 1999).

De acordo com MATSUDO, MATSUDO e BARROS (2001), o novo paradigma da atividade física para a promoção de saúde recomenda a prática de pelo menos 30 minutos por dia, de atividades de intensidade moderada, na maior parte dos dias ou de preferência todos os dias de forma contínua ou acumulada.

Os exercícios devem ser progressivos quanto à sua intensidade e complexidade, criativos e motivantes, de fácil execução e compreensão, devem proporcionar comunicação e integração social e ser diversificados (caminhada, natação, ginástica, musculação, jogos, dança, hidroginástica) (CARVALHO \& MOTA, 2002).

As sessões podem ser de no mínimo 30', 45' a 60', com intensidade entre 50 e $75 \%$ da freqüência cardíaca máxima (ACSM, 1998). As diferentes partes da aula em grupo com características mais dinâmicas devem ser respeitadas compondo-se de: aquecimento (de 10' a 15'), parte específica (de 20' a 30') que deve incluir diversos exercícios como os aeróbicos, de RML, agilidade, coordenação, equilíbrio e flexibilidade (de acordo com o tipo e objetivo da atividade) e parte final (5' a 10') de relaxamento, que podem incluir 
exercícios de respiração, relaxamento e flexibilidade (CARVALHO \& MOTA, 2002).

Um outro fator importante a ser considerado nas sessões está associado ao horário - se possível, as atividades devem ser realizadas entre 10:00 e 11:00 horas da manhã e entre 15:00 e 16:00 (CARVALHO \& MOTA, 2002), não esquecendo de levar em consideração o local da prática, o perfil do grupo de idosos e o tipo de atividade a ser desenvolvida.

O material e a música escolhidos nas sessões têm um importante significado quanto à motivação das aulas, pois potencializa a relação e a comunicação. Devem servir como um suporte para alcançar os objetivos propostos nas aulas com um bom aproveitamento em relação aos exercícios escolhidos na sessão (GEIS, 1996). É importante ressaltar que em determinados momentos o aluno deve saber que as correções e as explicações são importantes, principalmente, nas atividades que exijam uma maior atenção/concentração a música será interrompida (GEIS, 1996).

A seguir as atividades desenvolvidas nos departamentos relacionadas com o programa:

1) Departamento de Ginástica - neste departamento temos atualmente as aulas de Alongamento e Multi Platinum. Na grade de horários são oferecidas $5 \mathrm{X}$ vezes por semana as aulas de Alongamento e $2 \mathrm{X}$ por semana as aulas do Multi Platinum, com duração de 45 minutos respectivamente. Os alunos freqüentam as aulas em função do que foi previamente recomendado na prescrição de treinamento experimental. 
> Alongamento - nos idosos a flexibilidade é limitada por vários fatores como: formato das superficies articulares, adesões, contraturas e cicatrizes nos tecidos moles, componentes contráteis, ligamentos e tendões e fáscia (ACHOUR JUNIOR, 2002). É considerado um componente essencial para a boa execução dos movimentos, sendo um dos mais importantes fatores de segurança para o idoso, pois auxilia na prevenção de acidentes (OKUMA, 1998).

Uma das definições de flexibilidade está relacionada com a capacidade e a característica de um indivíduo executar os movimentos de grande amplitude, ou sob forças externas, ou ainda que requeiram a movimentação de muitas articulações (WEINECK, 1999).

A sua capacidade declina de 20 a $30 \%$ aos 70 anos, aumentando percentualmente após os 80 anos. Os tendões, ligamentos e fáscias apresentam uma redução no número de células, redução de mucopolissacarídeos, de fibras elásticas e perda de água (MEIRELLES, 2000). Os tecidos conectivos dos idosos respondem significativamente aos exercícios de alongamento estático com tensão moderada e com duração relativamente prolongada, de maneira que se possa promover a estabilidade músculo-articular (ACHOUR JUNIOR, 2002).

$\mathrm{Na}$ aula de Alongamento Platinum o professor deve saber da restrição de cada aluno e adequar quando necessário as modificações dos movimentos e posturas. Deve-se trabalhar de preferência as maiores articulações (quadril, costas, ombros, joelho, pescoço e tronco). As características da aula de Alongamento Platinum de acordo com recomendações do ACSM (2000b) devem conter: 
- Objetivos:

1) Desenvolver o auto-conhecimento por meio da consciência e da autonomia corporal;

2) Enfatizar a importância do exercício e sua necessidade de aplicação e adaptação ao cotidiano;

3) Melhorar a sua flexibilidade e o equilíbrio nas AVDs.

- Conteúdo: flexibilidade, relaxamento, equilíbrio, mobilidade articular, exercícios respiratórios e interação social.

\section{-Procedimento:}

1) Deve-se iniciar com um aquecimento e mobilização das articulações nas posições em pé, sentado ou em movimento.

2) Ficar em cada posição de 10 a 15 segundos e no máximo 30 segundos e depois trocar de lado. Repetir pelo menos três vezes para cada posição ou movimento, podendo chegar até cinco repetições por grupo muscular.

3) As sessões podem ser variadas com atividades em duplas, trios, que estimulem a interação social e o reforço positivo.

- Recursos: Fit ball, bolinhas de borracha de diferentes densidades e tamanhos, colchonetes, travesseiro, bastões, rubber bands, barra, música.

- Cuidados e precauções: evitar exercícios de alongamento com forte tensionamento tornando mais suscetível a lesões. Em idosos com baixo nível de flexibilidade ter cuidado nos exercícios nas posições em pé ou sentado, devido ao encurtamento freqüente dos isquiotibiais, pois há uma limitação da extensão 
do joelho ou na flexão do quadril com o joelho estendido, podendo ainda diminuir a curvatura da coluna lombar e com isso aumentar a sobrecarga na coluna. Esta carga maior poderá comprometer a função e a estrutura da coluna lombar (ACHOUR JUNIOR, 2002).

FIGURA 2 - Alongamento Platinum
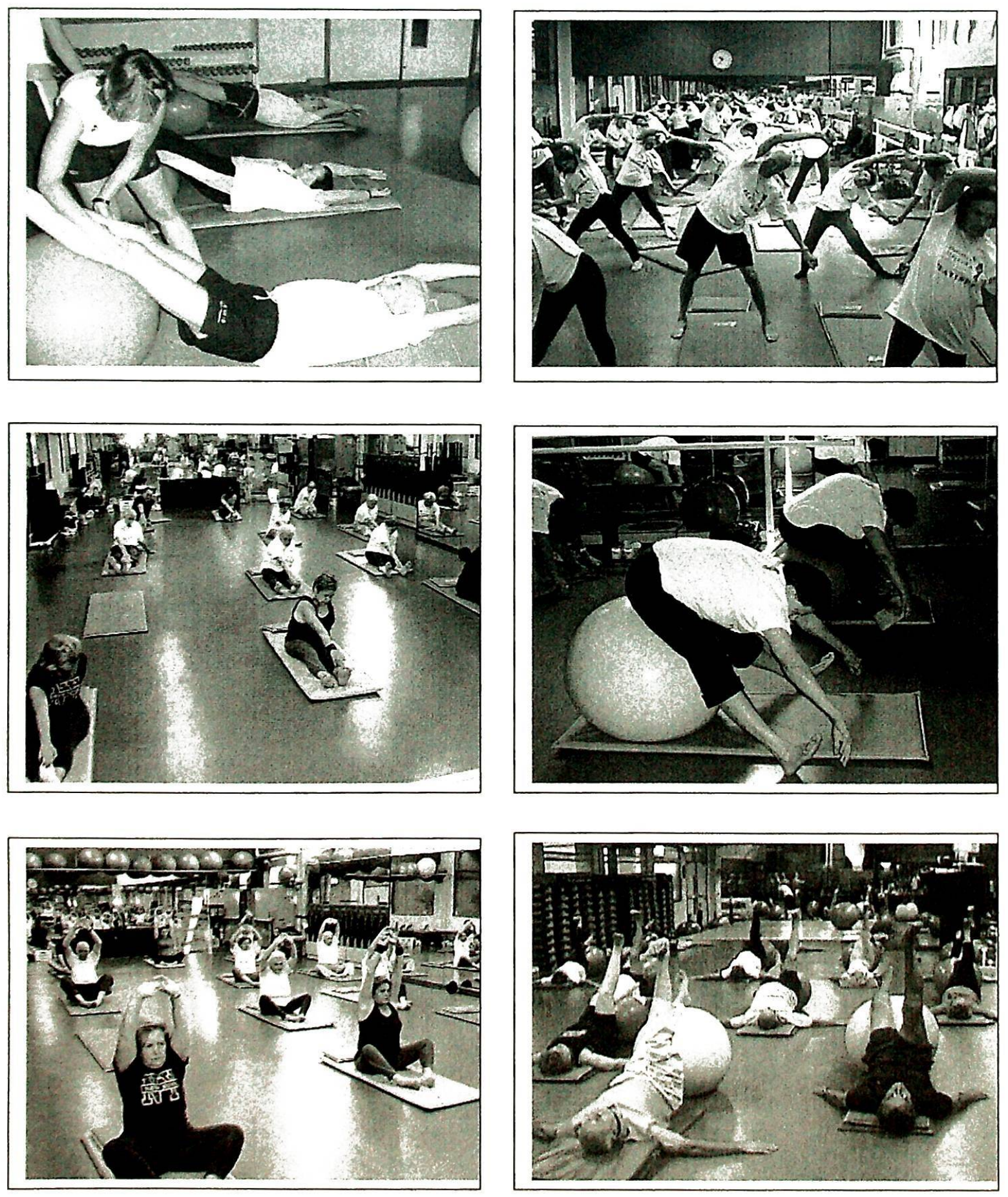
> Multi Platinum - esta é uma aula de condicionamento físico funcional em grupo onde as principais capacidades da aptidão física são trabalhadas: RML, coordenação, equilíbrio, agilidade. Exercícios que estimulem o tempo de reação, concentração e memória e treinamento funcional (propriocepção), que também são realizados como elemento de motivação.

Este tipo de aula tem grande importância visto que o ser humano interage continuamente com o ambiente em que vive e está sujeito a ser influenciado pelas mudanças do meio e assim, ter que se adequar rapidamente a essas mudanças de maneira eficiente (FONSECA, 2004). Assim sendo, a necessidade de ter o mínimo de competência motora para que haja essa interação é de extrema importância, uma vez que os movimentos corporais são utilizados para a realização das AVDs.

Foi constatado por SILVA, MATSUDO, MATSUDO e ANDRADE (1999), que exercícios de força com intensidades baixas e moderadas não são suficientes para promover melhoras na mobilidade em indivíduos idosos, mas contribuem para a melhora do equilíbrio e na velocidade do andar. Assim sendo, exercícios que estimulam a melhora das capacidades funcionais são importantes, na medida que promovam uma maior independência do idoso na realização da AVDs.

O treinamento funcional visa melhorar as capacidades funcionais do idoso devido ao princípio da especificidade, pois estimula o corpo humano de maneira a adaptá-lo para as atividades do dia-a-dia (CAMPOS \& CORAUCCI, 2004). A seguir, as características da aula de Multi Platinum, contendo: objetivos, conteúdo, procedimento, recomendações e recursos: 


\section{- Objetivos:}

1) Levar o idoso a ter condições físicas básicas para que possa melhorar a sua condição de vida diária - permanecer independente;

2) Aumentar a sua capacidade de reserva funcional;

3) Educar-se para prevenir as perdas funcionais, incapacidades ou lesões que possam levar à fragilidade física;

4) Diminuir o estresse e a ansiedade;

5) Melhorar o bem-estar geral e a saúde mental;

6) Aquisição de novas habilidades;

7) Melhorar nos aspectos cognitivos (concentração e memória), visuais (reação) e sensoriais (orientação espacial);

8) Melhorar as suas capacidades físicas: força, flexibilidade, resistência, equilíbrio, coordenação, agilidade e destreza;

9) Ampliar e melhorar as suas relações sociais.

- Conteúdo: força, flexibilidade, RML, equilíbrio, coordenação, agilidade, destreza, conhecimento do próprio corpo, orientação espacial, exercícios respiratórios, atividades rítmicas e recreativas, interação social.

\section{- Procedimento:}

1) Deve-se iniciar um aquecimento e mobilização das articulações durante 5 a 10 ' na posição em pé com ou sem deslocamento lateral e frontal.

2) Parte Principal: deve incluir exercícios funcionais, exercícios de RML, flexibilidade, força, equilíbrio, coordenação, agilidade, com duração de $25^{\prime}$ a 30 ', estimular os exercícios em duplas, trios ou em grupos. 
3) Parte Final, com duração de 5' a 10', composta por exercícios respiratórios e de relaxamento para recuperação da $\mathrm{FC}$.

4) As aulas devem estimular as variáveis de aptidão física, incluindo exercícios com diferentes materiais, jogos com bola, estafetas, exercícios que envolvam velocidade e rapidez e simulação de tarefas do dia-a-dia (subir e descer escada, sentar e levantar, agachamento, dirigir um automóvel, atravessar uma rua movimentada etc).

- Recomendações:

1) As informações teóricas devem ser dadas sempre no início e durante um novo exercício de maneira mais lenta, evitando uma grande quantidade de incertezas;

2) O idoso como iniciante, busca a idéia geral do movimento, assim enfatiza-se a sua estrutura geral, logo devemos dar poucos detalhes nas informações;

3) Como medida de segurança, os exercícios neuromotores, como por exemplo, os de equilíbrio, devem ser desenvolvidos sempre em situação de descanso, ou seja, no início da aula;

4) As demais atividades devem ser colocadas em diferentes momentos da aula, dependendo da intensidade e dos objetivos;

5) Evitar ensinar algo novo após uma atividade cansativa, principalmente se exigir muita atenção;

6) Todos os conteúdos devem estar presentes de acordo com a freqüência recomendada pelos princípios de treinamento.

- Recursos: caneleira, halter, fit ball, bolinhas de borracha de diferentes densidades e tamanhos, bastões, rubber bands, medicine ball, cordas, cones de tamanhos diferentes, arco, colchonetes, travesseiro, barra e música. 
FIGURA 3 - Multi Platinum
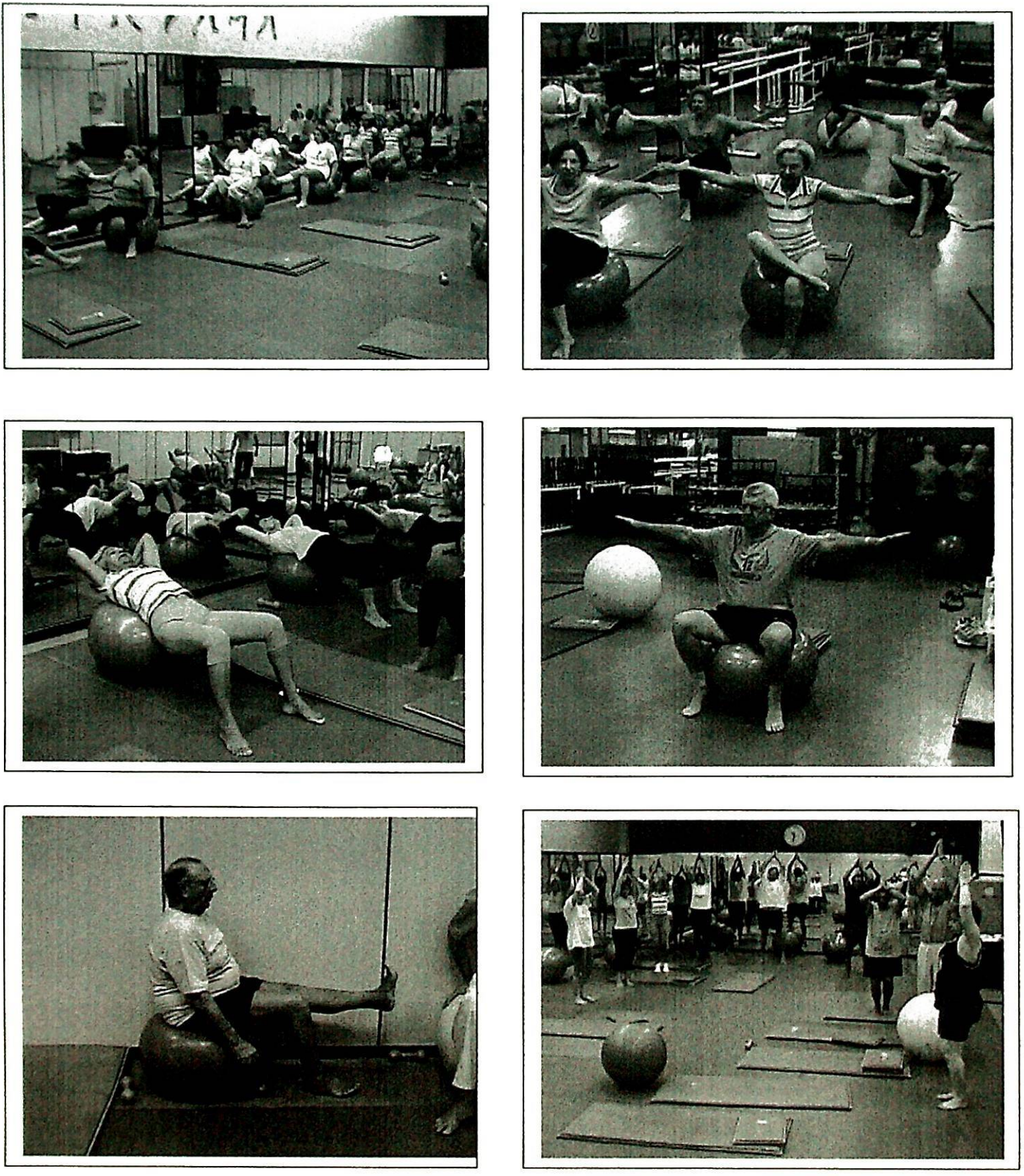
2) Departamento de Musculação e Cardiovascular - o manual técnico de musculaçào foi elaborado pelo Prof. Doutorando Sandor Bálsamo, da unidade de Brasília e é seguido atualmente como guia de prescrição de treinamento conforme segue:

- Musculação - neste departamento foram escolhidos os professores que têm o melhor perfil e interesse em trabalhar com os idosos em cada período. $\mathrm{O}$ professor escolhido é o responsável pelo grupo de idosos no período de 1 hora durante a sua jornada total de trabalho. A cada hora, nos horários de maior concentração de idosos na sala de musculação, um professor fica designado somente para atender aos idosos do programa, tanto para auxiliá-los com os equipamentos quanto nas correções.

Por ser uma atividade de extrema importância no programa e de acordo com os dados coletados, verificou-se que muitos alunos idosos têm:

1) Grande dificuldade em entender e manusear os equipamentos, levando um tempo maior para a compreensão da tecnologia do sistema tecnogym;

2) Insegurança e falta de informação sobre os benefícios da musculação, criando barreiras iniciais com medo de se machucar nos aparelhos;

3) Inibição (sentir que está incomodando) ao ter que se reportar ao professor a toda hora, pois na fase de adaptação o número de informações é muito grande, tendo dificuldades em saber qual a sua rotina de aparelhos.

Desta maneira, com um professor referência na sala de musculação, há uma tendência na diminuição dos impedimentos da prática como citados anteriormente, proporcionando uma integração maior entre os idosos, pois, a musculação é uma prática solitária e com isto sentem-se mais seguros no manuseio dos equipamentos e na prática. 
Com relaçào ao trabalho de força muscular, é de fundamental importancia na medida que proporciona o incremento da massa muscular e conseqüentemente a força muscular evitando quedas e preservando a capacidade funcional e independência (MATSUDO, MATSUDO \& BARROS, 2001). Os exercícios de força muscular devem priorizar os principais grandes grupos musculares (glúteos, quadríceps, posteriores da coxa, peitorais, dorsal, deltóides, abdominais) que são importantes nas AVDs (ACSM, 2000b; EVANS, 1999; FEIGENBAUM \& POLLOCK, 1999; FLECK \& KRAMER, 1999; FRONTERA, DAWSON \& SLOVIK., 2001). As características das sessões de treinamento de musculação devem conter:

- Objetivos:

1) Minimizar a sarcopenia;

2) Melhorar o padrão motor (autonomia);

3) Prevenir e tratar a osteoporose;

4) Aumentar a atividade espontânea.

- Procedimento:

1) Aquecimento e resfriamento de 10' a 15';

2) Freqüência de treinamento - após cada sessão deve haver um intervalo de 48 a 72 horas;

3) Série de exercícios - para os iniciantes, realizar apenas huma série para cada exercício, podendo chegar de duas a três séries no máximo por exercício, com intervalo de até 2' de descanso para recuperação metabólica entre uma série e outra; 
4) Repetição do exercício - não deve levar à falência total do músculo, deve estar entre 8 e 12 repetições com velocidade lenta;

5) Sobrecarga do exercício - deve apresentar características sub-máximas (75\% da carga máxima) e permitir a realização de oito a 12 repetições por exercício; 6) Progressão de treinamento - primeiro em volume (exercícios, séries e repetições) e depois na sua intensidade (peso e intervalo).

- Cuidados e precauções:

1) Nas primeiras oito semanas deve-se trabalhar com resistências baixas para permitir a adaptação dos tecidos conectivos;

2) A respiração deve ser normal durante a execução dos exercícios, evitando a apnéia;

3) Evitar o over training (super treinamento), iniciando com uma freqüência semanal de pelo menos $2 \mathrm{X}$ vezes por semana.

4) Nunca usar uma resistência que não permita a execução de pelo menos oito repetições;

5) Executar os movimentos com velocidade controlada (evitar movimentos balísticos).

- Cardiovascular - os tipos de atividades cardiovasculares mais recomendadas são as de baixo impacto como caminhada, ciclismo ou bicicleta ergométrica, natação, hidroginástica, remo e dança aeróbica de baixo impacto (MATSUDO, MATSUDO \& BARROS, 2001). Segundo Pesquisa da Nacional de Saúde dos Estados a caminhada é a atividade física mais realizada pelos idosos, representando $69 \%$ para os homens e $75 \%$ para as mulheres (CASPERSEN, KRISKA \& DEARWATER, 1994). 
O treinamento aeróbio é aquele realizado de maneira rítmica e contínua, envolvendo grandes grupamentos musculares, tendo como objetivo principal promover a melhoria do sistema cardiovascular e redução no percentual de gordura corporal. De acordo com ACSM (1998), o treinamento aeróbio deve ser realizado com uma freqüência de três a cinco vezes por semana, na intensidade de 60 a $90 \%$ da freqüência cardíaca máxima ou 50 a $85 \%$ do $\mathrm{VO}_{2}$ máx, com duração de 20' a 60’ de atividade aeróbia, podendo ser de uma única vez ou em duas ou mais etapas em função da disponibilidade de tempo e nível de aptidão física do praticante.

Deve-se ressaltar que a intensidade do treinamento aeróbio dependerá do condicionamento físico do idoso e de suas possíveis limitações/restrições. É recomendável para os alunos com patologias pré-existentes como cardiopatias, hipertensão, a realização de um teste de esforço máximo para iniciar o treinamento aeróbio vigoroso (ACSM, 1998).

No setor cardiovascular da academia, o aluno pode utilizar os diversos equipamentos disponíveis na sala, como bicicleta ergométrica com apoio e sem apoio, esteira, transport e stair master (simulador de escada), de acordo com as recomendações já prescritas no programa de treinamento. O aluno Platinum atualmente tem duas possibilidades de prática na sala cardiovascular:

1) Trabalho em grupo que antecede a prática na sala de ginástica, $2 x$ por semana com duração de 30 a 45'. O aluno tem a opção de freqüência livre para os outros dias da semana. O professor responsável deve ter todas as Fichas Controle do aluno Platinum, saber sua freqüência alvo, intensidade etc. Esta aula visa interagir o grupo, ensinar o idoso a manusear os equipamentos, estimular a sua autonomia após a fase de adaptação e trabalhar em conjunto com o professor 
responsável pelo período. Várias estratégias são utilizadas durante as aulas, como por exemplo, ter aulas na pista, de preferência em horários nos quais o sol não é tão forte, aulas na quadra , caminhadas em parques, no shopping etc.;

2) Trabalho individual com freqüência livre, no horário que for mais adequado ao praticante idoso, com a orientação do professor responsável pelo período.

FIGURA 4 - Musculação e Cardiovascular Platinum

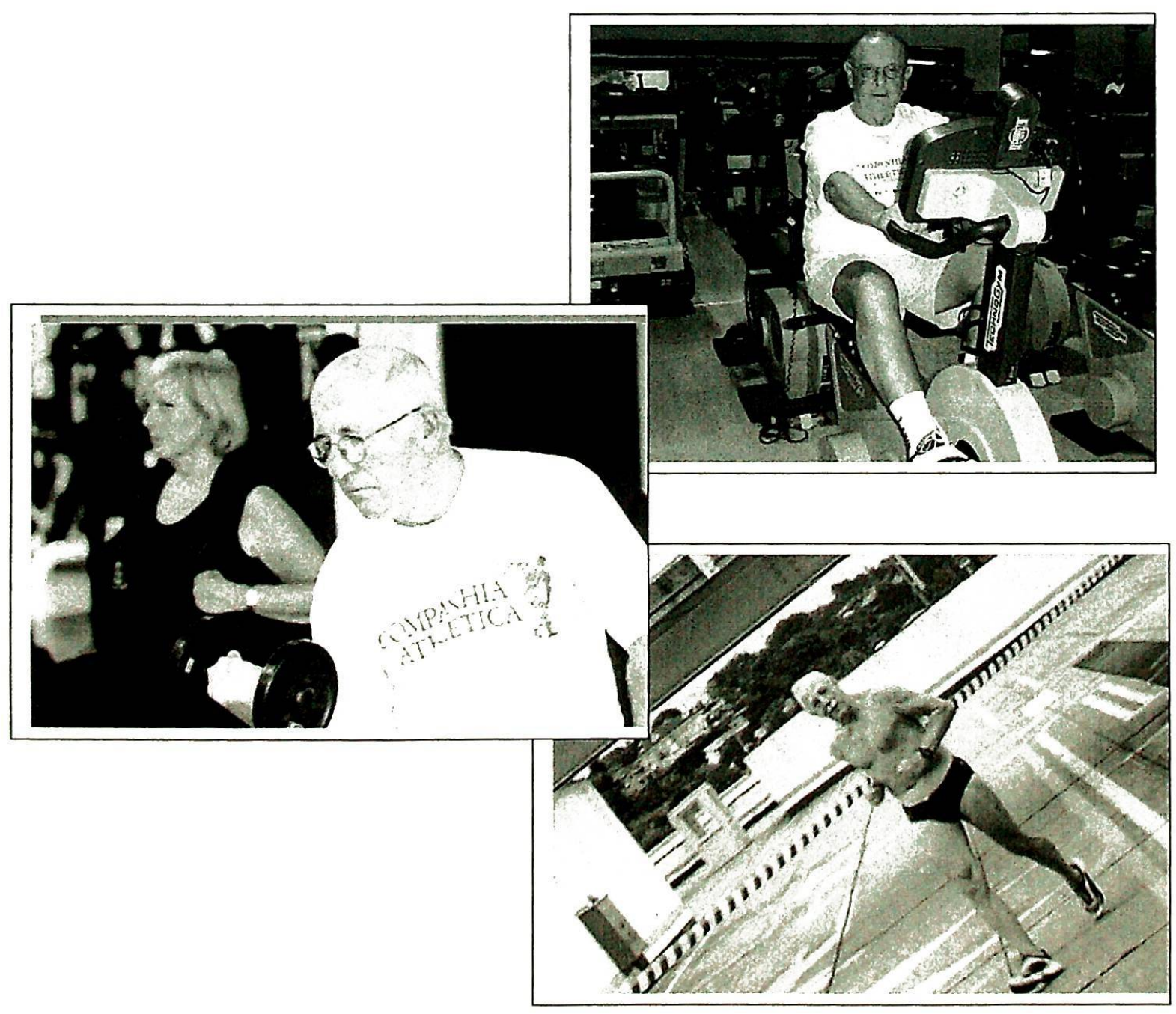


3) Departamento Aquático - Hidroginástica e Natação - a hidroginástica é uma atividade física que utiliza a água como elemento de resistência, possibilitando ao praticante fazer exercícios de acordo com o seu condicionamento físico de forma mais divertida e prazerosa, diminuindo o impacto nas articulações.

Atualmente, temos um grande número de adeptos, independentemente da idade dos indivíduos praticantes. A hidroginástica é utilizada como um meio na melhoria da qualidade de vida e de prevenção. ROCHA (1994), BONACHELA (1994) e MARQUES \& PEREIRA (1999) relatam que as propriedades físicas da água auxiliam, ainda mais os idosos, na movimentação das articulações, na flexibilidade, na força, na resistência, no sistema cardiorespiratório, no relaxamento, na eliminação das tensões mentais e na diminuição da tensão articular devido ao baixo impacto.

BONACHELA (1994) afirma que quanto aos aspectos psicológicos a hidroginástica permite que os seus praticantes sintam-se mais descontraídos e autoconfiantes, menos ansiosos, mais felizes e capazes de vencer as dificuldades, devido às propriedades físicas que o meio oferece.

Outro aspecto importante no programa de hidroginástica está relacionado à característica da piscina. Uma boa piscina para o trabalho aquático com idosos deve ter diversos planos de acesso como: degraus, rampas, barras de apoio ao redor das paredes das bordas e preferencialmente um piso antiderrapante, água bem tratada, profundidade crescente de modo a não ocorrerem quedas bruscas e temperatura ideal ficando entre $28^{\circ} \mathrm{C}$ e $30^{\circ} \mathrm{C}$, de acordo com as estações do ano (RAUCHBACH, 1990). 
Quanto ao Programa Platinum, o idoso pode freqüentar as duas piscinas existentes na academia avaliada para nadar ou fazer as aulas de hidroginástica em horários pré-determinados ou em freqüência livre, de preferência nos horários em que já existam grupos formados. Na grade de horários são oferecidas $2 \mathrm{X}$ por semana as aulas de Hidroginástica e de $2 \mathrm{X}$ a $5 \mathrm{X}$ as aulas de Natação com freqüência livre e duração de $45^{\prime}$. Os professores da Natação ou da Hidroginástica devem estar cientes de que o aluno é Platinum e das restrições que cada um possa apresentar, tomando as precauções necessárias para cada caso. Antes de iniciar a primeira aula, o professor deve ter a Ficha Controle do seu aluno Platinum contendo o seu histórico de saúde e programa de treinamento.

De acordo com BARBOSA (2001), BONACHELA (1994), PIRES, NOGUEIRA, RODRIGUES, AMORIM e OLIVEIRA (2004) são características do programa de hidroginástica:

\section{- Objetivos:}

1) Utilizar a água como mecanismo para desenvolver o auto-conhecimento por meio da consciência e da autonomia corporal;

2) Enfatizar a importância do exercício na água e seus benefícios;

3) Fortalecer, principalmente, os músculos estabilizadores do joelho, quadril e tronco;

4) Melhorar o equilíbrio, trabalhando com a instabilidade dos membros inferiores;

5) Melhorar a condição cardiovascular, resistência muscular localizada e força;

6) Desenvolver o rítmo e a coordenação;

7) Promover a socialização. 
- Contelido: flexibilidade, relaxamento, equilíbrio, mobilidade articular, exercícios aeróbios, exercícios de resistência muscular localizada, exercícios respiratórios.

\section{- Procedimento:}

1) Deve-se iniciar a aula com um pré-aquecimento e mobilização das articulações de forma ativa ou passiva variando de 5' a 10';

2) O trabalho aeróbio deve durar de $15^{\prime}$ a $20^{\prime}$. A intensidade deve ser trabalhada na faixa- alvo da freqüência cardíaca (65 a 85\%) ou na faixa de relativa intensidade em relação ao esforço percebido (Escala de Borg);

3) Os exercícios devem ser contínuos e rítmicos, utilizar preferencialmente os grandes músculos e manter sempre as pernas e braços em movimento, pois consomem mais calorias e energia do que somente os de braço;

4) Respeitar a condição individual de cada aluno com relação às possíveis patologias existentes e ao condicionamento físico;

5) Aumentar o estímulo de acordo com a adaptação do grupo;

6) Finalizar a aula com no mínimo 5' de alongamento/relaxamento;

7) Explorar os quatro lados da piscina, como estímulo do cognitivo na execução dos exercícios.

- Recomendações - (AEA, 2001)

1) Utilizar as principais posições da hidroginástica durante as aulas: neutra, suspensão, ancorada e rebote para que se enriqueça o repertório motor do idoso;

2) Todas as aulas devem conter exercícios aeróbicos e neuromusculares; 
3) Não esquecer de hidratar os alunos sempre durante e após o término do trabalho cardiovascular.

- Recursos: tubo, halter, colete, tornozeleira flutuante, pranchinhas, bola, luva, step, faixa, trampolim aquático e música.

- Cuidados e precauções -

1) Não ultrapassar a amplitude máxima dos movimentos (MARQUES, 1996);

2) Não prolongar exercício na presença de dor (MARQUES, 1996);

3) Uso de medicamentos (YAZBECK \& BATISTELLA, 1994);

4) Não levar à exaustão (MATSUDO \& MATSUDO, 1992);

FIGURA 5 - $\underline{\text { Hidroginástica Platinum }}$
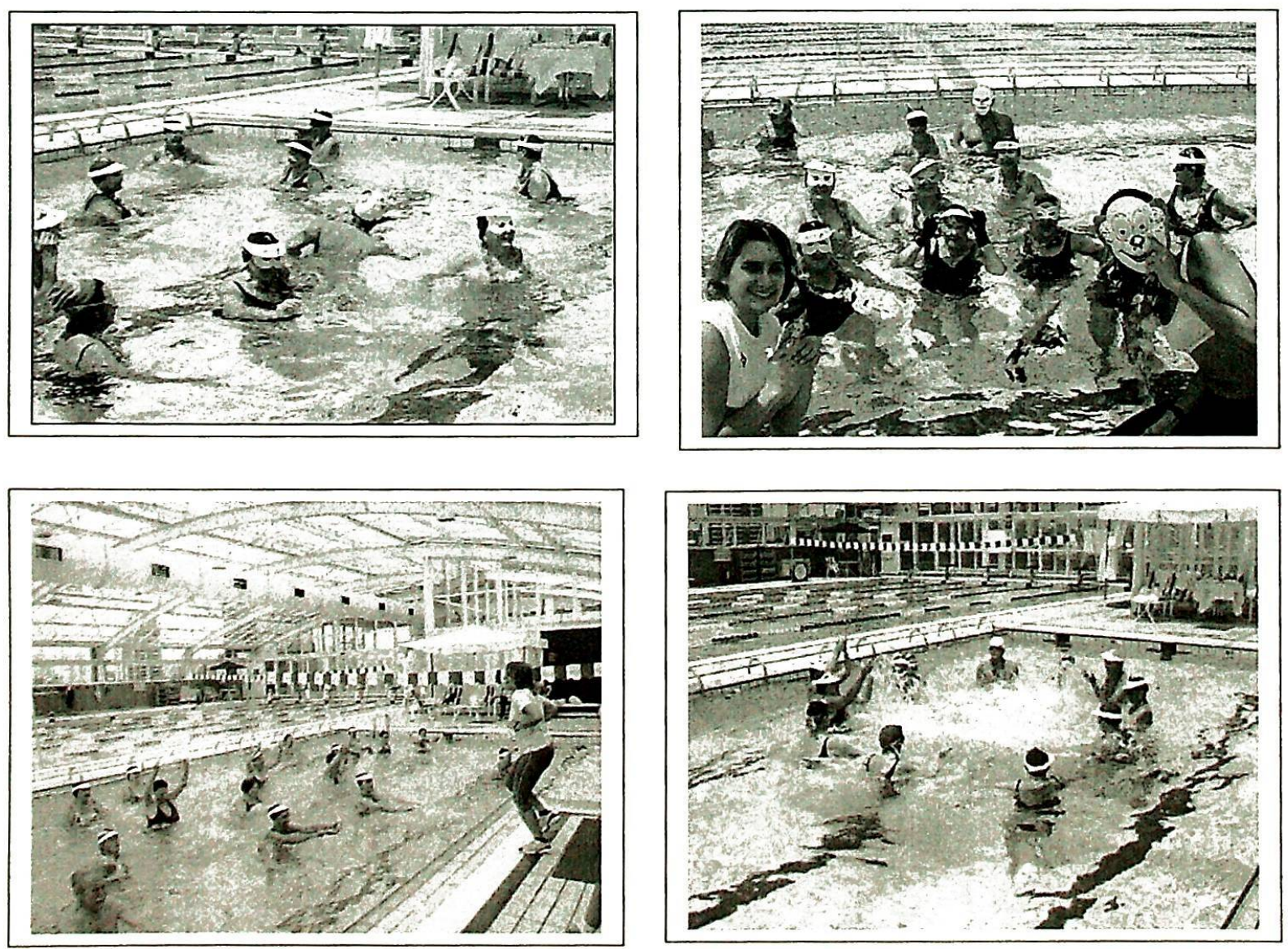


\section{METODOLOGIA}

A presente pesquisa trata-se de um estudo descritivo, envolvendo delineamento transversal, com distribuição de freqüência de dados nominais sob a forma de tabela. Esse tipo de pesquisa descritiva se preocupa com o status dos indivíduos/alunos, que pode incluir técnicas de estudo exploratório (surveys), estudos de caso e questionários. A seguir os itens que compõem esta metodologia:

\subsection{Amostra}

A amostra desta pesquisa é composta pelos indivíduos de $\mathbf{6 0}$ anos ou mais, participantes do "Programa Platinum" de uma academia de grande porte, localizada na área urbana da cidade de São Paulo, na Zona Sul, pertencente à unidade do bairro Morumbi. Esta academia está consolidada no mercado há 20 anos e possui no total nove unidades localizadas nas principais capitais brasileiras. A unidade Morumbi foi selecionada por ser referência para o "Programa Platinum", em função de ter o maior número de alunos matriculados no programa e por suas atuais características destacando-se, dentre as $\mathbf{1 0}$ filiais em nível nacional.

A amostra foi selecionada intencionalmente por meio da participação voluntária dos interessados, concordando pela carta de consentimento específica para a participação na pesquisa ( $A N E X O$ I e II). 
Os indivíduos idosos investigados praticam atividade fisica regular por no mínimo três meses, em horários pré-determinados ou com freqüência livre, de acordo com a disponibilidade de horários dos praticantes.

Atualmente, o "Programa Platinum" contém 115 matriculados, que podem escolher em freqüentar ou não as aulas em grupo $\mathrm{e}$ as atividades individualizadas prescritas no programa de treinamento experimental.

Dos $\mathbf{1 1 5}$ matriculados, $\mathbf{7 5}$ efetivamente freqüentam o programa, os $\mathbf{4 0}$ restantes não o freqüentam em função da incompatibilidade de horários, por não se identificarem com o programa e por não se acharem pertencentes à categoria dos idosos.

Do total dos 75 indivíduos participantes do "Programa Platinum", 43 se dispuseram a participar da pesquisa respondendo ao questionário padrão (ANEXO III). Os 32 restantes, não participaram em função do tempo mínimo de participação no programa (três meses), das licenças médicas e/ou motivos diversos (viagens na época da coleta dos dados da pesquisa, alunos recém classificados pela idade cronológica como alunos Platinum pelo cadastro automatizado da academia). Assim sendo, o número de participantes que constituíram a amostra da pesquisa foi de $\mathbf{4 3}$ indivíduos idosos participantes do programa.

Dos quantitativos anteriormente expostos, os $\mathbf{7 5}$ alunos que realmente freqüentam o programa representam $\mathbf{6 5 \%}$ em relação do total dos $\mathbf{1 1 5}$ matriculados. Destes 75 alunos, 43 participaram efetivamente da pesquisa, o que representa $\mathbf{5 7 \%}$.

Os números anteriormente obtidos e referenciados na pesquisa, ênfase para a amostra, têm representatividade e credibilidade, pois atendem às 
recomendações estatísticas, segundo os autores COSTA (1992) e THOMAS \& NELSON (2002).

\subsection{Questionário}

Foram utilizadas perguntas fechadas de múltipla escolha com itens a serem assinalados, sobre período de freqüência, tempo de permanência no programa, etc. e perguntas abertas.

Para verificar as características desta população de idosos na unidade Morumbi foi utilizado o modelo de questionário, descrito abaixo:

ANEXO III - um questionário adaptado de ANTONIAZZI (1994), que busca definir no primeiro bloco o perfil do praticante de atividade física da academia investigada, quanto à idade (data de nascimento), ao sexo, estado civil, período de freqüência, , tempo de prática, motivos que levaram o praticante idoso a freqüentar o "Programa Platinum", atividades mais freqüentadas do "Programa Platinum" (questões 1, 2, 3, 4, 5, 6, 7).

No segundo bloco, nas questões 8, 9, 10, verificou-se o nível de satisfação do praticante idoso quanto às atividades que freqüenta, aos objetivos atingidos e ao estímulo/ incentivo do professor que o acompanha nas atividades.

No terceiro bloco, nas questões $11,12,13$, verificou-se os padrões de atendimento (recepção e professores) e explicações recebidas ao entrar na academia quanto ao funcionamento do "Programa Platinum". No quarto e último bloco, nas questões 14, 15 e 16, verificou-se o nível de motivação do praticante idoso em continuar no programa, os seus pontos positivos e negativos e sugestões para melhorá-lo. 


\subsection{Coleta de dados}

O questionário foi aplicado no próprio local de prática da atividade fĩsica, respondido pelos próprios participantes na unidade investigada. Houve, na unidade um evento especial, com um café da manhã oferecido pela academia para que pudesse reunir o máximo possível de participantes de uma só vez.

Os que não puderam participar do evento tiveram um contato por telefone e pessoalmente para agendar a aplicação do questionário. Neste contato inicial fez-se necessário contar com a colaboração dos coordenadores e professores do programa para o bom desenvolvimento do processo de coleta.

Os dados coletados inicialmente na unidade avaliada foram utilizados como um pré-teste (piloto). A aplicação do questionário foi feita pelo próprio pesquisador, por meio de uma apresentação inicial sumária dos objetivos do trabalho e da sua forma, no qual $\mathbf{1 5}$ alunos idosos puderam optar entre participar ou não da pesquisa.

Posteriormente, verificou-se a necessidade de adaptação do questionário piloto em três ocasiões, resultando no questionário final conforme ANEXO III, o qual foi aplicado definitivamente na amostra dos 43 alunos, conforme citado anteriormente.

\subsection{Tratamento Estatístico}

Por recomendação de professor do I.M.E - Instituto de Matemática e de Estatística da USP, os resultados estão apresentados na forma de tabelas de freqüência. Para a análise dos dados, utilizou-se a estatística descritiva, que 
permite descrever sob diversos ângulos o conjunto de dados representados pela amostra de $\mathbf{4 3}$ indivíduos participantes do "Programa Platinum".

\section{APRESENTAÇÃO E DISCUSSÃO DOS RESULTADOS}

Conforme exposto na metodologia, capítulo 4 , os indivíduos constantes da amostra responderam aos 16 ítens e sub-ítens do questionário padrão $(A N E X O I I I)$. Os resultados da pesquisa, a seguir, são apresentados $\mathrm{e}$ discutidos de acordo com os quatro blocos de questões, utilizando-se o referencial teórico estudado para a interpretação dos dados obtidos, que se seguem:

- Bloco 1 - Perfil dos praticantes do Programa Platinum - questões 1, 2, 3, $4,5,6,7$, que definem o perfil (fatores pessoais) do praticante de atividade física da academia investigada, quanto à idade, sexo, estado civil, período de freqüência, tempo de prática, motivos de freqüência e atividades mais freqüentadas no "Programa Platinum".

- Bloco 2 - Nível de Satisfação pelo Programa Platinum - questões 8, 9, 10, que caracteriza o nível de satisfação do praticante idoso quanto às atividades que freqüenta, aos objetivos atingidos e ao estímulo/ incentivo do professor que o acompanha nas atividades.

- Bloco 3 - Atendimento da Recepção - questões 11, 12, 13, que verifica os padrões de atendimento da recepção e dos professores, bem como as explicações recebidas ao entrar na academia relativo ao funcionamento do "Programa Platinum". 
- Bloco 4 - Pontos Positivos e Negativos do Programa Platinum - questões $14,15,16$ que verifica os pontos positivos e negativos do "Programa Platinum", bem como sugestões para a melhoria do mesmo.

Posterior à pesquisa de campo tabulou-se os dados, que foram explicitados sob a forma de tabelas de freqüência contendo aspectos quantitativos, percentual (\%) e desvio padrão (DP) vinculados aos quesitos contidos nos blocos de 1 a 4 .

A seguir os resultados, sob a forma de tabelas, segundo a itemização dos quesitos contidos no questionário (ANEXO III), relativo ao instrumento de avaliação do "Programa Platinum":

\subsection{Perfil dos praticantes do Programa Platinum}

Conforme citado anteriormente no capítulo três, na estruturação de um programa supervisionado de AF para idosos devemos considerar os determinantes que influenciam a adesão nos programas supervisionados de AF. Os fatores pessoais na adesão inicial exercem grande influência sobre o comportamento para a prática de $\mathrm{AF}$, permitindo ainda traçar o perfil do praticante (ANDREOTTI \& OKUMA, 2003).

Segundo DISHMAN (1993), os fatores pessoais têm grande importância na medida que podem identificar os indivíduos que possivelmente terão uma resistência maior em participar de programas de AF e assim requerendo intervenções.

Das diversas características existentes dos determinantes pessoais, foi analisado o perfil do praticante idoso quanto à idade, sexo, estado civil, período 
de freqüência, tempo de prática, motivos de freqüência e atividades mais freqüentadas no "Programa Platinum".

TABELA 1 - Distribuição dos entrevistados quanto à idade e sexo

\begin{tabular}{cccccccc}
\hline \hline Faixa Etária & Masc & \% Masc & \% Total & Fem & \% Fem & \% Total & Total \\
\hline 60 \% 6 anos & 0 & $0,00 \%$ & $0,00 \%$ & 14 & $42,42 \%$ & $32,56 \%$ & 14 \\
66 a 70 anos & 7 & $70,00 \%$ & $16,28 \%$ & 10 & $30,30 \%$ & $23,26 \%$ & 17 \\
71 a 75 anos & 0 & $0,00 \%$ & $0,00 \%$ & 4 & $12,12 \%$ & $9,30 \%$ & 4 \\
76 a 80 anos & 2 & $20,00 \%$ & $4,65 \%$ & 3 & $9,09 \%$ & $6,98 \%$ & 5 \\
mais de 81 anos & 1 & $10,00 \%$ & $2,33 \%$ & 2 & $6,06 \%$ & $4,65 \%$ & 3 \\
\hline Total & 10 & $100 \%$ & $23,26 \%$ & 33 & $100 \%$ & $76,74 \%$ & 43 \\
\hline Média de Idade 71,10 & & & 67,97 & & & 68,70 \\
\hline \hline
\end{tabular}

A TABELA 1 , apresenta a faixa etária dos alunos de 60 a 81 anos divididos em cinco grupos (60 a 65 anos, 66 a 70 anos, 71 a 75 anos, 76 a 80 anos e mais de 81 anos), bem como os quantitativos relativos ao sexo (masculino e feminino), respectivos percentuais parciais, totais e médias.

As informações na TABELA 1 revelam que dos $\mathbf{4 3}$ alunos pesquisados integrantes do programa, a maioria é do sexo feminino $76,74 \%$, $(n=33)$, sendo que $42,42 \%$ integram a faixa etária de 60 a 65 anos, a seguir a faixa de 66 a 70 anos. Quanto ao sexo masculino $23,26 \%,(n=10)$, tem-se que $70 \%$ pertencem à faixa etária dos 66 a 70 anos, vindo a seguir a faixa de 76 a 80 anos representando $20 \%$. A tabela também revela que do total, $32,56 \%$ dos alunos estão inseridos na faixa etária de 60 a 65 anos, com média de idade de 68,70 
anos, sendo 71,10 anos para o sexo masculino e 67,97 anos para o sexo feminino.

De acordo com as características sócio-demográficas relativas à idade e sexo dos individuos idosos apresentados na TABELA 1 pode-se observar que, a maior parte dos praticantes que aderiram ao Programa Platinum é composto por mulheres, com a idade média de 67,97 anos, o que corrobora dados apresentados anteriormente na revisão de literatura (FARIA JUNIOR, 1994; WRIGHT, 2001; SLEZYNSKI ${ }^{11}$ \& BLONSKA, 1994 apud ANDREOTTI \& OKUMA, 2003). Com relação à idade das praticantes percebe-se que a maioria $(42,42 \%, n=14)$ integra a faixa etária de 60 a 65 anos, e poderiam estar classificadas no perfil dos idosos ativos despreocupados, que representam atualmente $40,4 \%$ da população de idosos com predominância de mulheres e com idades entre 60 e 79 anos (MARTINS; JANUÁRIO \& TABACH, 2000). Sugere-se que por estarem num grupo propenso a estar rodeadas por pessoas, o seu engajamento seja maior em programas de AF supervisionado.

Quanto ao sexo masculino, verificou-se que a maioria $70,0 \%,(n=7)$ pertence à faixa etária de $\mathbf{6 6}$ a 70 anos. De acordo com LEBRÃO \& PELÁEZ (2003), 26,5\% da população de idosos são praticantes regulares de AF, sendo mais freqüente no grupo de 60 a 75 anos, dos quais $29,5 \%$ são do sexo masculino. Assim sendo, os homens em qualquer idade fazem mais exercícios do que as mulheres (60 a 75 anos, 75 anos e mais).

\footnotetext{
" SLEZYNSKY, J.; BLONSKA, W. Physical activity of the third age population. In: MARQUES, A. T.; GAYA, A.; CONSTANTINO, J. M. (Eds.). Physical activity_and health in elderly: proceedings of the first conference of EGREPA (European Group for Research into Elderly and Physical Activity). Porto: University of Porto, 1994. p. 414-5.
} 
Apesar das mulheres apresentarem um menor percentual, 24,5\% quanto à prática regular de AF em relação aos homens (LEBRÃO \& PELÁEZ, 2003), ou seja, são menos ativas, percentualmente sua representatividade é muito maior na adesão aos programas supervisionados de AF. Uma das explicações para essa predominância deve-se a alguns fatores como: mais oportunidades para os homens de encontros sociais aceitáveis socialmente fora de casa e o preconceito em relação às atividades desenvolvidas nos programas supervisionados de AF, por serem consideradas não exaustivas o suficiente ou até mesmo femininas demais (ANDREOTTI \& OKUMA, 2003).

TABELA 2 - Distribuição dos entrevistados quanto ao estado conjugal segundo $\underline{\operatorname{sexo}}$

\begin{tabular}{ccccccc}
\hline \hline Estado Conjugal & Masc & $\mathbf{\%}$ & Fem & $\mathbf{\%}$ & Total & $\%$ \\
\hline Casados / unidos & 9 & $\mathbf{9 0 , 0 0 \%}$ & 18 & $54,55 \%$ & 27 & $62,79 \%$ \\
Solteiro & 0 & $0,00 \%$ & 1 & $3,03 \%$ & 1 & $2,33 \%$ \\
Viúvos & 1 & $10,00 \%$ & 12 & $36,36 \%$ & 13 & $30,23 \%$ \\
Divorciados / separados & 0 & $0,00 \%$ & 2 & $6,06 \%$ & 2 & $4,65 \%$ \\
\hline Total & 10 & $100,00 \%$ & 33 & $100,00 \%$ & 43 & $100,00 \%$ \\
\hline \hline
\end{tabular}

A TABELA 2 apresenta o estado conjugal do sexo masculino e feminino dos alunos, seus respectivos subtotais e totais, bem como seus percentuais separadamente. A maioria dos pesquisados integrantes do programa $62,79 \%,(\mathrm{n}=27)$ se encontra na categoria de casados/unidos, vindo a seguir os viúvos 30,23\%, $(\mathrm{n}=13)$. Quanto ao sexo masculino 90,00\%, $(\mathrm{n}=9)$ estão na categoria casados/unidos, vindo a seguir os viúvos 10,00\%, $(n=1)$, em relação ao 
sexo feminino, 54,55\%, $(n=18)$ se encontra na categoria casados/unidos e $36.36 \%,(n=12)$ de viúvos.

Em relação ao estado conjugal dos praticantes de AF do Programa Platinum, observa-se que a maioria é casada $62,79 \%,(n=27)$, tanto os homens quanto as mulheres, índice semelhante aos encontrados por LEBRÃO e PELÁEZ (2003), que verificou que 57\% dos idosos são casados, compondo-se de $29,5 \%$ de viúvas, $8,5 \%$ de separados ou divorciados e 4,9\% de solteiros. É interessante ressaltar que no grupo avaliado do Programa Platinum, há uma grande incidência de viúvos, representando $30,23 \%$ da amostra.

Desse total, observa-se que a maioria está concentrada no sexo feminino 36,36\%, $(n=12)$, o que corrobora as informações apresentadas anteriormente na pesquisa de LEBRÃO e PELÁEZ (2003), confirmando que a velhice é feminina, pela maior longevidade da mulher, ou seja, sua expectativa de vida é maior do que a dos homens e estes, com casamentos mais tardios e maior facilidade de recasamento.

TABELA 3 - Tempo de permanência no Programa Platinum

\begin{tabular}{ccccccc}
\hline \hline Tempo de permanência & Masc & $\mathbf{\%}$ & Fem & $\%$ & Total & $\%$ \\
\hline 3 a 6 meses & 4 & $40,00 \%$ & 7 & $21,21 \%$ & 11 & $25,58 \%$ \\
7 a 12 meses & 2 & $20,00 \%$ & 7 & $21,21 \%$ & 9 & $20,93 \%$ \\
13 a 24 meses & 2 & $20,00 \%$ & 10 & $30,30 \%$ & 12 & $27,91 \%$ \\
25 a 36 meses & 0 & $0,00 \%$ & 3 & $9,09 \%$ & 3 & $6,98 \%$ \\
mais de 36 meses & 2 & $20,00 \%$ & 6 & $18,18 \%$ & 8 & $18,60 \%$ \\
\hline Total & 10 & $100 \%$ & 33 & $100 \%$ & 43 & $100 \%$ \\
\hline \hline
\end{tabular}


A TABELA 3 apresenta o tempo de permanência dos alunos no programa divididos em cinco grupos (3 a 6 meses, 7 a 12 meses, 13 a 24 meses, 25 a 36 meses, mais de 36 meses), bem como os quantitativos relativos ao sexo (masculino e feminino), respectivos percentuais parciais e totais. Os dados da TABELA 4 revelam que existe pequena diferença quantitativa percentual no que tange ao seu tempo de permanência no programa, pois $27,91 \%,(n=12)$ encontram-se na faixa de 13 a 24 meses de permanência, vindo a seguir com $25,58 \%,(n=11)$ na faixa de 3 a 6 meses e 20,93, $(n=9)$ na faixa de 7 a 12 meses. Apenas $18,60 \%,(n=8)$ têm o seu tempo permanência na faixa de mais de 36 meses no programa de AF.

Quanto aos sexos, temos 40,00\%, $(n=4)$ dos homens na faixa dos 3 a 6 meses de tempo de permanência, vindo a seguir de maneira eqüalizada $20,00 \%$, $(\mathrm{n}=2)$ as faixas 7 a 12 meses, 13 a 24 meses e mais de 36 meses de permanência. Em relação às mulheres tem-se que $30,30 \%$, $(n=10)$ encontram-se na faixa dos 13 a 24 meses de tempo de permanência no programa de AF, vindo a seguir também de maneira eqüalizada $21,21 \%,(n=7)$ as faixas 3 a 6 meses e 7 a 12 meses, sendo que a faixa com mais de 36 meses perfaz $18,18 \%$, $(n=6)$.

De acordo com as informações citadas acima, observou-se que do total dos alunos praticantes do Programa Platinum 27,91\%, $(n=12)$ estão na faixa de 13 a 24 meses de freqüência e logo a seguir com percentual muito próximos a faixa de 3 a 6 meses de freqüência, indicando a entrada de muitos alunos novos no programa. Em relação aos sexos, verifica-se que os homens estão há menos tempo no programa 40,00\%, $(n=4), 3$ a 6 meses, ou seja, são alunos mais recentes, porém quando analisamos os tempos de permanência subseqüentes, observamos que dos 7 aos 24 meses e após os 36 meses, os percentuais são 
iguais $20,00 \%$ se distanciando apenas no período de 25 a 36 de freqüência $0,00 \%$. Pode-se deduzir então que, se continuarem nesta mesma proporção, a tendência é que os homens se mantenham assíduos no programa de $\mathrm{AF}$, visto que de uma maneira geral a sua saúde percebida é mais satisfatória em relação às mulheres (NERI, 2001).

Quanto às mulheres, verifica-se que, a maioria $30,30 \%,(n=10)$ está no programa de $\mathrm{AF}$ por um período de 13 a 24 meses, com percentuais eqüalizados no período de 3 a 12 meses $(21,21 \%)$. Da mesma maneira, podemos fazer previsões positivas também em relação às mulheres, pois nos períodos de 25 a 36 meses, apesar de apresentarem índices menores, percebe-se que há um crescimento de acordo com o maior tempo de permanência. Embora a literatura citada anteriormente afirme que as mulheres relatam mais doenças e são menos satisfeitas com a sua saúde (NERI, 2001), outros estudos apontam que os ganhos de saúde percebidos e a condição física têm sido associados com o aumento de tempo de adesão entre homens e mulheres (STONES, KOZMA \& STONES, 1987).

TABELA 4 - Período de freqüência no Programa Platinum

\begin{tabular}{ccccccc}
\hline \hline Período & Masc & $\mathbf{\%}$ & Fem & $\mathbf{\%}$ & Total & $\mathbf{\%}$ \\
\hline Manhã & 10 & $83,33 \%$ & 33 & $17,06 \%$ & 43 & $93,48 \%$ \\
Tarde & 2 & $16,67 \%$ & 1 & $2,94 \%$ & 3 & $6,52 \%$ \\
Noite & 0 & $0,00 \%$ & 0 & $0,00 \%$ & 0 & $0,00 \%$ \\
\hline Total & 12 & $100,00 \%$ & 34 & $100,00 \%$ & 46 & $100 \%$ \\
\hline \hline
\end{tabular}


A TABELA 4 apresenta o período de freqüência dos alunos no programa divididos em três grupos (manhã, tarde e noite), bem como os quantitativos relativos ao sexo (masculino e feminino), respectivos percentuais parciais e totais. Os resultados da TABELA 5 revelam que dos 43 alunos pesquisados integrantes do programa acrescentou-se a esse total mais três alunos os quais freqüentam dois períodos, perfazendo um total de 46. Desse total, $93,48 \%, \quad(n=43)$ freqüentam o período da manhã, e apenas $6,52 \%, \quad(n=3)$ freqüentam o período da tarde. Quanto ao sexo masculino tem-se que 83,33\%, $(n=10)$ freqüentam o programa no período da manhã, e apenas $16,67 \%,(n=2)$ freqüentam à tarde. Em relação ao sexo feminino verificou-se que 97,06\%, $(n=43)$ freqüentam o programa no período da manhã e apenas $2,94 \%$, $(n=3)$ freqüentam à tarde.

Conforme CARVALHO e MOTA (2002), um importante fator a ser considerado nas sessões de um programa de AF está associado ao horário das atividades desenvolvidas. Percebe-se que do total de praticantes idosos do Programa Platinum, a maior parte freqüenta o período da manhã 93,48\%, $(n=43)$, corroborando os dados dos autores anteriormente citados, pois recomendam que as atividades físicas devem ser realizadas de preferência entre 10:00 e 11:00 horas da manhã.

Apesar do período da tarde representar um percentual menor 6,52\%, $(n=3)$ em relação ao período da manhã, deve-se incentivar também a prática de AF neste período com a formação de novos grupos e com atividades diferenciadas. Desta maneira, o volume excessivo de alunos que se concentram no período da manhã possam migrar naturalmente para as outras opções de 
horários e assim, manter um número de participantes adequados por sessão para que nào se perca a qualidade no atendimento.

TABELA 5 - Determinantes de freqüência no Programa Platinum

\begin{tabular}{ccccccc}
\hline \hline Motivos de Freqüência & Masc & $\mathbf{\%}$ & Fem & $\mathbf{\%}$ & Total & $\mathbf{\%}$ \\
\hline Saúde & 10 & $\mathbf{1 0 0 , 0 0 \%}$ & 33 & $100,00 \%$ & 43 & $100,00 \%$ \\
Qualidade de vida & 8 & $\mathbf{8 0 , 0 0 \%}$ & 28 & $84,85 \%$ & 36 & $83,72 \%$ \\
Sedentarismo & 4 & $\mathbf{4 0 , 0 0 \%}$ & 9 & $27,27 \%$ & 13 & $30,23 \%$ \\
Indicação médica & 3 & $30,00 \%$ & 17 & $51,52 \%$ & 20 & $46,51 \%$ \\
Estética & 3 & $30,00 \%$ & 15 & $45,45 \%$ & 18 & $41,86 \%$ \\
Falta de atividade & 3 & $30,00 \%$ & 12 & $36,36 \%$ & 15 & $34,88 \%$ \\
Atividade social & 3 & $30,00 \%$ & 9 & $27,27 \%$ & 12 & $27,91 \%$ \\
Procura por novas amizades & 2 & $20,00 \%$ & 7 & $21,21 \%$ & 9 & $20,93 \%$ \\
Cansaço diário & 1 & $10,00 \%$ & 4 & $12,12 \%$ & 5 & $11,63 \%$ \\
Solidão & 1 & $10,00 \%$ & 1 & $3,03 \%$ & 2 & $4,65 \%$ \\
\hline \hline
\end{tabular}

A TABELA 5 apresenta os determinantes de freqüência dos alunos no programa, distribuídos em 11 grupos (indicação médica, sedentarismo, solidão, falta de atividade, cansaço diário, procura por novas amizades, qualidade de vida, estética, saúde, atividade social e outros), bem como os quantitativos relativos ao sexo (masculino e feminino), respectivos percentuais parciais e totais. As informações apresentadas nesta tabela revelam que os maiores determinantes de freqüência foram: saúde $(100 \%, n=43)$, qualidade de vida $(83,72 \%, n=36)$, indicação médica $(46,51 \%, n=20)$, estética $(41,86 \%, n=18)$ e falta de atividade $(34,88 \%, n=15)$. Observou-se que $100 \%,(n=10)$ dos homens 
freqüentam o programa por motivo de saúde, vindo a seguir a qualidade de vida $80,00 \%,(n=8)$, sedentarismo $40,00 \%,(n=4)$ e com $30,00 \%,(n=3)$ envolvendo: indicaçào médica, falta de atividade, estética e atividade social. As mulheres de maneira similar também freqüentam o programa por motivo de saúde $100 \%$, $(n=33)$, qualidade de vida 84,85\%, $(n=28)$, indicação médica $51,52 \%,(n=17)$, estética 45,45\%, $(n=15)$, falta de atividade $36,36 \%,(n=12)$.

Existe um consenso entre os profissionais da saúde que a prática regular de AF é um fator determinante para se atingir um envelhecimento saudável (MATSUDO, 2001).

Os principais determinantes relatados tanto por homens quanto pelas mulheres foram: saúde $100 \%,(n=43)$, qualidade de vida $83,72 \%,(n=36)$ e indicação médica $46,51 \%,(n=20)$. Nota-se que a saúde foi a mais citada pelos praticantes idosos, sendo um importante fator pessoal que, de acordo com DISHMAN (1993), é um determinante que influencia na adesão. ANDREOTTI (2001) relata que os indivíduos são motivados por diversas razões ao iniciar um programa de $\mathrm{AF}$, tais como: conhecimento e crença nos benefícios da $\mathrm{AF}$, quanto aos aspectos fisiológicos e pscicológicos (WEINBERG \& GOULD, 1995), indicação médica (DISHMAN, 1988), reabilitação (FARIA JÚNIOR, 1994), prevenção de patologias e manutenção da saúde em relação à melhora do condicionamento físico e das capacidades intelectuais e mentais (DANTAS, 1994; FARIA JÚNIOR, 1994), ocupação do tempo livre com atividade saudável (DANTAS, 1994), possibilidade de convivência, socialização (DANTAS, 1994) e ampliação das relações interpessoais (FARIA JÚNIOR, 1994), bem-estar (FARIA JÚNIOR, 1994), sentir-se participante e produtivo (DANTAS, 1994), retardar o envelhecimento (DANTAS, 1994), buscar uma melhor estética corporal (DANTAS, 1994). 
Segundo WEINBERG e GOULD (1995), um aspecto importante na adesão inicial a programas de AF é ter o conhecimento dos diversos benefícios que ela pode trazer para a saúde tanto no aspecto fisiológico quanto no psicológico, pois afirmam que os indivíduos que acreditam que a $\mathrm{AF}$ tem pouco significado para a sua vida (saúde e qualidade) têm uma probabilidade maior de desistência. Deste modo, associar o interesse inicial do praticante (saúde) ao conhecimento dos benefícios da AF pode auxiliar na sua manutenção no programa de AF.

A procura por qualidade de vida foi um motivo que representou um percentual elevado para os dois grupos: $(80,00 \%)$ para os homens e $(84,85 \%)$ para as mulheres. Apesar de encontrarmos muitas academias voltadas para a melhoria dos aspectos estéticos dos usuários/praticantes, verificamos que quando um programa de $\mathrm{AF}$ se propõe a oferecer serviços que ajudam na aquisição de um estilo de vida mais saudável, consegue ir ao encontro das necessidades apontadas pelos praticantes.

Podemos entender por qualidade de vida para o idoso quando se tem energia suficiente para participar das atividades de lazer, quando tem um mínimo de aptidão física que o permita realizar as AVDs com o mínimo de esforço, quando tem reservas energéticas suficientes para se restabelecer rapidamente após uma doença, quando existe um sentimento de bem-estar e sentido de existência pessoal (CARVALHO \& MOTA, 2002).

Para os homens, o sedentarismo (40\%) é o terceiro motivo mais citado. DISHMAN (1988) afirma que o seu combate é um elemento fundamental para melhorar a qualidade de vida quando associado com a prática de AF. Tornase então um importante indicativo a ser levado em consideração, pois apesar da população ter o conhecimento que com a prática regular da AF podemos ter uma 
melhor qualidade de vida, o índice de sedentários ainda é muito elevado no Brasil, pois 60 a $65 \%$ da população é físicamente inativa (IBGE, 1998; MATSUDO, MATSUDO \& BARROS 2001).

Outro motivo observado foi a indicação médica, representando o segundo determinante mais apontado pelos praticantes do Programa Platinum. De acordo com DISHMAN (1988); ANDREOTTI e OKUMA (2003) a promoção efetiva da $\mathrm{AF}$ pelos médicos é um determinante potencialmente forte de adesão aos indivíduos idosos, pois muitos têm o contato aumentado à medida que envelhecem. ANDRADE et al. (2000) corroboram os dados anteriormente citados reafirmando que os agentes facilitadores no ambiente para o envolvimento regular com a prática de $\mathrm{AF}$, revelaram que os indivíduos acima dos 50 anos realizam as atividades em função de orientação médica como primeira opção.

TABELA 6 - Atividades Praticadas no Programa Platinum

\begin{tabular}{ccccccc}
\hline \hline Atividades & Masc & $\mathbf{\%}$ & Fem & $\mathbf{\%}$ & Total & $\mathbf{\%}$ \\
\hline Natação & 4 & $40,00 \%$ & 3 & $9,09 \%$ & 7 & $16,28 \%$ \\
Hidroginástica & 3 & $30,00 \%$ & 17 & $51,52 \%$ & 20 & $46,51 \%$ \\
Alongamento & 10 & $\mathbf{1 0 0 , 0 0 \%}$ & 29 & $87,88 \%$ & 39 & $90,70 \%$ \\
Multi Platinum & 7 & $70,00 \%$ & 24 & $72,73 \%$ & 31 & $72,09 \%$ \\
Musculação & 9 & $\mathbf{9 0 , 0 0 \%}$ & 25 & $75,76 \%$ & 34 & $79,07 \%$ \\
Esteira & 8 & $\mathbf{8 0 , 0 0 \%}$ & 25 & $75,76 \%$ & 33 & $76,74 \%$ \\
Bicicleta Ergométrica & 6 & $\mathbf{6 0 , 0 0 \%}$ & 16 & $48,48 \%$ & 22 & $51,16 \%$ \\
\hline \hline
\end{tabular}


A TABELA 6 apresenta as atividades praticadas pelos alunos no programa distribuidos em sete grupos (natação, hidroginástica, alongamento, multi platimum. musculação, esteira e bicicleta ergométrica), bem como os quantitativos relativos ao sexo (masculino e feminino), respectivos percentuais parciais e totais. As informações obtidas na TABELA 6 revelam que as atividades mais praticadas, na escala decrescente foram: alongamento $90,70 \%$, $(n=39)$, musculação 79,07\%, $(n=34)$, esteira $76,74 \%,(n=33)$ e multi platinum $72,09 \%,(\mathrm{n}=31)$. As atividades mais praticadas pelo sexo masculino foram: alongamento $100,00 \%,(n=10)$, vindo a seguir a musculação $90,00 \%,(n=9)$, esteira 80,00\%, $(n=8)$, multi platinum 70,00\%, $(n=7)$, bicicleta ergométrica $60,00 \%$, (n=6) e natação 40,00\%, $(n=4)$. Quanto ao sexo feminino temos também o alongamento $87,88 \%$, (n=29) como atividade mais praticada, musculação 75,76\%, $(n=25)$, esteira 75,76\%, $(n=25)$, multi platinum 72,73\%, $(n=24)$ e hidroginástica $51,52 \%,(n=17)$.

Em relação às atividades praticadas no Programa Platinum, observa-se que tanto os homens quanto as mulheres participam de mais de uma atividade no programa Platinum. De acordo com GHORAYEB (1993), quanto maior o número de atividades que o idoso tiver, quanto mais exercício fisico fizer melhor será sua qualidade de vida.

As atividades realizadas em grupo que tiveram maior representatividade foram o Alongamento 90,70\%, $(n=39)$ e o Multi Platinum $72,09 \%,(n=31)$. As diferenças entre os sexos mostraram que as mulheres tiveram um maior interesse pelas atividades em grupo: Alongamento 87,88\%, $(\mathrm{n}=29)$, Musculação e Esteira 75,76\%, $(\mathrm{n}=25)$ seguidos do Multi Platinum $72,73 \%,(n=24)$ e Hidroginástica 51,52\%, $(n=17)$. Apesar da Musculação e da 
Esteira serem consideradas atividades individuais, nota-se que as mulheres conseguem, mesmo assim, ter um convívio social durante a realização destas atividades.

Quanto aos homens, as atividades mais freqüentadas mostraram que houve um interesse menor nas atividades em grupo, apesar do Alongamento $100 \%,(n=10)$ e do Multi Platinum 70\%, $(n=7)$ apresentarem percentuais elevados. Essa representatividade pode ser devida à grande importância dada aos dois tipos de aulas, no momento da prescrição de treinamento experimental. Outro fator importante a ser considerado nestas duas aulas está relacionado com a quebra gradual de preconceito, pois são atividades com um percentual elevado de freqüência feminina. Observa-se, no entanto, que a Musculação $90 \%$, $(n=9)$ e as atividades cardiovasculares com Esteira 80\%, $(n=8)$ e Bicicleta $60 \%,(n=6)$ têm uma grande procura, caracterizando-se como atividades mais individualizadas.

Assim sendo, devemos incentivar a prática das atividades em grupo, pois fazer parte de um grupo permite aos idosos uma nova identidade física e social, passando a ter um compromisso maior com o próprio grupo, a viver o sentimento de confiança, a sentir-se novamente estimulado a competir, a ser companheiro e a apoiar-se mutuamente (OKUMA, 1997). Para SABA (2001) e AMORIM (2002), o comprometimento é um elemento que orienta e incentiva a maioria das atividades humanas e a partir do momento em que se enriquece o elo emocional entre indivíduo e atividade, círculo de prática, satisfação e resultado é estabelecido.

WANKEL (1988) corrobora as afirmações anteriores, enfatizando que cada vez mais é percebida a preferência da maioria das pessoas em querer se 
exercitar em grupo sendo a busca da interação social uma das fortes razões para o envolvimento na AF.

\subsection{Nível de Satisfação pelo Programa Platinum}

Procurou-se observar neste bloco se o nível de satisfação dos praticantes idosos em relação às atividades desenvolvidas, aos objetivos atingidos e ao estímulo dos professores são compatíveis com o que o programa de $\mathrm{AF}$ se propõe. Com relação às atividades propostas no Programa Platinum, desde o princípio, foram selecionadas atividades que proporcionassem bemestar/qualidade de vida como também benefícios físicos, psicológicos e sociais de acordo com os princípios de treinamento preconizados por ACSM (1998, 2004); MATSUDO (2001), entre outros já citados.

CARVALHO e MOTA (2002) enfatizam ainda que para que os idosos iniciem e mantenham a sua participação nas atividades físicas é necessário que haja uma adequação das AFs à condição do idoso, ou seja, na prescrição das atividades deve haver o equilíbrio entre o que deve ser realizado com o que o praticante quer realizar (seus próprios objetivos). O professor neste momento tem um papel de fundamental importância, deve conhecer as principais características, objetivos, necessidades e restrições de cada aluno do programa e assim, ser um elemento de apoio e estímulo na obtenção dos resultados almejados pelos praticantes.

Logo abaixo, segue a análise e discussão das TABELA 7, TABELA 8 e TABELA 9: 
TABELA 7 - Nivel de Satisfação (NS) dos entrevistados quantos às atividades freqüentadas no Programa Platinum

\begin{tabular}{cccccccc}
\hline N.S. Ativs. Freqüientadas & nota & Masc & $\mathbf{\%}$ & Fem & $\mathbf{\%}$ & Total & $\%$ \\
\hline Muito Insatisfeito & 1 & 0 & $0,00 \%$ & 0 & $0,00 \%$ & 0 & $0 \%$ \\
Insatisfeito & 2 & 0 & $0,00 \%$ & 0 & $0,00 \%$ & 0 & $0 \%$ \\
Um pouco satisfeito & 3 & 0 & $0,00 \%$ & 0 & $0,00 \%$ & 0 & $0 \%$ \\
Satisfeito & 4 & 3 & $\mathbf{3 0 , 0 0 \%}$ & 9 & $27,27 \%$ & 12 & $28 \%$ \\
Muito Satisfeito & 5 & 7 & $70,00 \%$ & 24 & $72,73 \%$ & 31 & $72 \%$ \\
\hline Total & 10 & $100 \%$ & 33 & $100 \%$ & 43 & $100 \%$ \\
\hline Média Nota & & 4,700 & & 4,727 & & 4,720 & \\
\hline DP & & 0,483 & & 0,452 & & 0.454 & \\
\hline \hline
\end{tabular}

A TABELA 7 apresenta o nível de satisfação (NS) dos alunos quanto às atividades freqüentadas no programa, distribuídos em cinco grupos (muito insatisfeito, insatisfeito, um pouco satisfeito, satisfeito e muito satisfeito), cujas notas variam de $l$ a 5 bem como os quantitativos, percentuais parciais e totais envolvendo os sexos masculino e feminino com respectivas notas média e desvio padrão. Observa-se que, tanto para homens quanto para as mulheres, o nível de satisfação em relação às atividades freqüentadas foi elevado, a maioria se revelou muito satisfeito e satisfeito.

Do total dos alunos pesquisados integrantes do programa constatou-se que o NS muito satisfeito $(72,73 \%, \mathrm{n}=31)$ representa sua maioria vindo a seguir o satisfeito $(27,27 \%, n=12)$, cuja nota média foi de 4,72 e o desvio padrão de 0,45 .

Os resultados da TABELA 7 são bem claros quanto ao nível de satisfação do praticante, revelando que tanto para os homens quanto para as 
mulheres o NS obteve na sua maioria a nota máxima (cinco), equivalente a muito satisfeito. Esses dados mostram uma nota média elevada $(\mathbf{4 , 7 2})$ e um pequeno desvio padrão $(\mathbf{0 , 4 5})$, significando que houve um equilíbrio entre as notas dos respondentes.

De acordo com a Cartilha da Qualidade da UDESC (Universidade do Estado de Santa Catarina) (1996), o nível de satisfação é constatado quando provém de um programa que está bem organizado para que todos os objetivos do programa sejam alcançados. JURAN (1992) afirma que a satisfação do praticante só é alcançada quando existe uma relação entre as características do trabalho (programa) com as necessidades dos praticantes, ou seja, deve haver uma correspondência entre ambas.

Para que esta relação ocorra (características do trabalho X necessidades individuais) é necessário que haja um planejamento, ou seja, um método de trabalho. Conforme citado anteriormente por TURRA, ENRICONE, SANTANNA e ANDRÉ (1992), torna-se necessário termos o conhecimento da realidade da população, determinar os objetivos, selecionar e organizar os conteúdos, procedimentos e avaliação.

Assim sendo, individualizar o atendimento ao idoso, adequar as tarefas às suas possibilidades, fazer com que se sintam competentes emergindo o sentimento de prazer, divertimento e satisfação são fundamentais para continuarem interessados pelo que fazem, refletindo dessa maneira num alto grau de satisfação, conforme foi verificado pelos resultados observados. 
TABELA 8 - Nível de Satisfação (NS) dos entrevistados quantos aos objetivos atingidos ao freqüentar o Programa Platinum

\begin{tabular}{cccccccc}
\hline \hline N.S. Ativs. Frequientadas & nota & Masc & $\%$ & Fem & $\%$ & Total & $\%$ \\
\hline Muito Insatisfeito & 1 & 0 & $0,00 \%$ & 0 & $0,00 \%$ & 0 & $0 \%$ \\
Insatisfeito & 2 & 0 & $0,00 \%$ & 0 & $0,00 \%$ & 0 & $0 \%$ \\
Um pouco satisfeito & 3 & 0 & $0,00 \%$ & 4 & $12,12 \%$ & 4 & $9,00 \%$ \\
Satisfeito & 4 & 3 & $\mathbf{3 0 , 0 0 \%}$ & 5 & $15,15 \%$ & 8 & $19,00 \%$ \\
Muito Satisfeito & 5 & 7 & $\mathbf{7 0 , 0 0 \%}$ & 24 & $72,73 \%$ & 31 & $72,00 \%$ \\
\hline Total & & 10 & $100 \%$ & 33 & $100 \%$ & 43 & $100 \%$ \\
\hline Média Nota & 4,700 & & 4,606 & & 4,628 & \\
\hline DP & 0,483 & & 0,704 & & 0,655 & \\
\hline \hline
\end{tabular}

A TABELA 8 apresenta o nível de satisfação (NS) dos alunos quanto aos objetivos atingidos no programa, distribuídos em cinco grupos (muito insatisfeito, insatisfeito, um pouco satisfeito, satisfeito e muito satisfeito), cujas notas variam de 1 a 5 , bem como os quantitativos, percentuais parciais e totais envolvendo os sexos masculino e feminino com respectivas notas média e desvio padrão.

Do total dos alunos pesquisados integrantes do programa constatou-se que o NS muito satisfeito $(72,00 \%, \mathrm{n}=31)$ representa sua maioria vindo a seguir o satisfeito $(19,00 \%, n=8)$ cuja nota média foi de 4,62 e o desvio padrão de 0,65 . 
O nível de satisfação dos praticantes do Programa Platinum em relação aos objetivos atingidos revela um NS com boa representatividade $\mathbf{( 7 2 , 0 \% )}$ ) e nota média $(\mathbf{4 , 6 2})$ significativa. Esses dados sugerem que o exercício planejado de acordo com os princípios de treinamento recomendados por ACSM $(1998,2000)$ de maneira estruturada e com objetivos alcançáveis, representa uma boa estratégia para que os praticantes permaneçam ativos e no programa. Devem ser traçados objetivos que possam ser alcançados a curto prazo, pois da mesma maneira que o jovem, o idoso precisa sentir que pode ter êxito, que pode ser bem sucedido quanto ao que foi proposto no seu programa de treinamento.

ANDREOTTI (2001) e OKUMA (1997) corroboram a afirmação anterior acrescentando que, na medida que se oferecem desafios realísticos aos alunos, é mantida a motivação para a AF proporcionando a sensação de competência e auto-determinação.

Nota-se ainda que em relação às mulheres $(\mathbf{1 2 , 1 2 \% ,}, \mathbf{n = 4})$ foi relatado pouca satisfação (nota 3 ), o que pode ter ocorrido em função do tempo de permanência no programa, pois, muitas se encontravam no período de $\mathbf{3}$ a $\mathbf{6}$ meses, ou seja, pouco tempo para poder avaliar o programa.

Em relação aos homens $(\mathbf{7 0 , 0 \%}, \mathbf{n}=7)$ a maioria se mostrou muito satisfeito (nota média de 4,70) com os objetivos alcançados,ou seja, freqüentam com boa regularidade o programa podendo atingir melhores benefícios com a prática regular de AF. Este é um dado interessante, que pode ser explicado pela concordância com LEBRÃO e PELÁEZ (2003), visto que os homens, em qualquer idade, fazem mais exercícios do que as mulheres (60 a 75 anos, 75 anos e mais). 
TABELA 9 - Nivel de Satisfaçào (NS) dos entrevistados quanto ao estímulo do professor para melhora de desempenho

\begin{tabular}{cccccccc}
\hline N.S. Ativs. Frequientadas & nota & Masc & $\%$ & Fem & $\%$ & Total & $\%$ \\
\hline Muito Insatisfeito & 1 & 0 & $0,00 \%$ & 0 & $0,00 \%$ & 0 & $0 \%$ \\
Insatisfeito & 2 & 0 & $0,00 \%$ & 0 & $0,00 \%$ & 0 & $0 \%$ \\
Um pouco satisfeito & 3 & 0 & $0,00 \%$ & 1 & $3,03 \%$ & 1 & $2,33 \%$ \\
Satisfeito & 4 & 3 & $30,00 \%$ & 3 & $9,09 \%$ & 6 & $13,95 \%$ \\
Muito Satisfeito & 5 & 7 & $\mathbf{7 0 , 0 0 \%}$ & 29 & $87,88 \%$ & 36 & $83,72 \%$ \\
\hline Total & 10 & $100 \%$ & 33 & $100 \%$ & 43 & $100 \%$ \\
\hline Média Nota & 4,700 & & 4,848 & & 4,814 & \\
\hline DP & 0,483 & & 0,442 & & 0,450 \\
\hline
\end{tabular}

A TABELA 9 apresenta o nível de satisfação (NS) dos alunos quanto ao estímulo do professor no programa, distribuídos em cinco grupos (muito insatisfeito, insatisfeito, um pouco satisfeito, satisfeito e muito satisfeito), cujas notas variam de $l$ a 5 , bem como os quantitativos, percentuais parciais e totais envolvendo os sexos masculino e feminino com respectivas notas média e desvio padrão.

O nível de satisfação (NS) dos praticantes quanto ao estímulo do professor no programa mostra que houve um efeito positivo da intervenção do professor, $(83,72 \%, n=36)$ classificaram como muito satisfeito (nota média 4,81) e apenas $(13,95 \%, n=6)$ se mostraram satisfeitos.

CARVALHO e BARBOSA (2003) enfatizam ainda que o bom andamento de um programa de AF para idosos depende muito do perfil do 
professor. Sabe-se que o professor é uma parte importante dentro do processo de identificaçào do praticante nas atividades escolhidas do programa. O bom andamento de um programa de AF para idosos também depende do perfil do professor. A sua marca pessoal pode determinar o sucesso ou o fracasso do programa de AF (BARBOSA, 2000).

De acordo com OKUMA (1997), a relação professor - aluno revelou ser de grande importância na motivação de muitos alunos para continuarem a sua participação no programa de AF.

Assim sendo, estes resultados podem ser explicados pela simpatia e conhecimento que o professor exerce perante o grupo, podendo aumentar o nível de adesão ao programa.

\subsection{Atendimento da Recepção}

Neste bloco, de acordo com os objetivos específicos citados anteriormente, procurou-se observar se o atendimento diferenciado da recepção e dos professores, bem como as explicações sobre o funcionamento do Programa Platinum ao praticante idoso foi um fator determinante na continuidade ao programa de exercícios. Em função de algumas modificações que foram implantadas no Programa Platinum com o incremento de novas atividades e metodologias de trabalho, o atendimento recebeu uma atenção especial. $\mathrm{Na}$ primeira fase, a recepção e os professores receberam treinamento diferenciado para que pudesse adequar a melhor forma de atendimento ao cliente.

É fundamental que a excelência no atendimento deva ser considerada como uma ferramenta significativa para cativar o cliente, pois sabemos que 
atualmente a globalização e o desenvolvimento tecnológico equilibram a qualidade dos produtos esportivos.

Deste modo, devemos ressaltar a importância de se implantar a sistematização deste procedimento, ou seja, preocupar-se desde o primeiro momento em que o idoso vêm à recepção pedir informações gerais sobre o programa de AF até o encaminhamento para o responsável pelo programa na academia.

TABELA 10 - Nível de Atendimento da recepção da academia ao ingressar no Programa Platinum

\begin{tabular}{cccccc}
\hline \hline Nível de atendimento & Masc & $\mathbf{\%}$ & Fem & $\%$ & Total \\
\hline Sim cordialmente & 10 & $\mathbf{1 0 0 \%}$ & 33 & $100 \%$ & $100 \%$ \\
Não cordialmente & 0 & $0 \%$ & 0 & $0 \%$ & $0 \%$ \\
\hline Total & 10 & $100 \%$ & 33 & $100 \%$ & $100 \%$ \\
\hline \hline
\end{tabular}

A TABELA 10 apresenta o nível de atendimento da recepção aos alunos quando do ingresso no Programa Platinum, distribuídos em três blocos: no bloco 1 tem-se o nível de atendimento (sim cordialmente e não cordialmente) para ambos os sexos envolvendo aspectos numéricos e percentuais; no bloco 2 tem-se os motivos masculinos envolvendo seis grupos (gentileza, atenção, educação, presteza, treinamento da academia e informações esclarecedoras); no bloco 3 tem-se os motivos femininos envolvendo os mesmos grupos do masculino, bem como os seus aspectos numéricos e percentuais. Os dados apresentados revelam que o nível de atendimento da recepção foi sim cordialmente $(100,00 \%, \mathrm{n}=43)$ para ambos os sexos. 
TABELA $10 \mathrm{~A}$ - Principais qualidades quanto ao atendimento da recepção da academia para o sexo masculino

\begin{tabular}{ccc}
\hline \hline Qualidades Masculinas & Total & $\mathbf{\%}$ \\
\hline Gentileza & 4 & $\mathbf{4 0 , 0 0 \%}$ \\
Atenção & 3 & $\mathbf{3 0 , 0 0 \%}$ \\
Educação & 3 & $\mathbf{3 0 , 0 0 \%}$ \\
Presteza & 2 & $20,00 \%$ \\
Treinamento da acad. & 1 & $10,00 \%$ \\
Informações esclarecedoras & 1 & $10,00 \%$ \\
\hline \hline
\end{tabular}

TABELA $10 \mathrm{~B}$ - Principais qualidades quanto ao atendimento da recepção da academia para o sexo feminino

\begin{tabular}{ccc}
\hline \hline Qualidades Femininas & Total & $\mathbf{\%}$ \\
\hline Gentileza & 8 & $24,24 \%$ \\
Atenção & 16 & $48,48 \%$ \\
Educação & 7 & $21,21 \%$ \\
Presteza & 10 & $30,30 \%$ \\
Treinamento da acad. & 3 & $9,09 \%$ \\
Informações esclarecedoras & 10 & $30,30 \%$ \\
\hline \hline
\end{tabular}


Os resultados revelam um ótimo desempenho no nível de atendimento da recepçào da academia ao praticante do Programa Platinum, com unanimidade $(100,00 \%, n=43)$ para ambos os sexos. Sugere-se que, o principal motivo que levou a esse resultado satisfatório tanto para os homens quanto para as mulheres foi o atendimento inicial que o praticante idoso recebeu ao ingressar na academia.

Os diferenciais se pautaram na gentileza, educação, atenção e presteza, sendo que a gentileza $(\mathbf{4 0 , 0 0 \%}, \mathbf{n}=\mathbf{4})$ se destacou como o principal determinante masculino e a atenção $(48,48 \%, n=16)$ o principal determinante feminino.

Atualmente, é percebido que o grande diferencial está nos procedimentos de atendimento, ou seja, na forma como se atende o cliente que chega à recepção pedindo informações sobre os programas e preços praticados, portanto atendê-lo de maneira personalizada pode se tornar um grande diferencial na decisão de se tornar um aluno da academia.

TABELA 11 - Nível de Atendimento dos Professores do Programa Platinum

\begin{tabular}{cccccc}
\hline \hline Nível de atendimento & Masc & $\mathbf{\%}$ & Fem & $\mathbf{\%}$ & Total \\
\hline Sim cordialmente & 10 & $\mathbf{1 0 0 \%}$ & 33 & $100 \%$ & $100 \%$ \\
Não cordialmente & 0 & $0 \%$ & 0 & $0 \%$ & $0 \%$ \\
\hline Total & 10 & $100 \%$ & 33 & $100 \%$ & $100 \%$ \\
\hline \hline
\end{tabular}

A TABELA 11 apresenta o nível de atendimento dos professores aos alunos do Programa Platinum, distribuídos em três blocos: no bloco 1 tem-se o nível de atendimento (sim cordialmente e não cordialmente) para ambos os 
sexos envolvendo aspectos numéricos e percentuais; no bloco 2 tem-se os motivos masculinos envolvendo seis grupos (gentileza, atenção, educação, presteza. treinamento da academia e orientação individualizada/capacitação); no bloco 3 tem-se os motivos femininos envolvendo os mesmos grupos do masculino acrescidos de entusiasmo e paciência, bem como os seus aspectos numéricos e percentuais. Os dados contidos na TABELA 11 revelam que do total dos alunos pesquisados do programa constatou-se que o nível de atendimento dos professores foi sim cordialmente $(100,00 \%, n=43)$ para ambos os sexos.

TABELA $11 \mathrm{~A}$ - Principais qualidades quanto ao atendimento dos professores do Programa Platinum para o sexo masculino

\begin{tabular}{ccc}
\hline \hline Qualidades Masculinas & Total & $\mathbf{\%}$ \\
\hline Gentileza & 3 & $\mathbf{3 0 , 0 0 \%}$ \\
Atenção & 1 & $10,00 \%$ \\
Educação & 2 & $20,00 \%$ \\
Presteza & 3 & $\mathbf{3 0 , 0 0 \%}$ \\
Treinamento da acad. & 1 & $10,00 \%$ \\
Orientação indv./capacitação & 4 & $40,00 \%$ \\
\hline \hline
\end{tabular}


TABELA $11 \mathrm{~B}$ - Principais qualidades quanto ao atendimento dos professores do Programa Platinum para o sexo feminino

\begin{tabular}{ccc}
\hline \hline Qualidades Femininas & Total & $\%$ \\
\hline Gentileza & 5 & $15,15 \%$ \\
Atenção & 14 & $42,42 \%$ \\
Educação & 2 & $6,06 \%$ \\
Presteza & 8 & $24,24 \%$ \\
Treinamento da acad. & 0 & $0,00 \%$ \\
Orientação indv./capacitação & 26 & $78,73 \%$ \\
Entusiasmo & 4 & $12,12 \%$ \\
Paciência & 1 & $3,03 \%$ \\
\hline \hline
\end{tabular}

Com relação ao atendimento dos professores aos alunos idosos praticantes do Programa Platinum, verificou-se também uma excelente qualidade, revelando total aprovação pelos usuários $(\mathbf{1 0 0 , 0 0 \%}, \mathbf{n}=\mathbf{4 3})$. As principais qualidades que justificaram esse desempenho estão relacionadas com a gentileza, presteza, atenção e orientação individualizada no atendimento em conjunto com a capacitação do professor. A orientação individualizada e competência profissional se destacaram como principal qualidade entre o sexo masculino $(\mathbf{4 0 , 0 0 \%}, \mathbf{n}=\mathbf{4})$ e feminino $(\mathbf{7 8 , 7 9 \%}, \mathbf{n}=\mathbf{2 6})$.

De acordo com BARBOSA, (2000) o professor é uma parte importante dentro do processo de identificação do praticante nas atividades escolhidas do programa. A sua marca pessoal pode determinar o sucesso ou o fracasso do programa de AF. Outro fator importante está relacionado com a simpatia e o 
conhecimento que o professor exerce, podendo aumentar o nível de adesão ao programa. Assim sendo, o tipo de atividade, o conhecimento e a característica do professor devem ser levadas em consideração (WEINBERG \& GOULD, 1995).

Desta maneira, torna-se evidente a necessidade do professor ser treinado na área de AF e envelhecimento, bem como se identificar com os conteúdos da área em questão e com o praticante. Ter simpatia, ser paciente, interessado e disposto são pré-requisitos importantes nesta interação aluno/professor/programa de AF (CARVALHO \& BARBOSA, 2003).

\section{TABELA 12 - Explicações precisas e claras quanto ao funcionamento do $\underline{\text { Programa Platinum }}$}

\begin{tabular}{cccccc}
\hline \hline Nível de atendimento & Masc & $\mathbf{\%}$ & Fem & \multicolumn{1}{c}{$\%$} & Total \\
\hline Sim - explicações claras & 10 & $\mathbf{1 0 0 , 0 0 \%}$ & 32 & $96,97 \%$ & $97,67 \%$ \\
Não - explicações confusas & 0 & $0,00 \%$ & 1 & $3,03 \%$ & $2,33 \%$ \\
\hline Total & 10 & $100,00 \%$ & 33 & $100,00 \%$ & $100,00 \%$ \\
\hline \hline
\end{tabular}

A TABELA 12 apresenta as explicações precisas e claras aos alunos quanto ao funcionamento do Programa Platinum, distribuídos em três blocos: no bloco 1 tem-se o nível de atendimento (sim- explicações claras e nãoexplicações confusas) para ambos os sexos envolvendo aspectos numéricos e percentuais; no bloco 2 tem-se os motivos masculinos envolvendo três grupos (receberam informações esclarecedoras, orientação individualizada e treinamento da academia); no bloco 3 tem-se os motivos femininos envolvendo os mesmos grupos do masculino acrescido da aula experimental, bem como os seus aspectos numéricos e percentuais. Os dados apresentados na TABELA 12 
revelam que do total dos alunos pesquisados do programa constatou-se que simexplicaçòes claras $(97,67 \%, n=42)$ e não-explicações confusas $(2,33 \%, n=1)$.

TABELA 12A - Principais qualidades de informação sobre o funcionamento do Programa Platinum para o sexo masculino

\begin{tabular}{ccc}
\hline \hline $\begin{array}{c}\text { Qualidades de informação } \\
\text { Masculinas }\end{array}$ & Total & $\mathbf{\%}$ \\
\hline Receberam inform. esclarec. & 8 & $\mathbf{8 0 , 0 0 \%}$ \\
Orientação individualizada & 2 & $\mathbf{2 0 , 0 0 \%}$ \\
Treinamento da acad. & 1 & $10,00 \%$ \\
\hline \hline
\end{tabular}

TABELA 12B - Principais qualidades de informação sobre o funcionamento do Programa Platinum para o sexo feminino

\begin{tabular}{c|c|c}
\hline \hline $\begin{array}{c}\text { Qualidades de informação } \\
\text { Femininas }\end{array}$ & Total & $\mathbf{\%}$ \\
\hline Receberam inform. esclarec. & 24 & $72,73 \%$ \\
\hline Orientação individualizada & 16 & $48,48 \%, \%$ \\
\hline Treinamento da acad. & 0 & $0,00 \%$ \\
\hline Aula experimental & 2 & $6,06 \%$ \\
\hline \hline
\end{tabular}

Na última análise do Bloco 3, observou-se que quase na sua totalidade $\mathbf{9 7 , 6 7 \%}, \mathbf{n}=\mathbf{4 2})$ os indivíduos/alunos do Programa Platinum entenderam a 
proposta do programa quanto ao seu funcionamento, recebendo explicações claras e precisas.

Quando foi perguntado o porque de ter recebido explicações claras e precisas quanto ao funcionamento do programa, as informações esclarecedoras foram o principal motivo para homens $(\mathbf{8 0 , 0 0 \%}, \mathbf{n = 8})$ e mulheres $(\mathbf{7 2 , 7 3 \%}, \mathbf{n = 2 4 )}$. A orientação individualizada aparece novamente como um

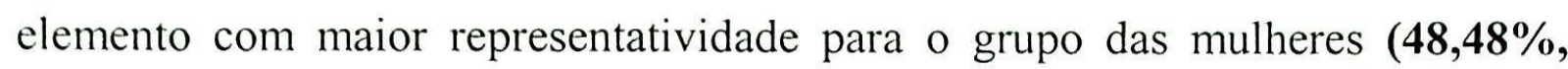
$n=16)$.

Baseado nestes dados, conforme AMORIM et al. (2002) devemos organizar a programação e o planejamento específico dos mecanismos de exposição, principalmente na exposição das informações, podendo contribuir para a mudança do conhecimento e comportamento populacional.

\subsection{Pontos Positivos e Negativos do Programa Platinum}

Pretende-se relacionar e observar os pontos positivos e negativos do Programa Platinum, como também as sugestões para melhorar o programa, verificando se o mesmo atende aos anseios dos praticantes idosos da academia.

De acordo com DISHMAN (1988b) os fatores ambientais ou situacionais, tais como as características do programa de AF (intensidade da AF, programa individual ou em grupo, horários, freqüência, etc.), as características do professor e os pertinentes ao programa de AF podem promover e permitir a participação em programas supervisionados. Ressalta ainda que, os ambientes que apóiam e reforçam as mudanças de comportamento dos praticantes associados à remoção das possíveis barreiras (dificuldades) favorecem a manutenção da adesão. 
Com relaçào às características do programa de $\mathrm{AF}$ para idosos, deve haver o cuidado para que se definam as características das atividades, pois podem impedir ou estimular a sua participação em programas específicos (DISHMAN, 1993).

Estratégias como flexibilidade de horários, atividades em grupo, atividades adequadas ao nível de aptidão física do idoso, atividades gratificantes e divertidas e o perfil do professor são alguns dos fatores que levam o idoso a aderir inicialmente aos programas (ANDREOTTI, 2001).

A seguir, os principais pontos positivos, negativos e sugestões para melhorar o Programa Platinum. A TABELA 13, apresenta os pontos positivos do Programa Platinum expressos pelos alunos, os quais estão distribuídos em vinte e um grupos (nenhum, diversidade de horários, diversidade de atividades, orientação precisa dos exercícios para a correção, exercícios bem dosados /individualidade, programa personalizado, programa estimulante, liberdade de escolha da AF, melhora fisica e mental geral, grupo agradável e divertido, proporcionar novas amizades, aulas ministradas com dois professores, professores qualificados, professores preocupados com o bem-estar e saúde, professores afetivos e atenciosos, professores com boa comunicação, dependências limpas, equipamentos modernos, equipamentos em ótimo estado, estacionamento gratuito e academia bem localizada).

A TABELA 14 apresenta os pontos negativos do Programa Platinum expressos pelos alunos os quais estão distribuídos em onze grupos (nenhum, maior atenção e orientação dos professores de musculação, respeito dos horários pelos alunos, novos horários para iniciantes, pouco tempo de aula, muitos alunos para pouco espaço fisico, mais equipamentos-bolas, caneleiras e 
pesos, ar condicionado nào ajustável da salal, conversa nos equipamentos de musculaçào. o uso de celulares na musculação, mais professores).

TABELA 13 - Pontos Positivos do Programa Platinum

\begin{tabular}{|c|c|c|c|c|c|}
\hline Pontos Positivos & Masc & $\%$ & Fem & $\%$ & Total \\
\hline nenhum & 0 & $0,00 \%$ & 1 & $3,03 \%$ & $2,33 \%$ \\
\hline diversidade de horários & 1 & $10,00 \%$ & 5 & $15,15 \%$ & $13,95 \%$ \\
\hline diversidade de atividades & 2 & $20,00 \%$ & 5 & $15,15 \%$ & $16,28 \%$ \\
\hline orient. precisa dos exercs/correção & 3 & $30,00 \%$ & 11 & $33.33 \%$ & $32,56 \%$ \\
\hline exercs. bem dosados / indiv. & 3 & $30,00 \%$ & 15 & $45,45 \%$ & $41,86 \%$ \\
\hline programa personalizado & 1 & $10,00 \%$ & 10 & $30,30 \%$ & $25,58 \%$ \\
\hline programa estimulante & 1 & $10,00 \%$ & 7 & $21,21 \%$ & $18,60 \%$ \\
\hline liberdade de escolha das AF & 0 & $0,00 \%$ & 3 & $9,09 \%$ & $6,98 \%$ \\
\hline melhora fisica e mental geral & 2 & $20,00 \%$ & 13 & $39,30 \%$ & $34,88 \%$ \\
\hline grupo agradável e divertido & 4 & $40,00 \%$ & 8 & $24,24 \%$ & $27,91 \%$ \\
\hline proporcionar novas amizades & 0 & $0,00 \%$ & 4 & $12,12 \%$ & $9,30 \%$ \\
\hline aulas ministradas com 2 profs. & 0 & $0,00 \%$ & 2 & $6,06 \%$ & $4,65 \%$ \\
\hline professores qualificados & 3 & $30,00 \%$ & 3 & $9,09 \%$ & $13,95 \%$ \\
\hline profs. preoc. bem-estar e saúde & 0 & $0,00 \%$ & 7 & $21,21 \%$ & $16,28 \%$ \\
\hline profs. afetivos e atenciosos & 1 & $10,00 \%$ & 12 & $36,36 \%$ & $30,23 \%$ \\
\hline profs. com boa comunicação & 0 & $0,00 \%$ & 2 & $6,06 \%$ & $4,65 \%$ \\
\hline dependências limpas & 1 & $10,00 \%$ & 1 & $3,03 \%$ & $4,65 \%$ \\
\hline equipamentos modernos & 1 & $10,00 \%$ & 1 & $3,03 \%$ & $4,65 \%$ \\
\hline equipamentos em ótimo estado & 1 & $10,00 \%$ & 1 & $3,03 \%$ & $4,65 \%$ \\
\hline estacionamento gratuito & 1 & $10,00 \%$ & 1 & $3,03 \%$ & $4,65 \%$ \\
\hline academia bem localizada & 1 & $10,00 \%$ & 1 & $3,03 \%$ & $4,65 \%$ \\
\hline
\end{tabular}


Com relação aos pontos positivos do Programa Platinum percebe-se que os principais fatores apontados foram: exercícios bem dosados respeitando a individualidade (41,86\%), melhora física e mental geral $(34,88 \%)$, orientação precisa dos exercícios/correção (32,56\%), professores afetivos e atenciosos $(30,23 \%)$. Observamos uma preocupação do grupo com relação à intensidade da atividade, na adequação dos exercícios, no respeito à individualidade e na maneira precisa de se orientar os exercícios e as correções.

Apesar do grupo ser heterogêneo, nas aulas coletivas, a individualidade é preservada na medida em que é permitido a cada aluno realizar os exercícios que pode fazer. Como estratégia é criado para cada exercício pelo menos três graus de dificuldade (iniciante, intermediário e avançado) adequando-se a melhor opção para cada caso. Para ministrar as aulas utilizamos sempre dois professores para facilitar as intervenções. Não podemos deixar de enfatizar que respeitar a individualidade também está relacionado com a segurança do que é desenvolvido no programa.

DISHMAN (1988) corrobora esses dados enfatizando que, o tipo e a quantidade apropriada de AF pode incentivar e reforçar a participação em programas regulares.

A procura por melhorar a saúde física e mental geral pelo grupo foi outro fator relevante. Podemos considerar como um dado positivo visto que, em nosso país, o número de sedentários é muito elevado. Dados publicados pelo último levantamento do IBGE (1998) estimam que 60 a 65\% da população são fisicamente inativos.

Após os 20 anos, o envelhecimento começa a deteriorar muitas funções. SPIRDUSO (1995) cita que em torno de 50\% desse declínio pode ser atribuído ao desuso ou inatividade física. Desta maneira, o combate ao 
sedentarismo, de acordo com DISHMAN (1988a), é um elemento fundamental para melhorar a qualidade de vida quando associado com a prática de atividade física.

A participação do idoso em um programa de exercício regular é considerado como um recurso eficiente de intervenção na redução ou na prevenção dos declínios funcionais próprios do envelhecimento. Sendo assim, os benefícios associados à atividade física e o exercício regular contribuem para um estilo de vida mais saudável e independente (ACSM, 1998).

O papel do professor reaparece com um ponto positivo do Programa Platinum: tanto para homens quanto para mulheres, a afetividade e atenção são características fundamentais no desenvolvimento do programa. Percebe-se que é um elemento de motivação na permanência do programa de AF. OKUMA (1997) relata em sua tese que o foco de atenção dos professores sempre estava voltado para o aluno, sensibilizando o grupo em função da constante preocupação na personalização do atendimento.

Quanto aos pontos negativos, verificou-se que na sua maioria, os praticantes idosos não apontam nenhum $(72,50 \%)$ problema em relação ao programa, indicando um alto nível de satisfação. Os principais pontos negativos do Programa Platinum que se seguem, conforme tabela abaixo, estão relacionados, na sua maioria, com os fatores situacionais vinculados às características do programa de AF. 
TABELA 14 - Pontos Negativos do Programa Platinum

\begin{tabular}{cccccc}
\hline \hline Pontos Negativos & Masc & $\%$ & Fem & $\%$ & Total \\
\hline nenhum & 6 & $66,67 \%$ & 23 & $74,1 \% \%$ & $72,50 \%$ \\
maior atenção e orient. dos profs. musc. & 1 & $11,11 \%$ & 1 & $3,23 \%$ & $5,00 \%$ \\
respeito dos horários pelos alunos & 1 & $11,11 \%$ & 2 & $6,45 \%$ & $7,50 \%$ \\
novos horários p/iniciantes & 1 & $11,11 \%$ & 2 & $6,45 \%$ & $7,50 \%$ \\
$\quad$ pouco tempo de aula & 0 & $0,00 \%$ & 1 & $3,23 \%$ & $2,50 \%$ \\
muitos alunos p/ pouco espaço fisico & 0 & $0,00 \%$ & 3 & $9,68 \%$ & $7,50 \%$ \\
mais equip.(bolas,caneleiras,pesos) & 0 & $0,00 \%$ & 1 & $3,23 \%$ & $2,50 \%$ \\
ar condicionado não ajustável (Salal) & 0 & $0,00 \%$ & 1 & $3,23 \%$ & $2,50 \%$ \\
conversa nos equip. musc. & 1 & $11,11 \%$ & 0 & $0,00 \%$ & $2,50 \%$ \\
uso de celulares na musc. & 1 & $11,11 \%$ & 0 & $0,00 \%$ & $2,50 \%$ \\
$\quad$ mais professores & 1 & $11,11 \%$ & 0 & $0,00 \%$ & $2,50 \%$ \\
\hline \hline
\end{tabular}

De acordo com WEINBERG e GOULD (1995) as características do programa de AF como tipo de aula, intensidade, relação professor-aluno e fator estrutural interferem diretamente no sucesso ou no fracasso do programa.

Tanto para os homens quanto para as mulheres com pequenas diferenças entre si, os fatores que mais incomodaram foram: respeito dos horários pelos alunos $(\mathbf{7 , 5 0 \%})$, novos horários para iniciantes $(\mathbf{7 , 5 0 \%})$, muitos alunos para pouco espaço físico $(\mathbf{7 , 5 0 \% )}$ e maior atenção e orientação dos professores de musculação $(\mathbf{5 , 0 0 \%})$.

Com relação ao respeito dos horários pelos alunos, muitos reclamaram em função dos atrasos para iniciar as sessões das aulas em grupo, principalmente do departamento de Ginástica. Pode-se deduzir que esses atrasos ocorram em função das aulas serem seqüenciadas, sem intervalo. Se eventualmente alguma aula anterior à do Programa Platinum iniciar atrasada, o 
efeito será em cascata, atrasando todo o restante das aulas que se seguem. Uma das soluçòes seria haver intervalo entre as aulas.

Quanto à questão relacionada a novos horários para iniciantes, atualmente o Programa Platinum não tem diferenciação por níveis. Os grupos são heterogêneos, o que sugere diferentes níveis de aptidão física na mesma aula. Deste modo, quando falamos em novos horários para iniciantes, nos deparamos com um outro problema estrutural, que está relacionado com o número de salas da unidade Morumbi. O seu número é reduzido e muito concorrido por todas as outras modalidades que a academia oferece na grade de horários da Ginástica.

O local onde as aulas em grupo são realizadas tem uma limitação de espaço, recaindo em outro ponto negativo citado pelos alunos quanto a ter muitos alunos na aula para pouco espaço físico. Esses fatores estruturais não dependem diretamente da característica do programa em si, portanto, a solução para esses fatores negativos depende diretamente da administração da academia.

Finalizando, a análise do último ponto negativo citado pelos alunos do programa em relação ao atendimento da musculação, solicitam maior atenção e orientação dos professores, podendo este dado ser considerado como uma barreira à manutenção da atividade e até mesmo do programa de AF, visto que muitos alunos têm por opção só participar das atividades individualizadas (cardiovascular e musculação).

Mesmo utilizando a estratégia de se colocar um professor a cada hora na musculação, percebe-se que os alunos praticantes do programa necessitam de atenção mais personalizada neste departamento. Conforme a TABELA 6, verificou-se a que a musculação é uma atividade com alto índice de participação $(\mathbf{7 9}, 07 \%, \mathbf{n}=34)$, sendo recomendada na prescrição de treinamento para todos os alunos do programa, salvo algumas exceções. 
Deste modo, apesar dos pontos negativos relativos ao Programa Platinum representarem um percentual pequeno $(27,50 \%)$ em relação aos alunos que nào tiveram nenhuma reclamação, devem ser considerados para que se possa diminuir a possível desistência ou desmotivação pela prática das atividades do programa.

TABELA 15 - $\underline{\text { Sugestões dos entrevistados para melhorar o Programa Platinum }}$

\begin{tabular}{cccccc}
\hline \hline Sugestões & Masc & $\mathbf{\%}$ & Fem & $\%$ & Total \\
\hline nada a melhorar & 3 & $33,33 \%$ & 12 & $38,71 \%$ & $37,50 \%$ \\
divisão níveis inic., interm. e avanç. & 2 & $\mathbf{2 2 , 2 2 \%}$ & 6 & $19,35 \%$ & $20,00 \%$ \\
reestruturar horários/atrasos & 1 & $11,11 \%$ & 1 & $3,23 \%$ & $5,00 \%$ \\
mais acompanhamento/correção na musc. & 1 & $11,11 \%$ & 1 & $3,23 \%$ & $5,00 \%$ \\
aulas de hidrog. & 1 & $11,11 \%$ & 1 & $3,23 \%$ & $5,00 \%$ \\
aulas de yoga adequadas p/ 3a idade & 0 & $0,00 \%$ & 3 & $9,68 \%$ & $7,50 \%$ \\
aula em grupo na musc.c/ superv. profs. & 0 & $0,00 \%$ & 1 & $3,23 \%$ & $2,50 \%$ \\
aulas de dança & 0 & $0,00 \%$ & 1 & $3,23 \%$ & $2,50 \%$ \\
intervalo entre uma aula e outra & 1 & $11,11 \%$ & 2 & $6,45 \%$ & $7,50 \%$ \\
manter o interesse e compet. profs. e acad. & 2 & $\mathbf{2 2 , 2 2 \%}$ & 1 & $3,23 \%$ & $7,50 \%$ \\
salas maiores & 0 & $0,00 \%$ & 2 & $6,45 \%$ & $5,00 \%$ \\
melhor iluminação no palco da sala & 0 & $0,00 \%$ & 1 & $3,23 \%$ & $2,50 \%$ \\
mais material p/ as aulas de ginástica & 0 & $0,00 \%$ & 1 & $3,23 \%$ & $2,50 \%$ \\
manter as confraternizações & 0 & $0,00 \%$ & 2 & $6,45 \%$ & $5,00 \%$ \\
dvd do programa & 0 & $0,00 \%$ & 1 & $3,23 \%$ & $2,50 \%$ \\
\hline \hline
\end{tabular}

A TABELA 15 apresenta sugestões para melhorar o Programa Platinum expressos pelos alunos os quais estão distribuídos em quinze grupos (nada a melhorar, divisão em níveis iniciantes, intermediários e avançados, 
reestruturar os horarios/atrasos, mais acompanhamento/correção na musculação, aulas de hidroginástica, aulas de yoga adequadas para a 3aidade, aula em grupo na musculação com supervisão dos professores, aulas de dança, intervalo entre uma aula e outra, manter o interesse e competência pelos professores e academia, salas maiores, melhor iluminação no palco da sala, mais material para as aulas de ginástica, manter as confraternizações e DVD do programa).

De acordo com os dados observados nas sugestões para melhorar o Programa Platinum, verificou-se que $(\mathbf{3 7 , 5 0 \%}, \mathbf{n}=\mathbf{1 5})$ dos praticantes idosos do programa acreditam que o programa não precisa melhorar sob nenhum aspecto. Dos que opinaram, percebe-se que as principais sugestões estão novamente relacionadas com os fatores situacionais vinculados às características do programa de AF. As principais sugestões apontadas pelos alunos como

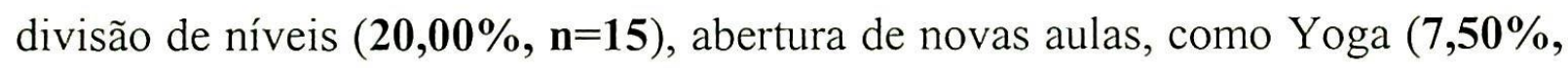
$\mathbf{n}=3)$, instituir intervalos entre uma aula e outra evitando os atrasos $(\mathbf{7 , 5 0 \% ,}, \mathbf{n}=\mathbf{3})$ e manutenção do interesse e competência dos professores/academia (gerentes) em relação ao Programa Platinum $(7,50 \%, \mathbf{n}=3)$.

Assim sendo, segundo VAVRA (1996) descobrir o que o cliente quer é uma ferramenta importante de comunicação, na medida que a organização tem interesse em seus clientes para saber qual o seu nível de satisfação em relação ao serviço prestado.O cliente/aluno ao consentir participar deste tipo de pesquisa, sente-se apreciado e esperançoso que seus comentários/opiniões sejam usados para aprimorar a qualidade do produto e do serviço prestado. 


\section{CONCLUSÕES}

Considerando os resultados da pesquisa e deste estudo e em concordância com a literatura, pode-se analisar o Programa Platinum quanto ao grau de satisfação do praticante idoso em relação à sua estrutura, organização/planejamento e funcionamento/atendimento.

Desta forma, foi possível traçar o perfil dos praticantes do programa: a maioria é composta pelo sexo feminino, na faixa etária de 60 a 65 anos, com predomínio na categoria de casados/unidos e com grande incidência de viúvas, o tempo de prática no programa revelou que a maioria tem 13 a 24 meses de permanência, freqüenta predominantemente o periodo da manhã e participa na sua maioria das aulas de Alongamento, Musculação, Esteira e Multi Platinum.

Os principais determinantes relatados que levaram os idosos a freqüentar o Programa Platinum tanto para os homens quanto para as mulheres foram: saúdelqualidade de vida e indicação médica. Constatou-se a necessidade que os praticantes idosos tinham de obter informações precisas e claras quanto ao funcionamento do programa, bem como das orientaçôes sobre a maneira correta de executar os exercícios na busca da saúdelqualidade de vida.

Em relação ao seu nível de satisfação (NS) quanto às atividades desenvolvidas, revelou que tanto para os homens quanto para as mulheres o NS obteve na sua maioria a nota máxima ( inco), equivalente a muito satisfeito. Quanto aos objetivos atingidos, revela um NS com boa representatividade equivalente a muito satisfeito; o estímulo do professor mostrou que houve um efeito positivo da sua intervenção para a melhora do desempenho dos praticantes, fazendo com que se sintam muito satisfeitos. Portanto, a avaliação positiva 
relatada pelos praticantes idosos do Programa Platinum revela que as estratégias utilizadas no programa são compatíveis com as que o programa de AF se propõe.

Quanto ao atendimento prestado pela recepção, os resultados revelam um ótimo desempenho, agradando em $(100 \%, \mathrm{n}=43)$ os participantes do programa; em relação ao atendimento dos professores, verificou-se também uma excelente qualidade, revelando total aprovação dos usuários $(100 \%, \mathrm{n}=43)$.

As orientações recebidas pelos participantes ao ingressar na academia quanto ao Programa Platinum, revelaram-se próximo de sua totalidade, claras e precisas.

Assim sendo, disseminar a idéia da adoção da prática de exercícios físicos como um estilo de vida saudável para todos os períodos da vida é de fundamental importância, inclusive para os idosos. As academias têm um papel significativo neste procedimento, podendo ser uma estratégia a mais que auxilie no processo de envelhecimento da população idosa, proporcionando atividade física orientada e segura, informação e reintegração social.

Os praticantes idosos sentem-se muito satisfeitos quando lhes é proporcionado atendimento de qualidade, estrutura e planejamento, fazendo com que se sintam motivados a freqüentar as atividades oferecidas pelo programa de $\mathrm{AF}$, bem como auxiliando na aderência e no comportamento preventivo quanto à saúde.

Deste modo, os resultados desse trabalho de pesquisa sob a forma de recomendações técnicas e /ou poderão vir a subsidiar, tanto no âmbito acadêmico como no profissional, a bibliografia e o conhecimento científico criando-se uma referência para consultas e aplicações nesta área, que se revela pouco explorada e carente de propostas e soluções em nível local, estadual e nacional. 
Os conhecimentos e informações adquiridos poderão também ser transferidos para outras metrópoles brasileiras e servir de orientação presente e futura a órgãos e instituições públicas e privadas vinculadas a esta área de atividades que objetivem a melhoria da qualidade de vida dos idosos.

\section{CONSIDERAÇÕES FINAIS}

Em função dos dados obtidos na pesquisa e para a melhoria do "Programa Platinum", recomendamos:

- Eqüalizar o número de praticantes idosos do sexo feminino e masculino por meio de melhor divulgação interna do Programa Platinum, incentivando a participação masculina e de casais, para se obter melhor representatividade, pois as mulheres representaram na pesquisa em questão 76,74\% (TABELA 1).

- Intensificar com monitoramento dos alunos durante sua permanência no programa pela adoção de ações preventivas, como telemarketing semanal para os faltosos, comunicação via internet sobre as aulas especiais do mês, dicas de saúde e culturais, etc., para que se possa diagnosticar em tempo hábil os possíveis problemas que acarretam a sua desistência, visando ao aumento de permanência dos praticantes idosos do "Programa Platinum" (TABELA 3). 
- Melhorar a ações de marketing por parte da academia tendo em vista o aumento de participações dos alunos no período da tarde, por meio de divulgaçòes internas, externas e na classe médica (TABELA 4).

- Manter a realização de atividades sociais como eventos, confraternizações, aulas especiais, passeios, palestras, viagens que permitam a formação contínua de novas amizades (TABELA 5) para que os laços afetivo-sociais se mantenham por um tempo maior favorecendo a adesão ao programa..

- Incentivar a prática das atividades aquáticas (natação e hidroginástica) principalmente para a população masculina (TABELA 6), cuja freqüência é menor em relação às mulheres, bem como melhorar a acessibilidade dos idosos para chegar às piscinas (escadas/elevadores).

- Estudar com a administração da academia estratégias para melhorar os aspectos quanto a: respeitar os horários de aulas por alunos e professores (atrasos), novos horários para os iniciantes, otimizar o espaço fisico das salas de aula, maior atenção e orientação dos professores de musculação (TABELA 14).

- Melhorar, conforme sugestão dos entrevistados, os seguintes pontos: divisão das aulas por níveis (iniciantes, intermediários e avançados); aulas de yoga adequadas para os idosos; adoção de intervalos entre as aulas; manter o interesse e a competência dos professores e da academia ao "Programa Platinum". 
Concluindo, face à nossa experiência profissional e observações, acrescentamos:

- Manter o padrão de excelência quanto ao atendimento da recepção e dos professores, estabelecendo para tanto um perfil adequado de todos os profissionais que trabalham diretamente com os idosos, a saber: estar sempre sorridente, ser educado, ser auto-confiante, ser pró-ativo, ser um bom ouvinte, dar atenção sincera e amor/carinho, formação / treinamento adequado,orientar(propor), ter o comprometimento com a segurança do aluno, ter interesse real pelo idoso (disponibilidade de tempo, querer conhecê-lo,consideração e tolerância).

- Melhorar o sistema informatizado de cadastro da academia para que o aluno regular, que ao completar 60 anos de idade se transforma em aluno Platinum, possa ser devidamente monitorado pelo coordenador recebendo toda a assistência e orientação que possa necessitar. Da mesma forma, o coordenador também precisa ser notificado mensalmente da inclusão desses novos alunos para que possa entrar em contato com os mesmos.

Para finalizar, gostaríamos de citar a poesia de um aluno do "Programa Platinum", da unidade do Rio de Janeiro, que evidencia o verdadeiro espírito do programa: 


\section{COMPANHIA ATHLETICA}

Athletica é academia,

É saúde. é alegria

Pra quem deseja viver

Com mais paz e harmonia.

Corpo e alma em comunhão.

Pra concentrar a atenção

No exercício marcado,

Professora ou Professor

Estão sempre ao nosso lado.

Nesta confiança sadia,

Progressos a cada dia

São fruto da amizade.

Ambiente puro e são

Conquista o coração

E gera felicidade.

Novos amigos à vista!

Todo dia chega alguém

Que nos traz nova amizade.

E neste convívio ameno

$\mathrm{O}$ mundo fica pequeno

Dentro da grande cidade.

Francisco Antônio Pires, 82 anos

Rio de Janeiro, fevereiro de 2005. 


\section{REFERÊNCIAS}

ACHOUR JUNIOR, A. Exercícios de Alongamento: anatomia e fisiologia. São Paulo: Manole, 2002.

ALBRECHT, K. Revolução nos serviços: como as empresas podem revolucionar a maneira de tratar os seus clientes. 3.ed. São Paulo: Pioneira, 1992.

AMERICAN COLLEGE OF SPORTS MEDICINE (ACSM). Position stand on exercise and physical activity for older adults. Medicine and Science in Sports and Exercise, Baltimore, v.30, n.6, p.992 - 1008, 1998.

. ACSM's guidelines for exercise testing and prescription. 6.ed. Lippincott: Williams \& Wilkins, 2000a.

. Manual do ACSM para teste de esforço e prescrição de exercícios. 5.ed. Rio de Janeiro: Revinter, 2000b.

. Physical activity programs and behavior counseling in older adult populations. Medicine and Science in Sports and Exercise, Madison. v.36, n.11, p.1997-2003, 2004.

ADAMS, G. M. Exercise Physt:laboratory manual. 3 ed. California: State University of Fullerton, 1998.

AQUATIC EXERCISE ASSOCIATION (AEA) - Manual do profissional de fitness aquático. Rio de Janeiro: Shape, 2001. 
ALVES, L. C. Determinantes da autopercepção de saúde dos idosos do Município de São Paulo, 1999/2000. 2004. Dissertação (Mestrado) - Faculdade de Ciências Econômicas, Universidade Federal de Minas Gerais, Belo Horizonte.

AMORIM, P. R. S.; MIRANDA, M.; CHIAPETA, S. M. V.; GIANNICHI, R. S.; SPERANCINI, M. A. C.; OSÉS, A. Estilo de vida ativo ou sedentário: impacto sobre a capacidade funcional. Revista Brasileira de Ciências do Esporte, Campinas, v. 23, n.3, p. 49-63, 2002.

ANDRADE, E.; MATSUDO, S.; MATSUDO, V.; ARAÚJO, T.; ANDRADE, D.; OLIVEIRA, L.; FIGUEIRA, A. Barriers and motivacional factors for physical activity adherence in elderly people in developing country [abstract]. Medicine Sports Exercise, v. 33, n.7, p. 141, 2000.

ANDREOTTI, M. C. Fatores que influenciam a adesão de idosos a um programa de educação física Supervisionado. 2001. Dissertação (Mestrado) Escola de Educação Física e Esporte. Universidade de São Paulo, São Paulo.

ANDREOTTI, M. C.; OKUMA, S. S. Perfil Sócio-Demográfico e de Adesão Inicial de Idosos ingressantes em um Programa de Educação Física. Revista Paulista de educação Física, São Paulo, v.17, n.2, p.142-53, 2003.

ANDREOTTI, R. A. Efeitos de um programa de educação física sobre as atividades de vida diária dos idosos. 1999. Dissertação (Mestrado) - Escola de Educação Física e Esporte. Universidade de São Paulo, São Paulo. 
ANDREOTTI, R. A.;OKUMA, S. S. Validação de uma bateria de testes de atividades da vida diária para idosos fisicamente independentes. Revista Paulista de educação Física, n.13, p. 46-66, 1999.

ANTONIAZZI, R. C. A condição física do idoso. 1994. Dissertação (Mestrado) - Universidade Federal de Sta. Maria.

BARBOSA, J. H. P. Educação física em programas de saúde. In: CURSO de extensão universitária de educação física na saúde. Batatais: Centro Universitário Claretiano-CEUCLAR - 2001.

BARBOSA, R. M. S. P. Educação física gerontológica. Rio de Janeiro: Sprint, 2000.

BENEDETTI, T.R; PETROSKI, E.L. Idosos asilados e a prática de atividade física. Revista Brasileira de Atividade Física e Saúde, v. 3, p. 5-16, 1999.

BERGER, B. G.; McINMAN, A. Exercise and quality of life In: BOUCHARD, C.; SHEPARD, R. J.; STEPHENS, T.; SUTTON, J. R.; MCPHERSON, B. D. (Ed). Exercise, fitness and health. Champaign: Human Kinetics, 1990. Cap.34, p. $729-760$.

BERQUÓ, E. Considerações demográficas sobre o envelhecimento. In: SEMINÁRIO INTERNACIONAL SOBRE ENVELHECIMENTO POPULACIONAL: uma agenda para o fim do século. 1996, Brasília. Anais... Brasília: [s.ed.], 1996. 
BIREME. DeCS (Descritores em Ciências da Saúde). Disponível em:

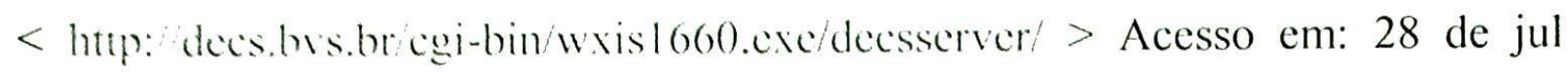
2004.

BLAIR, S. Prova de esforço e prescrição de exercício: ACMS (American College of Sports Medicine). Rio de Janeiro: Revinter, 1994.

BONACHELA, V. Manual básico de hidroginástica. Rio de Janeiro: Sprint, 1994.

BROWN, M.; HOLLOSZY, J. O. Effects of a low intensity exercise program on selected physical performance characteristics of 60 to 71 year olds. Ageing Clinical and Experimental Research, v.3, p. 129-139, 1991.

BUCHNER, D. M. Understanding variability in studies of strength training in older adults: a meta-analytic perspective. Top Geriatric Rehabilitation, v.8, n.1, 1993.

CAMPOS, M. A.; CORAUCCI, B. N. Treinamento funcional resistido para a melhoria da capacidade funcional e reabilitação de lesões musculoesqueléticas. Rio de Janeiro: Revinter, 2004.

CARVALHO, J. Aspectos metodológicos no trabalho com idosos: In: MOTA, J.; CARVAlHo, J. (Eds). Actas do Seminário A qualidade de vida no idoso: o papel da actividade física. 1999, p. 95-104.

CARVALHO, J.; MOTA, J. Actividade física no idoso: justificação e prática.Oeiras: Câmara Municipal de Oeiras / Divisão do Desporto, 2002. 
CARVALHO, R. B. C.; BARBOSA, R. M. S. P. O envelhecimento e a atividade física. Rio de Janeiro: Guanabra Koogan, 2003. cap. 8, p.82-91.

CARTEE, G. D. Aging skeletal muscle: response to exercise. Exercise and Sports Sciences Reviews, Baltimore, v. 22, p. 91-120, 1994.

CASPERSEN, C. J.; KRISKA, A. M.; DEARWATER, S. R. Physical activity epidemiology as applied to elderly populations. Baillieres Clinical Rheumatology, v.8, p7-27, 1994,

CASTERSEN, L. Motivação para o contato social ao longo do curso de vida: uma teoria de seletividade socioemocional. In: NERI, A. (Org). Psicologia do envelhecimento. Campinas: Papirus, 1994. p. 111-144.

CHEN, W.; CHANG, J.; POLLOCK, M.; GRAVES, J.; PROBART, C.; SPLITTER, D. Effect of aerobic exercise training on anxiety reduction and health behaviors of healthy men and women 60 to 79 years of age. Research Qualify Exercise Sport, v.63, p. 33-38, 1992. Supplement I.

CORBIN, C. B.; LINDSEY, R. Concepts of physical fitness. New York, William C. Brown, 1996.

COSTA, S. F. Introdução à estatística. 2ed, Editora: HARBRA, 1992.

COTTON, R. (Ed). Exercise for older adults. ACE's guide for fitness professionals. Champaign, Human Kinetics, 1998. 
COUSINS, S. O.; KEATING, N. Life cycle patterns of physical activity among sedentary and active older women. Journal of Aging and Physical Activity, Champaign, v.3, p.340-359, 1995.

CREF - Conselho Regional de Educação Física, 2003.

DANTAS, E. Aspectos motivacionais para a prática de atividades físicas por gerontes. In: MARQUES, A. T.; GAYA, A.; CONSTANTINO, J. M., (Eds.). Physical activity and health in the elderly: proceedings of the first conference of EGREPA. Oeiras, University of Porto, 1994. p. 5189-5920.

DEBERT, G. G. A reinvenção da velhice. São Paulo: FAPESP/EDUSP, 1999.

DISHMAN, R. K. Motivation and exercise adherence. In: SILVA III, J.M.; WEINBERG, R. S. (Eds). Psychological foundations of sport. Champaign: Human Kinetics, 1984. Cap.29, p. 429-434.

- Overview.In: ;ed. Exercise adherence: its impact on public health. Champaign: Human Kinetics, 1988a.p.1-11.

. Determinants of physical activity and exercise for persons 65 years of age or older. American Academy of Physical Education Papers, n. 22, 1988b.

. Exercise adherence. In: SINGER, R. N.; TENNANT, L. K., (Ed.). Handbook of research in sport psychology. New York, McMillian, 1993. Cap.36, p.779-97. 
DISHMAN, R. K.; SALLIS, J. F. Determinants and interventions for physical activity and exercise. In: BOUCHARD, C.; SHEPARD, R. J.; STEPHENS, T., (Eds). Physical activity, fitness and health: international proceedings and consenses statement. Champaing: Human Kinetics, 1994. Cap.13, p. 215-238.

DISHMAN, R. K.; SALLIS, J. F.; ORENSTEIN, D. R. The determinants of physical activity and exercise. Public Health Report, v. 100, p.158-172, 1985.

EVANS, W. J. Exercise training guidelines for the elderly. Medicine and Science in Sports and Exercise, Madison, v.31, p.12-7, 1999.

FARIA JUNIOR, A. G. Idosos em movimento: mantendo a autonomia: população e expectativas. In: MARQUES, A. T.; GAYA, A.; CONSTANTINO, J. M. (Eds.). Physical activity and health in the elderly: proceedings of the first conference of EGREPA). Oeiras, University of Porto, 1994. p. 321-326.

FEIGENBAUM, M. S.; POLLOCK, M. L. Prescription of resistance training for health and disease. Medicine and Science in Sports Exercise, Madison, v.31, p.38-45, 1999.

FIATARONE, M. A. Physical activity and functional independence in aging. Research Quarterly for Exercise and Sport, Washington, v.67, n.3, p.70, 1996.

FIATARONE, M. A.; MARKS, E. C; RYAN, N. D. High-intensity strength training in nonagenarians: effects on skeletal muscle. Journal of American Medical Association, v.263, p.3029-3034, 1990. 
FIATARONE, M. A; O`NEILl, E. F; DOYLE, N; ClEMENTS, K. M; ROBERTS. S. B; KEHAYIAS, J. J; LIPSITZ, L. A; EVANS, W. J. Exercise training and supplementation for physical frailty in very elderly people. New England Journal of Medicine, v.330, p.1769-1775, 1994.

FIATARONE-SINGH, M. A. Body composition and weight control in older adults. In: LAMB, D. R, MURRAY, R. Perspectives in exercise science and sports medicine: exercise, nutrition and weight control.1998a.Carmel: Cooper, v. 111, p.243-288.

- Combined exercise and dietary intervention to optimize body composition in aging. In: HARMAN, D. et al. Towards prolongation of the healthy life span. New York: New York Academy of Sciences, 1998b. p. 378393, (Annals of the New York Academy of Sciences, 854).

FISCHER, N. M.; PENDERGAST, D. R.; CALKINS, E. Muscle rehabilitation in impaired elderly nursing home residents. Archive Phisysical Medicine and Rehabilitation, v.72, p.181-185, 1991.

FITNESS BRASIL.Disponível em: <www.fitnessbrasil.com.br> Acesso em: 10 de mar. 2005.

FLECK, S. J.; KRAEMER, W. J. Fundamentos do treinamento de força muscular. 2.ed. Porto Alegre: Artes Médicas, 1999.

FONSECA, M. C. O. Capacidade funcional de idosos participantes de programas diferenciados de atividade física. 2004. Monografia (Graduação) Escola de Educação Física e Esporte, Universidade de São Paulo, São Paulo. 
FREIRE, A. S.; RESENDE, M. C. Sentido de vida e envelhecimento. In: NERI, A. L. (Org.) Maturidade e velhice: trajetórias individuais e sócioculturais. Campinas: Papirus, 2001. p. $71-97$.

FRIES, J. S.; GURKIRPAL, G.; SINGH, D.; MORFELD, H. B.; HUBERT, N. E.: LANE, BRAWN JUNIOR, B. W. Running and the development of disability with age. Ann Int Med, v. 121, p.502-509, 1994.

FRONTERA, W. R.; DAWSON, D. M. ; SLOVIK. D. M. Exercício físico e reabilitação. Porto Alegre: Artimed, 2001. p.347-372, 2001.

GEIS, P. Tercera edad, e actividad física y salud. 2.ed. [S.1.]: Editorial Paidotrib, 1996.

GHORAYEB, C. Os benefícios da atividade física para idosos. 2000. Monografia (Graduação) - Escola de Educação Física e Esporte, Universidade de São Paulo, São Paulo.

GHORAYEB, N. Atividade física e esportiva no idoso. São Paulo: Associação Paulista de Medicina, 1993.

GONÇALVES, A. K. Ser idoso no mundo: o indivíduo idoso e a vivência de atividades físicas como meio de afirmação e identidade social.1999. Tese (Doutorado) - Faculdade de Psicologia, Universidade de São Paulo, São Paulo.

GURALNIK, J. M. L.; FERRUCI, E. M.; SIMONSICK, M. E., SALIVE e WALLACE, R. B. Lower-extremity function in persons over the age of 70 years as a predictor of subsequent disability. New England Journal of Medicine, v.332, p. 556-61, 1995. 
HAGERMAN, F. C; FIELDing, R. A; FIATARONE, M. A; GAUlT, J. A; KIRKENDALL, D. T; RAGG, K. E; EVANS, W. J. A 20-yr longitudinal study of Olympic oarsmen. Medicine and Science in Sports and Exercise, Madison. v.28, p.1150-1156, 1996.

HAKIM, A. A.; PETROVITCH, H.; BURCHFIELD, C.; ROSS, G. W.; RODRIGUEZ, B. L.; WHITE, K. Y.; CURB, D.; ABBOT, R. D. Effects of walking on mortality among nonsmoking retired men. New England Journal of Medicine, v.338, p. 94-9, 1998.

HARRIS, T.; KOVAR, M. G.; SUZMAN, R.; KLEIMAN, J. C.; FELDMAN, J. J. Longitudinal study of physical ability in the oldest-old. American Journal Public Health, v. 79, p. 698-702, 1989.

HEYWARD, V. Advanced fitness assessment and exercise prescription. 2 ed. Champaign: Human Kinetics, 1991.

HILLSDON, M. M.; BRUNNER, E. J.; GURALNIK, J. M.; MARMOT, M. G. Prospective study of physical activity and physical function in early old age. American Journal of Preventive Medicine, v.28, p.245-250, 2005.

HURLEY, B. F; HAGBERG, J. M. Optimizing health in older persons: aerobic or strength training? Exercise Sport Science Reviews, v.26, p.61-90, 1998.

IBGE, 1998. Pesquisa de padrão de vida. Disponível em: <www.ibge.gov.br.> Acesso em: abr. 2004.

IBGE, 2003. Disponível em:: <www.ibge.gov.br.> Acesso em: mar. 2003. 
INGRAM, D. K. Age-related decline in physical activity: generalization to nonhumans. Medicine Science Sports Exercise, v. 32, p. 1623-1629, 2000.

INTERNATIONAL HEALTH RACQUET AND SPORTCLUB ASSOCIATION (IHRSA), Fitness Business América Latina, n. 11, p. 16-21, 2004.

JURAN, J. M. A qualidade desde o projeto: novos passos para o planejamento da qualidade em produtos e serviços. São Paulo: Pioneira, 1992.

JETTE, A., M.; BOTTOMLEY, J. M. The greying of America. Opportunities for physical therapy. Physical Therapy, v.67, n.10, p.1537-1542, 1987.

KATZ, S. Assessing self-maintenance: activities of daily living, mobility and instrumental activities of daily living. Journal of the American Geriatrics Society, v.31, n. 12, p. 721-727, 1983.

KELL, R., T.; BELL, G.; QUINNEY, A. Musculoskeletal Fitness, Health Outcomes and Quality of Life. Sports Medicine, Auckland, v.31, n.12, p.863873, 2001.

LABORINHA, L. Planejamento de atividades físicas para a terceira idade. Atividades físicas para a terceira idade. Brasília: SESI,DN, 1997.p.49-65.

LARIZZATTI, M. F. Academias de ginástica - uma opção aos portadores de deficiência física. 1999. Dissertação (Mestrado) - Universidade Mackenzie, São Paulo. 
LARSSON, L. Physical training effects on muscle morphology in sedentary males at different ages. Medicine and Science in Sports and Exercises, Madison, v.14, p.203-206, 1982.

LAUKKANEN, P.; KAUPPINEN, M.; HEIKKINEM, E. Physical activity as a predictor of health and disability in 75 and 80 year old men and women: a fiveyear longitudinal study. Journal of Aging and Physical Activity, Champaign, v.6, p. 141-156, 1998.

Lebrão, M. L.; PelÁEZ, M.. Projeto SABE no Município de São Paulo: uma abordagem inicial. Brasília: OPAS, 2003. (SABE, Saúde, Bem-estar e Envelhecimento na América Latina e Caribe).

LEE, I. M.; HSIEH, C. C.; PAFFENBARGER, R. S. Exercise intensity and longevity in men: The Harvard alumni health study. JAMA, v.273, p.1179-1184, 1995.

LOPES, M. A.; SIEDLER, M. J. Atividade Física: agente de transformação dos idosos. Texto \& Contexto - A Enfermagem e o Envelhecer Humano. Florianópolis: Papa-Livro, v.6, n.2, p. 330-337, 1997.

McAULEY, E.; RUDOLPH, D. Physical activity, aging and psychological wellbeing. Journal of Aging and Physical Activity, Champaign, v.3, p.67-96, 1995.

MACEDO, I. F.; DUARTE, C. R.; MATSUDO, V. K. R. Análise da potência aeróbica em adultos de diferentes idades. Revista Brasileira de Ciência e Movimento, São Caetano do Sul,v.1, p. 7-13, 1987. 
MARQUES, A. A prática de atividade física nos idosos: as questões pedagógicas. Horizonte, v.8, n.74, p.11-17, 1996.

MARQUES, J.; PEREIRA. N. Hidroginástica: exercícios comentados: cinesiologia aplicada à hidroginástica. Rio de Janeiro: Ney Pereira, 1999.

MARQUES, S. Sports habits influence in sports practice of aged people. In: MARQues, A. T.; GAYA, A.; CONSTANTINO, J. M. (Eds.). Physical activity_and health in elderly: proceedings of the first conference of EGREPA (European Group for Research into Elderly and Physical Activity). Oeiras: University of Porto, 1994. p. 535.

MARTINS, F.; JANUÁRIO, M.; TABACH , O. Anos Dourados. 2000. Trabalho de conclusão de curso (MBA Executivo Internacional) FIA/FEA/USP, São Paulo.

MATSUDO, S. M. Envelhecimento e atividade física - atividades físicas para a terceira idade. Brasília: SESI/DN, 1997. p. 23-36.

. Envelhecimento e atividade física. Londrina: Midiograf, 2001. p.84.

MATSUDO, S. M.; MATSUDO, V. K. R. Prescrição de exercícios e benefícios da atividade física na terceira idade. Revista Brasileira de Ciências e Movimento, São Caetano do Sul, v. 05, n. 04, p. 19-30, 1992.

. Physical activity and ageing in developing countries. Perspectives, v.2, n.1, p. $65-84,2000$. 
Matsudo, S. M.; MAtSudo, V. K.; ARAÚJO, T. L. Perfil do nível de atividade fisica e capacidade funcional de mulheres maiores de 50 anos de idade de acordo com a idade cronológica. Atividade Física e Saúde, v. 6, n.1, p. 1224, 2001 .

MATSUDO, S. M.; MATSUDO, V. K.; BARROS, T. L. N. Efeitos benéficos da atividade física e saúde mental durante o processo de envelhecimento. Revista Brasileira de Atividade Física e Saúde, Londrina, v. 5, n. 3, p. 60-76, 2000.

MATSUDO, S. M.; MATSUDO, V. K. R; BARROS, T.L. N. Atividade Física e Envelhecimento: aspectos epidemiológicos. Revista Brasileira de Medicina e Esporte, v. 7, v. 1., p. 2-13, 2001.

MATSUDO, V. K. R. Aspectos gerais da avaliação. In: MATSUDO, S. M. M. Avaliação do idoso: física e funcional. Londrina: Midiograf, 2000.

MATSUDO, V. K.; MATSUDO, S. M.; ANDRADE D.; ARAÚJO, T.; ANDRADE, E.; OliveIRA, L. C.; BRAGGION, G. Promoção da saúde mediante o aumento do nível de atividade física: a proposta do programa Agita São Paulo. Revista Âmbito Medicina Esportiva, n.7, p. 5-15, 2001.

MAZO, G., Z.; LOPES, M. A.; BENEDETTI, T. B. Atividade física e o idoso: concepção gerontológica. Porto Alegre: Sulina, 2001.

MEIRELLES, M. E. A. Atividade física na terceira idade. 3ed. Rio de Janeiro: Sprint, 2000. 
MOREY, M. C.; COWPER, P. A.; FEUSSNER, J. R.; DiPASQUALle, R. C.; CROWLEY, G. M.: KITZMAN, D. W.; SUllivAN, R. J. Evaluation of a supervised exercise program in a geriatric population. Journal of The American Geriatric Society, v.37, n.4, p.348-354, 1989.

MOSCHIS, G. P. Marketing to older consumers. Westport: Quorum Book, 1992.

MURREL, A.; DIETZ, B. Fun support of sport teams: the effect of common group identify. Journal of Sport \& Exercise Psychology, Champaign, v.14, p. $28-39,1992$.

NADEL, M. A. Heart health: volume and revenue growth through clinically integrated medical fitness centers. Journal Cardiovasc Manag, v.14, n.2, p.225. 2003.

NERI A. L. Desenvolvimento e envelhecimento: perspectivas biológicas, psicológicas e sociológicas. Campinas: Papirus, 2001.

NIEMAN, D. C. Exercício e saúde: como se prevenir de doenças usando o exercício como seu medicamento. São Paulo: Manole, 1999. 
NÓBregA, A. C. L; FreitAA, E. V.; OLIVEIRA, A. B.; LEITÃO, M. B.; LAZZOLI, J. K.; NAHAS, R. M. ; BATISTA, C. A. S.; DRUMMOND, F. A; REZENDE, L.; PEREIRA, J.; PINTO, M.; RADOMINSKI, R. B.; LEITE, N.; ThIELE, E. S.; HERNANDEZ, A. J.; ARAÚJO, C. G. S.; TEIXEIRA, J. A. C.; CARVAlHO, T.; BORGE, S. F.; DE ROSE, E. H..Posicionamento Oficial da Sociedade Brasileira de Medicina do Esporte e da Sociedade Brasileira de Geriatria e Gerontologia: atividade física e saúde no idoso. Revista Brasileira de Medicina do Esporte, São Paulo, v.5, n.6, p.207- 211, 1999.

OKUMA, S. S. O significado da atividade física para o idoso: um estudo fenomenológico.1997. Tese (Doutorado) - Instituto de Psicologia, Universidade de São Paulo, São Paulo.

. O idoso e atividade física, fundamentos e pesquisa. 2.ed. Campinas: Papirus, 1998.

. Impacto da atividade física sobre a dimensão psicológica do idoso: uma análise sob a ótica da velhice bem-sucedida. In: CONGRESSO DE EDUCAÇÃO FÍSICA E CIÊNCIAS DO ESPORTE DOS PAÍSES DE LÍNGUA PORTUGUESA, 7., 1999, Florianópolis. Anais... Florianópolis: [s.ed.], 1999. p. 111-118.

. Por que e como avaliar o idoso. In: MATSUDO, S. M. M. Avaliação do idoso: física e funcional. Londrina: Midiograf, 2000. 
PAIN, B. M.; MATSUDO, S. M.; ANDRADE, E. L.; BRAGGION, G. F.; MATSUDO, V. K. R. Efeito de um programa de atividade física e na autopercepção da aptidão física em mulheres acima de 50 anos de idade. Revista Atividade Física e Saúde, Londrina, v.6, n.3, p.50-64, 2001.

PAINTER, P; HASKELL, W. L. Tomada de decisão para a programação de exercícios. In: AMERICAN COLLEGE OF SPORTS MEDICINE. Prova de esforço e prescrição de exercício. Rio de Janeiro: Revinter, 1994. p. 249-256.

PINI, M. C. Fisiologia esportiva. Rio de Janeiro: Guanabara Koogan, 1983.

PIRES, T. S.; NOGUEIRA, J. L.; RODRIGUES, A.; AMORIM, M. G.; OLIVEIRA, A. F. A recreação na terceira idade. Disponível em: $<$ http://www.cdof.com.br>. Acesso em: 10 de abr. 2004.

POLASTRI, P. F.; SILVA, V. M.; VILLAR, R.; ZAGO, A. S.; GOBBI, S. Alterações nos níveis de coordenação de pessoas da terceira idade através de um programa de atividade física generalizada. Revista Motriz, Rio Claro, v.5, n.1, p.115, 1999.

POLlOCK, M. L.; GAESSER, G. A.; BUTCHER, J. D.; DEPRÉS, J. P.; DISHMAN, R. K.; FRANKLIN, B. A.; GARBER, C. E. The recommended quantify and quality of exercise for developing and maintaining cardiorespiratory and muscular fitness in healthy adults. Medicine and Science in Sports and Exercise, Madison, v.30, n. 6, p.975-991, 1998. 
POLLOCK, M. L.; WILMORE, J. H. Exercícios na saúde e na doença avaliação e prescrição para prevenção e reabilitação. 2. ed. Rio de Janeiro: MEDSI, 1993.

PORTER, M. M.; VANDERVOORT, A. A; LEXELL, J. Aging of human muscle: structure, function and adaptability. Scandinavian Journal of Medicine \& Science in Sports, Copenhagen, v.5, p. 129-142, 1995.

PROFUTURO, Programa de Estudos do Futuro FIA/USP, 2001. Disponível em: <www.profuturo@fia.fea.usp.br>Acesso em: fev 2005.

POWERS, S. K.; HOWLEY, E. T. Fisiologia do exercício, teoria e aplicação ao condicionamento e desempenho. São Paulo: Manole, 2000.

PUGGaARD, L.; PEDERSEN, H. P.; SANDAGER, E.; KITGAARD, H. Physical conditioning in the elderly people. Scandinavian Journal of Medicine \& Science in Sports, Copenhagen, n.4, p. 47-56, 1994.

RAAB, D. M.; AGRE, J. C.; McADAM, M;. SMITH, E. L. Light resistance and stretching exercise in elderly women: Effect upon flexibility. Archives of Physical Medicine and Rehabilitation, v. 69, n.4, p.268-272, 1988.

RANTANEN, T, HEIKKINEN, E. The role of habitual physical activity in preserving muscle strength from age 80 to 85 years. Journal of Aging and Physical Activity, Champaign, v.6, p.121-132, 1998.

RAUCHBACH, R. A atividade física para a terceira Idade. Curitiba: Louise, 1990. 
RICKLI, R. E.; JONES, C. J. Senior fitness test manual. Champaign: Human Kinetics, 2001.

ROCHA, J. C. C. Hidroginástica teoria e prática. 2ed. Rio de Janeiro: Sprint, 1994.

ROGERS, M. A; EVANS, W. J. Changes in skeletal muscle with aging: effects of exercise training. Exercise and Sport Sciences Reviews, Baltimore, v.21, p. $65-102,1993$.

ROJO, F. J. G. Qualidade Total: uma nova era para os supermercados. Revista de administração e Empresas, v.38, n.4, p.30, 1998.

SABA, F.; ANTUNES, F. Gestão em Atendimento. Barueri: Manole, 2004.

SABA, F. K. F. Determinantes da prática de exercício físico em academias de ginástica. 1999. Dissertação (Mestrado) - Escola de Educação Física e Esporte, Universidade de São Paulo, São Paulo.

SANTAREM, J, M. Promoção da saúde do idoso, 1997 . Disponível em:

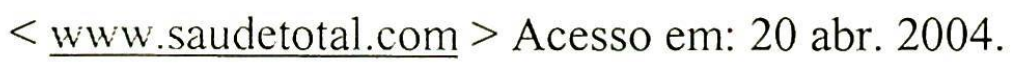

SCHOUERI JUNIOR, R. ; RAMOS L. R.; PAPALÉO NETTO, M. Crescimento populacional: aspectos demográficos e sociais. In: CARVALHO FILHO, E.T.; PAPALÉO NETTO, M. (Ed). Geriatria: Fundamentos, clínica e terapêutica. São Paulo: Atheneu, 1994.

SEEATESP - Sindicato das Academias Patronal, 2003. 
SHEPHARD, J. M.; BERRIDGE, M. On the generality of the "sit and reach" test: an analysis of flexibility data for aging population. Research Quaterly for Exercise and Sport, Washington, v.61, n.4, p.326-330, 1990.

SHEPHARD, R. Aging, physical activity, and health. Champaign: Human Kinetics, 1997, p. $18-29$,

SILVA, A. R; MATSUDO, S. M. M; MATSUDO, V. K. R; ANDRADE, E. L. Influência de um programa de exercícios com pesos na aptidão física de mulheres sedentárias maiores de 50 anos. In: Anais...SIMPÓSIO FITNESS BRASIL,2., Local, Editora, 1999.p.17.

SINDESPORTE - Sindicato dos funcionários de academias do estado de São Paulo, 2003.

SKINNER, J. S. Importance of aging for exercise testing and exercise prescription. In: SKINNER, J. S. Exercise testing and exercise prescription for special cases: theoretical basis and clinical application. Lippincott Williams \& Wilkins, 1993.

SPINK, K.; CARRON, A. Group cohesion and adherence in exercise classes. Journal of Sport\& Exercise Psychology, v.14, p.78 - 86, 1993.

SPIRDUSO, W. W. Physical dimensions of aging. Champaign: Human Kinetics, 1995.

SPIRDUSO, W.W; CRONIN, D. L. Exercise dose-response effects on quality of life and independente living in older adults. Medicine and Science in Sports and Exercise, Madison, v.33, n.6, S598-608, 2001. 
STONES, M. J.; KOZMA, A.;STONES, L. Fitness and health evaluations by older exercisers. Canadian Journal of Public Health, v.78, p.18-20, 1987.

STOUT, G. From hospitals to fitness centers-maintaining community health. Journal of Health Resource Manag; v.13, n.9, p.16-24, 1995.

SWOAP, R. A; NORVELL, N; GRAVES, J; POLLOCK, M. L. High versus moderate intensity aerobic exercise in older adults: psychological and physiological effects. Journal of Aging and Physical Activity, Champaign, v.2, p.293-303, 1994.

THOMAS, J. R.; NELSON, J. K. Método de pesquisa em atividade física, 3ed. Porto Alegre:Artmed, 2002.

TOSCANO, J. J. O. Academia de ginástica: um serviço de saúde latente Revista Brasileira de Ciência e Movimento, São Caetano do Sul, v.9, n.1, p.40-2, 2001. TURRA, C. G.; ENRICONE, D.; SANTANNA, F.; ANDRÉ, L. C. Planejamento de ensino e avaliação. Porto Alegre: Sagra,1992.

UNIVERSIDADE DO ESTADO DE SANTA CATARINA. Cartilha da qualidade. Florianópolis: UDESC, 1996.

UENO, L. M. ; OKUMA, S. S.; MIRANDA, L. M.; FILHO, W. J.; HO, L. L. Análise dos efeitos quantitativos e qualitativos de um programa de educação física sobre a flexibilidade do quadril em indivíduos com mais de 60 anos. Motriz, Rio Claro, v.6, n. 1, p.9-16, 2000. 
VARGaS, H. S. Psicologia do envelhecimento. São Paulo: Fundo Editorial BYK - Procienx, 1983.

VAN BOXTEL, M. P; PAAS, F. G; HOUX, P. J; ADAM, J. J; TEEKEN, J. C; JOLLES, J. Aerobic capacity and cognitive performance in a cross-sectional agings study. Medicine and Science in Sports and Exercise, Madison, v.29, p.1357-1365, 1997.

VAVRA, T. Seus clientes estão sendo satisfeitos? In: Score your customers by satisfaction, loyalty, profitability and potencial. National Center for Database Marketing, $\mathbf{1 8}^{\text {th }}$ National Conference. Orlando, 1996.

ZAGO, A. S.; GOBBI, S. Valores normativos da aptidão funcional de mulheres de 60 e 70 anos. Revista Brasileira de Ciência e Movimento, São Caetano do Sul, Brasília, v.2, n.2, p.77-86, junho, 2003.

WANKEL, L. M. Exercise adherence and leisure activity: patterns of involvement and interventions to facilitate regular activity. In: DISHMAN, R. K. (Ed.). Exercise adherence: its impact on public health. Champaign: Human Kinetics, 1988. Cap. 14, p. 369-396.

WEINBERG, R.; GOULD, D. Foundation of sport and exercise psychology. Champaign: Human Kinetics, 1995. Cap.20, p.379 - 398: Exercise adherence.

WEINECK, J. Biologia do esporte. São Paulo: Manole, 1991. . Treinamento ideal. São Paulo: Manole, 1999. 
WOOD, R. H.; REYES-ALVAREZ, R.; MARAJ, B.; METOYER, K. L.; WELSCH, M. A. Physical fitness, cognitive function and health-related quality of life in older adults. Journal of Aging and Physical Activity, Champaign, n.7, p.217-230, 1999.

WORLD HEALTH ORGANIZATION. Men, ageing and health. Geneva: WHO, 2001.

WRIGHT, J. Seminário PROFUTURO III - FEA/USP: resultados da pesquisa Delphi perfil do consumidor do futuro - Rodadas 1 e 2. São Paulo: FEA/USP, 2001.

YUASO, D. R. ; SGUIZZATTO, G. T. Fisioterapia em pacientes idosos. In: PAPALÉO NETTO, M. (Org.) Gerontologia: a velhice e o envelhecimento em visão globalizada. São Paulo: Atheneu, 2002. cap.30, p. 331-347.

YAZBEK, P.; BATTISTELLA, L. R. Condicionamento físico: do atleta ao transplantado. São Paulo: Sarvier, 1994. 


\section{ANEXO I - Termo de Consentimento Livre e Esclarecido}

Universidade de São Paulo

Escola de Educação Física e Esporte

Área de Biodinâmica do Movimento Humano

Data I

Termo de Consentimento Livre e Esclarecido

$\mathrm{Eu}$, sou voluntário para participar da pesquisa "Avaliação de um Programa de Atividade Física para idoso em Academia - Um Estudo Exploratório" que será realizada por Simone Carvalho Simões Pinheiro Lima, código USP 1962861, matriculada no curso de Pós - Graduação ao nível de Mestrado, na área de concentração Biodinâmica do Movimento Humano sob a orientação do Prof. Dr. Antônio Carlos Mansoldo.

Declaro que a investigadora forneceu a mim todas as informações relacionadas ao projeto de pesquisa, incluindo:

1) Explicação sobre a natureza e o propósito da pesquisa;

2) Os dados não serão usados para nenhum outro propósito que não o da pesquisa científica, sem a minha autorização prévia ou por escrito;

3) Declaro ter conhecimento que de forma a proteger os meus direitos e privacidade, todos os dados relacionados a minha pessoa serão sigilosos e preservados;

4) Eu tenho liberdade de desistir da minha participação do estudo a qualquer momento, sem nenhuma repercussão negativa.

Concordando com todos os itens acima, eu concordo em participar desta pesquisa.

Assinatura do Avaliado 


\section{ANEXO II - Carta de Apresentacão}

Prezado aluno,

Gostaria de contar com a sua participação da pesquisa ao nível de Mestrado sobre "Avaliação de um Programa de Atividade Física para idoso em Academia - Um Estudo Exploratório". Este questionário se propõe a avaliar o seu grau de satisfação em relação ao "Programa Platinum" quanto aos seus objetivos, atividades oferecidas, estrutura da academia e atendimento. Sua avaliação é para nós de fundamental importância, tanto para identificar as características do praticante da $3^{\text {a }}$ idade quanto para orientar as ações de melhoria na qualidade do programa de atividade física desenvolvido na academia.

É necessário que você responda o questionário da maneira mais precisa e sincera, respeitando suas percepções.

A sua participação é voluntária e os dados coletados serão utilizados somente para fins científicos/acadêmicos. Todos os dados coletados serão sigilosos e preservados.

Agradecemos pelo seu feed-back, pela sua disposição e atenção e, caso tenham qualquer dúvida dirijam-se à pessoa que está aplicando esse questionário.

\section{Simone Carvalho Simões Pinheiro Lima}

Escola de Educação Física e Esporte da USP

Email-simoni6@ig.com.br 


\section{ANEXO III - Questionário}

\section{"Proposta de instrumento de avaliação do Programa Platinum"}

1) Nome: Data de Nasc.:

2) Sexo:

( ) Feminino

( ) Masculino

3) Estado civil: ( ) Casado ( ) Solteiro ( ) Viúvo(a) ( ) Separado(a)

4) Período que freqüenta a academia: ( ) Manhã ( ) Tarde Noite

5) Há quanto tempo você está na academia e/ou "Programa Platinum”?

( ) 3 a 6 meses ( ) 7 meses a 12 meses ( ) 12 a 24 meses

( ) 24 a 36 meses ( ) + de 36 meses

6) O que o levou a freqüentar a academia e/ou "Programa Platinum"? (assinalar quantos itens forem necessários)

( ) indicação médica

( ) procura por novas amizades

( ) sedentarismo

( ) qualidade de vida

( ) solidão

( ) falta de atividade

( ) estética

( ) cansaço diário

( ) saúde

( ) outras.Quais?

( ) atividade social

7) Qual/quais atividades físicas que você freqüenta do "Programa Platinum" (assinalar quantos itens forem necessários)?

( ) Natação

( ) Hidroginástica

( ) Alongamento

( ) Multi Platinum

( ) Musculação

( ) Esteira

( ) Bicicleta Ergométrica 


\section{ANEXO III - Questionário (continuaç̃o)}

8) Qual o seu nível de satisfação em relação às atividades que você freqüenta?

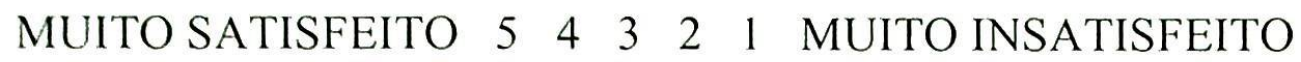

Muito satisfeito, satisfeito, um pouco satisfeito, insatisfeito, muito insatisfeito

9) Qual o seu nível de satisfação em relação aos objetivos atingidos ao freqüentar a academia e/ou "Programa Platinum"?

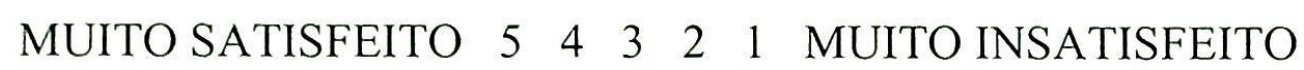

Muito satisfeito, satisfeito, um pouco satisfeito, insatisfeito, muito insatisfeito

10) Qual o seu nível de satisfação em relação ao estímulo e incentivo que o prof. lhe dá para você melhorar o seu desempenho/ resultados ou corrigir falhas?

MUITO SATISFEITO $\quad \begin{array}{lllllll}5 & 4 & 3 & 2 & 1 & \text { MUITO INSATISFEITO }\end{array}$

Muito satisfeito, satisfeito, um pouco satisfeito, insatisfeito, muito insatisfeito

11) Você foi cordialmente atendido pela recepção ao ingressar no "Programa Platinum"?
( ) Sim, por quê?
( ) Não, por quê?

12) Você é cordialmente atendido pelos professores do "Programa Platinum"?
( ) Sim, por quê?
( ) Não, por quê? 


\section{ANEXO III - Questionário (continuação)}

13) Você ao ingressar na academia teve explicações precisas e claras quanto ao funcionamento do "Programa Platinum"?

( ) Sim, por quê? ( ) Não, por quê?

14) Cite os pontos positivos do "Programa Platinum":

1.

2.

3.

4.

15) Cite os pontos negativos do "Programa Platinum": 1.

2.

3.

4.

16) Na sua opinião o que você gostaria de sugerir para que possamos melhorar o "Programa Platinum"? 


\section{ANEXO IV- Ficha Controle Aluno Platinum}

Nome

Tel Res

Profissào

Médico Resp.

$>$ Pratica Atividade Física?

> Avaliação Física Peso Com

D. Nasc. Estado Civil Especialidade Especialidade Início Cel 1

ão Qual atividade? Há quanto tempo? Altura

$>$ Composição Corporal - peso corporal peso gordo peso magro \% gordura Atual Alvo -

$>$ Flexibilidade (Sentar e Alcançar ) Alcance Máximo

$>$ Análise Postural -

> Avaliação Cardiovascular - VO2 indireto - Máx SubMáx a

$>$ Exames Complementares - Triglicerides

Data I Colesterol

Glicemia

Data Densitometria Óssea

$>$ Fumante? ( ) Sim ( ) Não Há quanto tempo?

$>$ Medicamentos -

$>$ Alterações Músculo-esqueléticas? ( ) Osteopenia

( ) Osteoporose

( ) Artrite

( ) Artrose

( ) Sarcopenia

Lesões muscular/articular

$>$ Dor na coluna -

( ) Cervical

( ) Dorsal

( ) Lombar

> Doenças cardiovasculares - ( ) Doença arterial coronariana （ ) Hipertensão

\footnotetext{
> Distúrbios Respiratórios - ( ) Asma ( ) Bronquite ( ) Enfizema Pulmonar ( ) DPOC

$>$ Distúrbios Metabólicos - ( ) Diabetes ( ) Obesidade ( ) Tireóide

$>$ Distúrbios Neurológicos - ( ) Arteroesclerose ( ) Alzheimer ( ) Mal de Parkinson

$>$ Distúrbios Visuais - ( ) Normal ( ) Diminuída

$>$ Distúrbios Auditivos - ( ) Normal ( ) Diminuída

$>$ Em caso de Emergencia contactar -
} 
ANEXO V - Escala de Auto-Percepcão do Desempenho de Atividades da Vida Diária (Andreotti e Okuma, 1999)

\begin{tabular}{|c|c|c|}
\hline & Atividade de vida diária & Classificação \\
\hline 1 & Alimentar-se & \\
\hline 2 & Tomar banho ( lavar os pés ) & \\
\hline 3 & Tomar banho ( lavar as costas ) & \\
\hline 4 & Pentear o cabelo & \\
\hline 5 & Cortar as unhas das mãos & \\
\hline 6 & Cortar as unhas dos pés & \\
\hline 7 & Vestir calça comprida & \\
\hline 8 & Vestir blusa sem botões & \\
\hline 9 & Abotoar blusas, casacos, etc. & \\
\hline 10 & Calçar meias & \\
\hline 11 & Calçar sapato de amarrar & \\
\hline 12 & Deitar na cama & \\
\hline 13 & Sentar em uma cadeira ( sem braços ) & \\
\hline 14 & Levantar de uma cadeira ( sem braços ) & \\
\hline 15 & Levantar da cama & \\
\hline 16 & Deitar no chão & \\
\hline 17 & Levantar do chão & \\
\hline 18 & Pegar um objeto do chão & \\
\hline 19 & Segurar um objeto de $5 \mathrm{~kg}$ ( por ex: um pacote de arroz ) por $5 \mathrm{~min}$. & \\
\hline 20 & Fazer a cama & \\
\hline 21 & Varrer a casa & \\
\hline 22 & Limpar os móveis da casa & \\
\hline 23 & Fazer faxina na casa & \\
\hline 24 & Descascar / cortar alimentos & \\
\hline 25 & Cozinhar & \\
\hline 26 & Subir degraus de ônibus & \\
\hline 27 & Descer degraus de ônibus & \\
\hline 28 & Entrar no carro & \\
\hline 29 & Sair do carro & \\
\hline 30 & Realizar trabalhos artesanais (crochê, tricô, pintura,etc.) & \\
\hline 31 & Realizar trab. manuais (pregar algo, colocar a chave na fechadura, discar telf. etc) & \\
\hline 32 & Andar $2-3$ quarteirões & \\
\hline 33 & Andar em subidas & \\
\hline 34 & Andar depressa & \\
\hline 35 & Andar $10-12$ quarteirões & \\
\hline 36 & Subir uma escada de $15-20$ degraus & \\
\hline 37 & Descer uma escada de $15-20$ degraus & \\
\hline 38 & Subir uma escadaria ( mais de 40 degraus ) & \\
\hline 39 & Descer uma escadaria ( mais de 40 degraus ) & \\
\hline 40 & Ficar muito tempo em pé ( aproximadamente meia hora ) & \\
\hline
\end{tabular}


ANEXO VI - Programa de Treinamento

Programa de Treinamento Experimental

\begin{tabular}{|l|l|l|l|l|l|l|}
\hline Horário & $2^{\mathrm{a}}$ Feira & $3^{\mathrm{a}}$ Feira & $4^{\mathrm{a}}$ Feira & $5^{\mathrm{a}}$ Feira & $6^{\mathrm{a}}$ Feira & Sábado \\
\hline & & & & & & \\
\hline & & & & & & \\
\hline & & & & & & \\
\hline & & & & & & \\
\hline
\end{tabular}

Programa realizado em:

Objetivo principal:

Prof(a):

Programa de Treinamento Experimental (cópia aluno Platinum)

\begin{tabular}{|c|c|c|c|c|c|c|}
\hline Horário & $2^{\mathrm{a}}$ Feira & $3^{\mathrm{a}}$ Feira & $4^{a}$ Feira & $5^{\text {a }}$ Feira & $6^{\mathrm{a}}$ Feira & Sábado \\
\hline & & & & & & \\
\hline & & & & & & \\
\hline & & & & & & \\
\hline & & & & & & \\
\hline
\end{tabular}

Programa realizado em:

Objetivo Principal:

Prof(a): 


\section{ANEXO VII - Grade de Horários - Programa Platinum}

\begin{tabular}{|c|l|l|l|l|l|}
\hline Horário & $2^{\text {a Feira }}$ & $3^{\text {a Feira }}$ & $4^{a}$ Feira & $5^{\text {a }}$ Feira & $6^{\text {a Feira }}$ \\
\hline $9: 45$ & $\begin{array}{c}\text { Multi Platinum } \\
\text { (S3) }\end{array}$ & $\begin{array}{l}\text { Multi Platinum } \\
\text { (S3) }\end{array}$ & $\begin{array}{l}\text { Alongamento } \\
\text { Platinum (S3) }\end{array}$ \\
\hline $10: 00$ & & $\begin{array}{l}\text { Alongamento } \\
\text { Platinum (S1) }\end{array}$ & $\begin{array}{l}\text { Alongamento } \\
\text { Platinum (S1) }\end{array}$ & \\
\hline $11: 15$ & $\begin{array}{l}\text { Alongamento } \\
\text { Platinum (S2 }\end{array}$ & $\begin{array}{l}\text { Natação ou } \\
\text { Hidroginástica }\end{array}$ & $\begin{array}{l}\text { Alongamento } \\
\text { Platinum ( S2) }\end{array}$ & $\begin{array}{l}\text { Natação ou } \\
\text { Hidroginástica }\end{array}$ & $\begin{array}{l}\text { Natação ou } \\
\text { Hidroginástica }\end{array}$ \\
\hline $14: 00$ & & $\begin{array}{l}\text { Deep Training } \\
\text { (Piscina P1) }\end{array}$ & & \\
\hline $14: 00$ & & $\begin{array}{c}\text { Multi Platinum } \\
\text { (S3) }\end{array}$ & & $\begin{array}{c}\text { Multi Platinum } \\
\text { (S3) }\end{array}$ & \\
\hline $14: 45$ & & $\begin{array}{l}\text { Alongamento } \\
\text { Platinum (S3) }\end{array}$ & & $\begin{array}{l}\text { Alongamento } \\
\text { Platinum (S3) }\end{array}$ & \\
\hline
\end{tabular}

\section{Acessórios e Vestimentas}

- Para as aulas de Alongamento, Musculação, Caminhada, Condicionamento Físico trazer:
1) Tênis com um bom amortecimento;
2) Bermuda e camiseta confortável;
3) Meia com boa absorção de suor;
4) Freqüêncímetro (Caminhada);
5) Garrafinha de água;
6) Boné ou viseira para os dias de sol e protetor solar;
7) Toalha de rosto.

- Para as aulas de Natação e Hidroginástica trazer:

1) Maiô ou sunga com boa sustentação e conforto;

2) Chinelo;

3) Toalha ou roupão para os dias mais frios;

4) Boné ou viseira para os dias de sol e protetor solar;

5) Garrafinha de água.

\section{Exames Complementares}

( ) Avaliação Física (a + recente);

( ) Atestado Médico para a prática das $\mathrm{AF}+$ dermatológico ( $\mathrm{p} / \mathrm{piscina})$;

( ) Ergométrico de Esforço Máximo (o + recente);

( ) Exame de sangue (triglicerides, colesterol, glicemia), (o + recente);

( ) Densitometria óssea $(a+$ recente $)$ - somente para as mulheres. 